\title{
Modern Approaches
}

in.: $\cdots$

Chemiloal and Biological Sciences

Edited by

Dr. Hari Shankar Biswas Assistant Professor

Department of Chemistry Surendranath College, Kolkata, India

Dr. Adity Sarbajna Assistant Professor

Department of Zoology Surendranath College, Kolkata, India

Dr. Sandeep Poddar Senior Research Director \& Executive Editor (Publications) Lincoln University College, Malaysia

Dr. Amiya Bhaumik * President Lincoln University College, Malaysia

Published by:

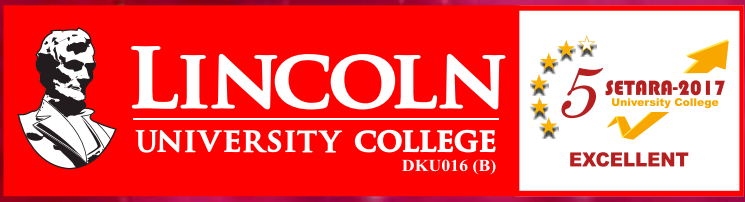

ISO 9001:2015 Certified 


\title{
Modern Approaches in Chemical and Biological Sciences
}

doi:10.31674/book.2020.macbs

\author{
Edited by \\ Dr. Hari Shankar Biswas \\ Assistant Professor \\ Department of Chemistry \\ Surendranath College, Kolkata, India \\ Dr. Adity Sarbajna \\ Assistant Professor \\ Department of Zoology \\ Surendranath College, Kolkata, India \\ Dr. Sandeep Poddar \\ Senior Research Director \& \\ Executive Editor (Publications) \\ Lincoln University College, Malaysia \\ Dr. Amiya Bhaumik \\ President \\ Lincoln University College, Malaysia
}

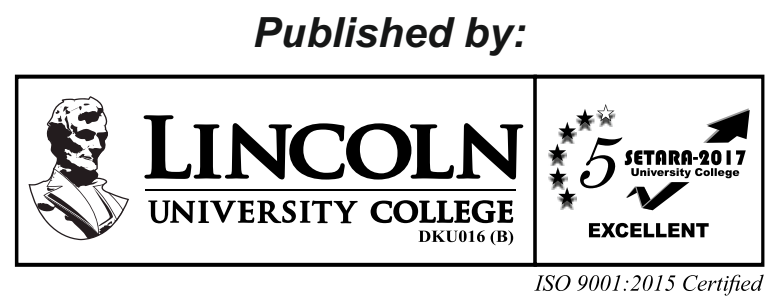


Copyright $\odot 2020$

Lincoln University College, Malaysia

All rights reserved

No part of this book can be reproduced or transmitted by any means, electronic or mechanical, including photocopying recording or by any information storage and retrieval system without prior written permission from the publisher.

Published by :

\section{LINCOLN UNIVERSITY COLLEGE}

Wisma Lincoln, No. 12, 14, 16 \& 18

Jalan SS 6/12, Off Jalan Perbandaran

47301, Petaling Jaya

Selangor Darul Ehsan

Malaysia

Tel.: +603-7806 3478

Fax: +603-7806 3479

Toll Free: 1-300-880-111

E-mail: info@lincoln.edu.my

Web.: www.lincoln.edu.my

ISBN : 978-967-16798-7-6

elSBN 978-967-16798-9-0

doi:10.31674/book.2020.macbs

\section{Printed By:}

PERCETAKAN HORIZON WAVES

27 Jalan Velox 2, Taman Industry Velox, 4800 Rawang Selangor, Malaysia 


\section{About the Editors}

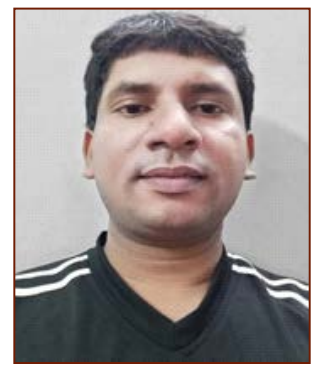

\section{Hari Shankar Biswas}

Assistant Professor and Head Department of Chemistry, Surendranath College, Kolkata, India

Rtn. Dr. Hari Shankar Biswas received has completed his Ph.D in material Science from Saha Institute of Nuclear Physics, University of Calcutta, India. Presently he is Assistant Professor and Head of the Department of Chemistry, Surendranath College, Kolkata. His Research interest is in an interdisciplinary research involving the design and synthesis of nanoscale functional materials, elucidation of the fundamental magnetic, electronic, optical and other physical properties of these materials, and the development of processes that lead to multifunctional objects for specific applications. He is the authored many renowned books and published more than 13 papers in International Journals.

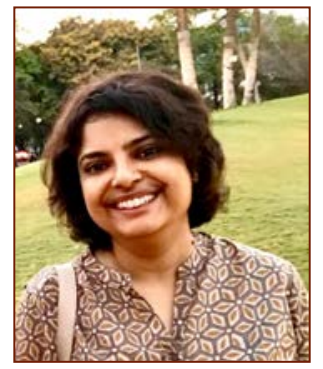

\section{Adity Sarbajna}

Assistant Professor, Department of Zoology

Surendranath College, Kolkata, India

Dr. Adity Sarbajna completed Ph.D. from the University of Calcutta on Aquaculture and Fisheries and has been engaged in active research in this field since 2005. Her work on fish growth, sex- reversal in fishes, stress, metal toxicity, anti-oxidant activity, feeding realms, and various aspects of fish culture has not only been confined to the laboratory but has been adopted by several farmers as best practice. She has received many awards in her academic career and has completed several research projects funded by various departments under the Government of West Bengal, India. She has authored quite several book chapters and scientific articles in national and international journals.

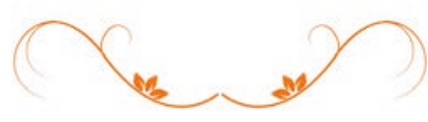




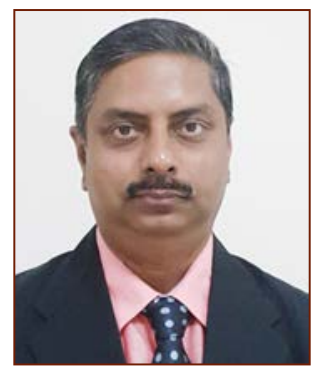

\section{Sandeep Poddar}

Senior Research Director \& Executive Editor (Publications) Lincoln University College, Malaysia

Dr. Sandeep Poddar is the Senior Research Director and Executive Editor (Publications), Member of Board of Studies, Lincoln University College, Malaysia. He has completed Ph.D in Zoology from Vivekananda Institute of Medical Sciences on Cytotoxicity. After completing Ph.D he pursued Post-Doctoral Research in different projects on Hemoglobinopathies and Oral Cancer mutation. He served as lecturer of Biotechnology in Vidyasagar Institute of Education Technology and Research under Burdwan University, Guest Lecturer of M.Sc Environmental Science \& M.Sc Zoology, Asutosh College, under University of Calcutta. He has been working as Chief Executive Editor and working as Reviewer of several International Journals. He has published several research papers, organized international conferences, and edited books in Malaysia. Dr. Sandeep is founderAssistant Secretary of Dr. Tarak Nath Podder Memorial Foundation, Kolkata.

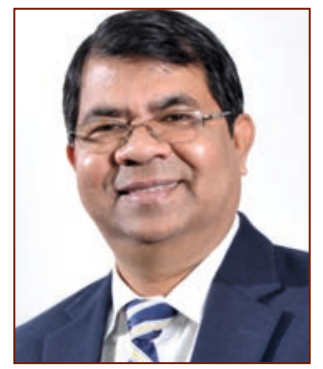

\section{Amiya Bhaumik}

President

Lincoln University College, Malaysia

Dr. Amiya Bhaumik is the Founder and Former ViceChancellor of Lincoln University College. He is purely from the field of education. Dr. Bhaumik is Executive Vice President of the International Education Consulting Group, St. Louis, USA since 1999. Dr. Amiya Bhaumik was Research Fellow of UNESCO, Paris. During this tenure, Dr. Bhaumik has traveled extensively to Europe, Africa, Asia and Latin America. He has served as Professor of Business Administration in University of Lucknow, India and in University of Malaya and many other places.

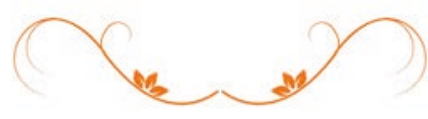




\section{EDitorial}

The developmental process in the field of chemical and biological sciences is continuously undergoing changes in search of further developments in efficiency, productivity, and profitability. Information-guided design strategies and tools could unveil the creativity of a wide range of scientists and engineers by combining expertise from implementation. This book "Modern Approaches in Chemical and Biological Sciences" discusses ways to promote the developing academic paradigm of the chemistry-biology continuum to advance this discovery and developmental process. Through a series of chapters this book tries to identify significant areas and opportunities in chemical biological sciences.

The different chapters of this book are contributed by different authors. The articles discuss about ionic liquids as the appropriate replacement for the Volatile Organic Compounds (VOCs) in the industrial and academic sectors as the solvents. The gradual probe desolvation may be another cause for thermosolvatochromism.

Determining the structure of small molecule like environment sensitive fluorophoresare is enormously important in bio-chemical and bio-physical research. In this chapters the researcher tries to find out the synthesis and photo-physical studies of a new family of fluorophores with keto-tetrahydrocarbazole (KTHC) framework. Photophysics of such fluorophores have been thought-provoking up to now. Such studies will therefore help to determine this new family of fluorophores as a potential biomarker.

Antibiotic resistance is a growing public health issue that may lead to epidemics of drugresistant bacterial species. So researchers tries to review the synthesis of ruthenium complexes with 2,3,5,6-tetrakis-(2-pyridyl)pyrazine (tppz) ligand to make its application easy. The biological application of ruthenium has augmented in the past few years, particularly after the understanding of the important of this bioactive metal as anticancer, antimicrobial, and antiviral agent.

Hypervalent iodine reagents have been used extensively in numerous oxidative transformations in organic synthesis due to their low toxicity, commercial accessibility, ease of handling and being environmentally friendly. The unique desulfurizing abilities of hypervalent iodine reagents have put forward a significant green synthetic device to synthesize a varied range of nitrogen containing bioactive heterocycles with a diverse application in medicinal chemistry.

Organic-inorganic hybrid fluorescent materials are getting immense attention in the scientific community and the industry due to their high performance and multifunctionality for numerous applications. Significant use of this novel materials includes high specific surface area, particularly well-controlled size, homogeneous distribution, and strong attachment to the interfacial surfaces. Researcher have prepared novel fluorescent organic-inorganic hybrid MCM-41 type materials, characterized for the detection of nitroaromatic explosives.

C-reactive protein (CRP) is a substance produced by the liver in response to inflammation. It is a highly conserved plasma homopentameric acute-phase inflammatory protein. Previously 
it was only considered to be a biomarker for inflammation. But now the future prospect shows the applicability of CRP molecule in diagnosis and monitoring of disease biology.

Rumen flukes causes pathogenic disease of domesticated ruminants, causing massive economic loss in dairy industry and meat production. It is regarded as a neglected tropical disease with maximum prevalence all over tropical and subtropical regions. A study on the medicinal plant Justicia adhatoda reported noteworthy anthelmintic effect in traditional procedure and was found to be anti-cestoidal activity against Paramphistomum sp. More studies are required based on the viability assays of these pathogens.

Climate change includes changes in environmental conditions which will disturb the distribution and biological performance of species. Worldwide patterns of marine biodiversity are immensely driven by ocean temperature. Global warming and acidification lessen the chances of survival of certain species of fish. Every developed and developing countries should decrease $\mathrm{CO}_{2}$ release to save marine biodiversity from altering the environment of the sea water.

Sex determination, in contrast to numerous developmental procedures, is considered by a lack of conservation throughout the vertebrates. The Nile tilapia, a gonochoristic teleost fish with an XXIXY sex-determining system, offers an excellent prototype for studying gonadal sex differentiation because genetic all-females and all-males are available. Different expression outline of miRNA was observed during development of testis and ovary which determine their role in the controlling the ovarian and testicular development and function.

The adaptive immune system (AIS) is captivating to both scientists and laymen. The AIS is specific yet immensely varied system that can combat innumerable pathogens and has a 'memory' that allows a quick response to pathogens encountered earlier. Many questions still need to be addressed in the field of Immunology, Evolutionary biology. Genetics and Molecular biology have presented deep understandings into the latest developments in this field and speculated the selective pressures that led to the development and conservation of the AIS.

This book elucidates new information, advances and outlook in research in chemical and biological sciences. This array of chapters facilitates exchange of ideas and tries to answer many current necessity and future perspective in different interdisciplinary research problems. The editors are thankful to the Principal, Surendra Nath College, Kolkata, India, Management of Lincoln University College, Malaysia for giving necessary support and permission to publish this book. The editors are also thankful to all the authors for their valuable contribution. We hope and expect that this book will provide an effective learning experience and referenced resource for all researchers and readers in this field.

\author{
Dr. Hari Shankar Biswas \\ Dr. Adity Sarbajna \\ Dr. Sandeep Poddar \\ Dr. Amiya Bhaumik
}




\section{CONTENTS}

Pages

Thermosolvatochromism: Absorbance Probe Response within Neat and

Aqueous lonic Liquids

Aabhra Sarkar and Siddharth Pandey

Role of tDMRT1, Sox9a, Cyp19a1 and Foxl2 in the sex-determining system of 11-17 Oreochromis niloticus: An Overview

Adity Sarbajna

Introducing a New Family of Fluorophores: Keto-tetrahydrocarbazole

Amrit Krishna Mitra

Synthesis of Mixed Ligand Complexes of Ruthenium with 2,3,5,6-Tetrakis-(2- 31-37 Pyridyl) Pyrazine Ligands: An Overview

Chhandasi GuhaRoy Sarkar

Exploration of Hypervalent lodine Reagents in the Synthesis of $38-46$ Nitrogen Containing Bioactive Heterocycles through Oxidative Desulfurization Strategy

Harisadhan Ghosh

Synthesis, Characterization and Potential Application of Novel 47-52 Hybrid Nanoporous Materials

Krishanu Sarkar

Evolution of Adaptive Immune System

Suman Tamang

Effects of Plant Extract on the Metabolic Activity of Rumen Flukes 59-63 In vitro

Sutapa Datta

Impacts of Climate Change on Marine Biodiversity

Tarikul Islam Golder

C-reactive Protein: Diagnostic Marker of Inflammation?

Waliza Ansar 

doi:10.31674/book.2020.macbs

\title{
Thermosolvatochromism: Absorbance Probe Response within Neat and Aqueous lonic Liquids
}

\author{
Abhra Sarkar ${ }^{1}$ and Siddharth Pandey ${ }^{2 *}$ \\ ${ }^{1}$ Department of Chemistry, Gurudas College, Kolkata, India \\ ${ }^{2}$ Department of Chemistry, Indian Institute of Technology Delhi, New Delhi, India \\ *Corresponding Author's E-mail: sipandey@chemistry.iitd.ac.in \\ abhra_321@rediffmail.com
}

\begin{abstract}
Ionic liquids despite some of their vital drawbacks have been established as the apt replacement for the volatile organic compounds (VOCs) in the industrial and academic sectors as the solvents. The main theme throughout this work is the manifestation and exploration of the unusual solvatochromic probe behavior of different absorption probes (under varied temperature) which, in turn, offers a substantial and prolific means of exploring modification/alteration of the physicochemical properties within ionic liquidbased 'green hybrid' solvent systems. As part of our 'thermosolvatochromism' studies of multicomponent ionic liquid based systems, we have selected neat ionic liquids $[\mathrm{bmim}]\left[\mathrm{BF}_{4}\right]$ \& $[\mathrm{bmim}]\left[\mathrm{PF}_{6}\right]$, equimolar aqueous ionic liquids and neat water to investigate the impact of temperature on the probe $\mathrm{E}_{\mathrm{T}}(33)$ response within these solvent systems. Two other probes, N,N-diethyl-4-nitroaniline and 4-nitroaniline, demonstrated the dipolarity/polarizability, HBD acidity, and HBA basicity altogether. In most cases considerable changes in $\lambda_{\max }$ of the probes were seen with variation in temperature registering altered dipolarity/polarizability, HBD acidity and HBA basicity of the cybotactic milieu.
\end{abstract}

Keywords: Thermosolvatochromism, Ionic Liquids, Absorbance probes, Kamlet-Taft parameters

\section{Introduction}

Cosolvent (preferably 'green') modified or binary mixed ionic liquids may alter the physicochemical properties of ionic liquids in a favorable way. Pandey and coworkers have been involved in investigations of IL-based multicomponent systems for the past few years [1-14]. Aqueous ionic liquid systems form an important and crucial subclass of such 'hybrid green' systems. Due to the possibility of strong intermolecular H-bonding interactions between water and ionic liquid [15-18], addition of water may potentially alter the physicochemical properties of ionic liquids in a significant and constructive way. In this regard, though the investigation of structural features of the solution [19] as well as measurement of bulk physicochemical properties [20] of aqueous ionic liquid 


\section{Thermosolvatochromism}

systems are of certain importance, the understanding of the behavior of solutes dissolved in aqueous ionic liquid may directly furnish crucial information on solutesolvent interaction(s), in the process, providing key insights on solute solvation within aqueous ionic liquid systems. This knowledge will help in further studies regarding the novel applications of these 'green' hybrid systems in several fields of science.

It is well-established that temperature has a significant effect on the physicochemical properties of solutions [21-25]. The solvatochromism of many probes is remarkably modulated or altered by a change in temperature; this phenomenon has been termed 'thermosolvatochromism'. Here we have discussed the thermosolvatochromism of various absorbance probes within neat and aqueous ionic liquid mixtures in order to explore the impact of temperature on physicochemical properties of these systems.

\section{Experimental Section}

\section{Materials}

The IL $[\mathrm{bmim}]\left[\mathrm{PF}_{6}\right]$ (ultra pure, halide content $<10 \mathrm{ppm}$, water content $<10 \mathrm{ppm}$ ) was purchased from Merck. Doubly-distilled deionized water was obtained from a Millipore, Milli-QAcademic water purification system having $\geq 18 \mathrm{M} \Omega$.cm resistivity. 2,6-Diphenyl4-(2,4,6-triphenyl-N pyridino) phenolate and 2,6-dichloro-4-(2,4,6-triphenyl- $\mathrm{N}$ pyridino)phenolate were purchased from Aldrich Chemical Co. and Fluka, respectively. 4-Nitroaniline (NA) and N,N-diethyl-4-nitroaniline (DENA) of highest purity were purchased from Spectrochem Co. Ltd. and Frinton laboratories, respectively. Ethanol $(99.9+\%)$ used to prepare dye stock solutions was obtained from SD Fine-Chem Ltd.

\section{Methods}

All absorbance probe stock solutions were prepared in absolute ethanol and promptly stored under refrigeration $\left(4 \pm 1^{\circ} \mathrm{C}\right)$ in amber-tinted glass vials. Desired volumes of ethanolic probe stock solutions were transferred to clean quartz cells, followed by ethanol removal using a controlled flow of high-purity dry nitrogen gas. [bmim] $\left[\mathrm{BF}_{4}\right]+$ water mixtures, prepared by mass using a Mettler Toledo AB104-S balance (precision = $\pm 0.0001 \mathrm{~g}$ ), were then added to each cuvette to achieve the sought probe concentration. A Varian Cary 100 Bio double-beam spectrophotometer with variable bandwidth and dual cell peltier accessory was used for the recording of temperature-controlled uv-vis molecular absorbance spectra.

\section{Results and Discussion}

In our present work a derivative of the betaine dye 30, 2,6-dichloro-4-(2,4,6triphenylpyridinium-1-yl)phenolate (betaine dye 33) is used due to certain advantages over betaine dye 30 [26]. $E_{T}^{N}$ values for neat and aqueous [bmim] $\left[\mathrm{PF}_{6}\right]$ and [bmim] $\left[\mathrm{BF}_{4}\right]$, respectively, are obtained from the response of the betaine dye 33 following the empirical relationship: 
$E_{\mathrm{T}}(33)=28591.5 / \lambda_{\text {max }}{ }^{\text {abs }}(\mathrm{nm})$

Additional insight into our systems has been provided using Kamlet-Taft solvatochromic indicators of solvent dipolarity/polarizability $\left(\pi^{*}\right), \mathrm{HBD}$ acidity $(\alpha)$, and hydrogen bond accepting (HBA) basicity $(\beta)[27-29]$ using the equations:

$$
\begin{aligned}
& \pi^{\star}=8.649-0.314 \nu_{\text {DENA }} \\
& \beta=-0.357 \nu_{N A}-1.176 \pi^{*}+11.12 \\
& \alpha=\frac{\left[E_{\tau}(30)-14.6\left(\pi^{*}-0.23 \delta\right)-30.31\right]}{16.5}
\end{aligned}
$$

The polarizability parameter, $\delta$, equals 0.00 for all nonhalogenated aliphatic solvents, 0.50 for all polyhalogenated aliphatics, and 1.00 for all aromatic solvents. [27] $E_{T}(30)$ were calculated from $E_{T}(33)$ by the relationship:

$E_{T}(30)=0.9953( \pm 0.0287) \times E_{T}(33)-8.1132( \pm 1.6546)$

$[R=0.9926$, standard error $=0.8320, n=20]$

$E_{T}(30)$ or $E_{T}(33)$ is also expressed in terms of normalized $E_{T}$ values, i.e.,

$E_{T}^{N}=\frac{\left[E_{T}(30)_{\text {SOLVENT }}-30.7\right]}{32.4}$

$E_{T}^{N}$ is easier to conceive as it is dimensionless and varies between 0 for TMS (extreme non-polar) and 1 for water (extreme polar).

We have measured the $E_{T}^{N}$ values within neat [bmim] $\left[\mathrm{PF}_{6}\right]$ in the temperature range $10-90^{\circ} \mathrm{C}$. On increasing temperature the lowest energy intramolecular charge-transfer absorption band of the betaine dye 33 is bathochromically shifted and $E_{T}^{N}$ values decrease with a slope of $-0.0008 /{ }^{\circ} \mathrm{C}$ shown in Figure 1 which agrees well with earlier studies (performed up to $70{ }^{\circ} \mathrm{C}$ ) [30] except that we have measured $E_{T}^{N}$ up to $90^{\circ} \mathrm{C}$. Gordon et. al. suggested that $E_{T}^{N}$ is a suitable indicator of HBD ability of the imidazolium ring hydrogens to the phenoxide group on betaine dye 33 [28]. The negative thermosolvatochromism registered (see Figure 1) by the probe response of $E_{T}(33)$ undoubtedly suggests a repetitive alteration of the dipolarity/polarizability and/or HBD ability of neat [bmim] $\left[\mathrm{PF}_{6}\right]$ with temperature and it has been observed that the change in $E_{T}^{N}$ values show a good linear correlation with temperature (Table 1). It has been shown by Gordon et. al. that this type of negative solvatochromism is the consequence of the increased differential stabilization of the highly dipolar zwitterionic betaine ground state $\left(\mu_{g}=15 \mathrm{D}\right)$ comparative to the less dipolar excited state $\left(\mu_{e}=6 \mathrm{D}\right)$ with decreased solution temperature [28]. This type of bathochromic shift may be attributed to the cumulative variation of the macroscopic properties like static dielectric constant, density, refractive index, viscosity, molar conductivity, among others, as well as to the weakened $\mathrm{H}$-bond donating ability of the milieu [8,31]. Interestingly, the FWHM increases from $97 \mathrm{~nm}$ to 115 nm on increasing temperature from $10-90^{\circ} \mathrm{C}$. 


\section{Thermosolvatochromism}

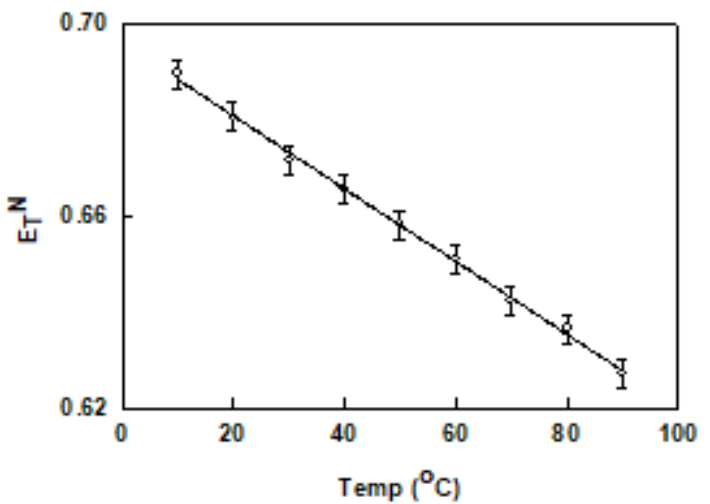

Figure 1: Variation in $\mathrm{E}_{\mathrm{T}}^{\mathrm{N}}$ with temperature within the temperature range $10-90{ }^{\circ} \mathrm{C}$ in neat $[\mathrm{bmim}]\left[\mathrm{PF}_{6}\right]$. Solid line shows fit according to equation reported in Table 1.

As part of our thermosolvatochromism studies of multicomponent ionic liquid based systems, we have selected neat ionic liquid $\left[\mathrm{bmim}^{-}\left[\mathrm{BF}_{4}\right]\right.$, equimolar aqueous [bmim] $\left[\mathrm{BF}_{4}\right]$ and neat water to investigate the impact of temperature on the probe response within these solvent systems. Earlier we had shown that simplistic solvation model suggests possible preferential solvation of a water soluble betaine dye 33 by $[\mathrm{bmim}]\left[\mathrm{BF}_{4}\right][7]$. Here we have presented the behavior of these dyes within aqueous $[\mathrm{bmim}]\left[\mathrm{BF}_{4}\right]$ at different temperatures. Within neat $[\mathrm{bmim}]\left[\mathrm{BF}_{4}\right]$ it is observed that on increasing temperature from $10-60{ }^{\circ} \mathrm{C}$, the lowest energy intramolecular chargetransfer absorption band of the betaine dye 33 is bathochromically shifted and the values of $E_{T}^{N}$ (obtained from $E_{T}(33)$ values) decrease significantly (Figure $2 A$ ) which agrees well with earlier studies [32]. It is interesting to note that temperature has more dramatic effect on $E_{T}^{N}$ within [bmim] $\left[\mathrm{BF}_{4}\right]$ as compared to that within [bmim] $\left[\mathrm{PF}_{6}\right]$. For equimolar aqueous [bmim] $\left[\mathrm{BF}_{4}\right]$ values decrease similarly in the lower temperature regime on increasing temperature from $10-70{ }^{\circ} \mathrm{C}$ (Figure $2 \mathrm{~A}$ ). In both the cases, i.e., for neat $[\mathrm{bmim}]\left[\mathrm{BF}_{4}\right]$ and for equimolar aqueous $\left[\mathrm{bmim}^{\mathrm{b}}\right]\left[\mathrm{BF}_{4}\right]$, the $E_{T}^{N}$ values follow a nonlinear relationship. In neat water on increasing temperature from $10-90^{\circ} \mathrm{C}$ the values decrease with a slope $-0.0010 /{ }^{\circ} \mathrm{C}$ (Figure 2A). The probe response of betaine dye 33 confirms the monotonic change in the dipolarity/polarizability and/or the HBD acidity within the neat and aqueous ionic liquid systems with temperature; interestingly the change in $E_{T}^{N}$ within neat [bmim] $\left[\mathrm{BF}_{4}\right]$ and for equimolar aqueous [bmim] $\left[\mathrm{BF}_{4}\right]$ do not follow linear relationship with temperature (Table 1). The FWHM for neat [bmim] $\left[\mathrm{BF}_{4}\right]$ increases significantly from $66 \mathrm{~nm}$ to $93 \mathrm{~nm}$ on increasing temperature from $10-60^{\circ} \mathrm{C}$, and $x_{[b m i n][B F 4]}=0.5$ solution also shows considerable increase in FWHM from $47 \mathrm{~nm}$ to 61 $\mathrm{nm}$ on increasing temperature from $10-70^{\circ} \mathrm{C}$, whereas there is no substantial change in FWHM for neat water with change in temperature. Notably, above $60{ }^{\circ} \mathrm{C}$ for neat [bmim] $\left[\mathrm{BF}_{4}\right]$ and above $70{ }^{\circ} \mathrm{C}$ for equimolar aqueous $[\mathrm{bmim}]\left[\mathrm{BF}_{4}\right]$ the lowest energy 
intramolecular charge-transfer absorption band of the betaine dye 33 is blurred rendering it difficult to perform thermosolvatochromic studies.

In order to further explore the possible reasons behind this behavior, we have obtained empirical Kamlet-Taft solvatochromic indicators of solvent dipolarity/polarizability $\left(\pi^{*}\right)$, $\mathrm{HBD}$ acidity $(\alpha)$, and HBA basicity $(\beta)$ of neat and aqueous [bmim] $\left[\mathrm{BF}_{4}\right]$ systems in the temperature range $10-90^{\circ} \mathrm{C}$. It is observed from Figure $2 \mathrm{~B}, \mathrm{C}$, and $\mathrm{D}$, respectively, that the empirical Kamlet-Taft solvatochromic parameters $\pi^{*}, \alpha$, and $\beta$ in neat $[\mathrm{bmim}]\left[\mathrm{BF}_{4}\right]$ decrease monotonically with increasing temperature, indicating a reduction in dipolarity/polarizability, HBD acidity, and HBA basicity with temperature. The same parameters within $X_{[b m i m[B F 4]}=0.5$ show similar monotonic reduction having different slopes or curvatures. In case of neat water we observe somewhat different trends where $\alpha$ (slope $=-0.0047 /{ }^{\circ} \mathrm{C}$ ) values decrease but $\pi^{*}$ and $\beta$ remain unchanged with temperature demonstrating a change in HBD acidity but no change in dipolarity/ polarizability and HBA basicity of water in the temperature range $10-90^{\circ} \mathrm{C}$. The probes $N, N$-diethyl-4-nitroaniline and 4-nitroaniline do not show any shift which results in temperature independence of $\pi^{*}$ and $\beta$. The goodness-of-fit in terms of $R^{2}$ and $\sigma$ has also been presented in Table 1.

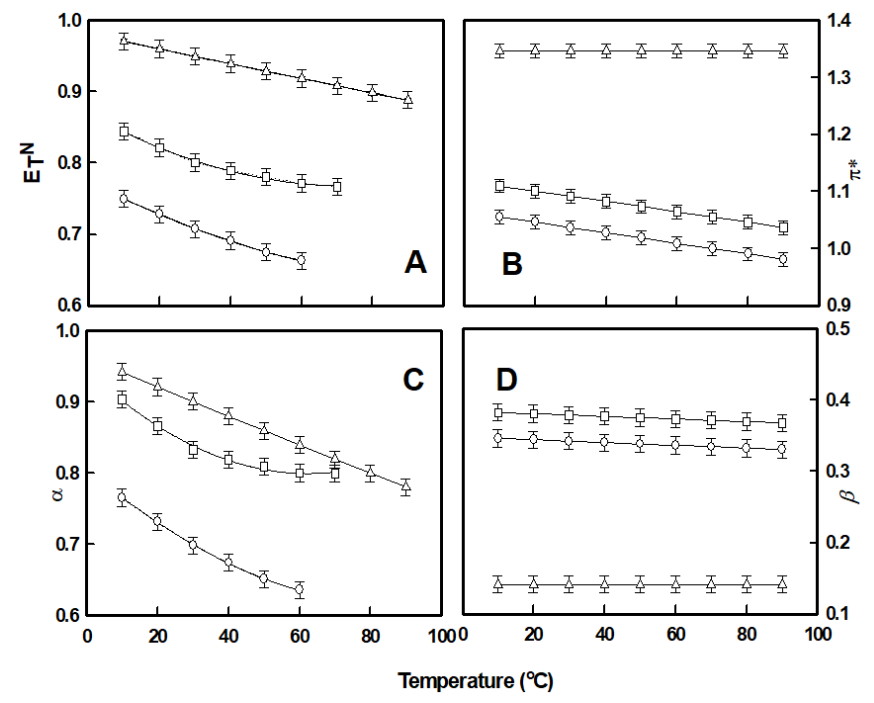

Figure 2: Variation in $E_{T}^{N}$ (panel A), empirical Kamlet-Taft parameters dipolarity/ polarizability $\left(\pi^{*}\right)(B)$, hydrogen-bond donating $(\mathrm{HBD})$ acidity $(\alpha)(\mathrm{C})$ and hydrogen-bond accepting $(\mathrm{HBA})$ basicity $(\beta)(D)$ with temperature within the temperature range $10-90^{\circ} \mathrm{C}$ in neat and aqueous [bmim] $\left[\mathrm{BF}_{4}\right]\left(\mathrm{O}\right.$ : neat $[\mathrm{bmim}]\left[\mathrm{BF}_{4}\right], \square$ : equimolar aqueous $[\mathrm{bmim}]\left[\mathrm{BF}_{4}\right], \Delta$ : neat water). Solid lines and curves show fits according to equations reported in Table 1. 


\section{Thermosolvatochromism}

This type of solvatochromism along with other modifications/alterations of physicochemical properties within neat and aqueous ionic liquids can be explained in terms of the changes in their static dielectric constant, viscosity, density, refractive index and molar conductivity with change in temperature along with microscopic HBD acidity and HBA basicity of the milieu. It has been shown earlier by Han et. al. that density of neat ionic liquids decrease linearly with temperature [31]. Further, the density of neat ionic liquids decreases with decrease in molecular weight of the anions. It has been shown by them as well that on increase in temperature the viscosity gradually decreases and molar conductivity increases showing a strong relationship between the viscosity $(\eta)$ and molar conductivity $(\Lambda)$ which is further represented by the StokesEinstein equation and the Nernst-Einstein equation:

$$
D=\frac{k T}{c \pi \eta r} \quad \text { and } \quad \Lambda=\frac{N e^{2}}{k T}\left(D_{+}+D_{-}\right)
$$

where $D$ is the self-diffusion coefficient of the ionic species $\left(D_{+}\right.$and $D_{-}$correspond to the self-diffusion coefficients for cations and anions, respectively), $k$ is the Boltzmann constant, $c$ is a constant determined by the boundary conditions, $r$ is the Stokes radius of the ion, $N$ is the Avogadro's number, and e represents the electric charge. Studies revealed that the self-diffusion coefficients of cations and anions of neat ionic liquids are approximately proportional to $T \eta^{-1}$, inferring ionic diffusions in neat ionic liquids to abide byeq 7 .

In aqueous solutions of ionic liquids, such as aqueous [bmim] [BF ${ }_{4}$, the higher dielectric constant of water plays a vital role. It has been seen that solvents with higher static dielectric constant affect the viscosity of the solvent mixture due to the difference in the ion-dipole interaction between the ions and solvents. Generally, water with higher static dielectric constant shows a strong interaction with ionic liquids to lower their viscosities on increasing temperature. It is also seen that increase in fluidity of the solvent mixture results in the increase in the molar conductance which also increases to a significant degree inferring a favorable ionic dissociation. It can be conceived that by forming a strong hydrogen bond with ionic liquid anion water forms a three dimensional network and tend to separate the anions and cations to break the aggregate structure of ionic liquid thus promoting the dissociation of the ionic liquid [15-20]. As a result we observe this type of thermosolvatochromism. In another approach El Seoud et. al. proposed that the reason for this type of thermosolvatochromism may be the desolvation of the probes with increasing temperature [32].

\section{Conclusion}

Thermosolvatochromism, as the name suggests, is distinctly seen from the probe responses of solvatochromic absorbance probes betaine dye 33, 4-nitroaniline, and $\mathrm{N}, \mathrm{N}$-diethyl-4-nitroaniline as a function of temperature within neat and aqueous 
'hydrophobic' ionic liquid [bmim] $\left[\mathrm{PF}_{6}\right]$ and aqueous 'hydrophilic' ionic liquid [bmim] $\left[\mathrm{BF}_{4}\right]$. The energy of transition $E_{T}^{N}$, empirical Kamlet-Taft parameters $\pi^{*}, \alpha$, and $\beta$, show considerable change in most cases with variation in temperature registering altered dipolarity/polarizability, HBD acidity and HBA basicity of the cybotactic milieu. The reason behind the thermosolvatochromism is the cumulative variation in macroscopic properties like static dielectric constant, density, viscosity, and refractive index with change in system temperature. Gradual probe desolvation, i.e., decreased stabilization of the ground state by neat and aqueous ionic liquid may be another cause for thermosolvatochromism.

Table 1: The goodness-of-fit equations, $R^{2}$, standard deviation, for the temperature dependent $E_{T}^{N}$ and Kamlet-Taft solvatochromic parameters for neat and aqueous $[\mathrm{bmim}]\left[\mathrm{PF}_{6}\right]$ and $[\mathrm{bmim}]\left[\mathrm{BF}_{4}\right]$.

\begin{tabular}{|c|c|c|c|}
\hline Composition & Equation & $R^{2}$ & $\sigma$ \\
\hline \multicolumn{4}{|c|}{$E_{T}^{N}$} \\
\hline Neat $[\mathrm{bmim}]\left[\mathrm{PF}_{6}\right]$ & $E_{T}^{N}=0.6960-0.0008 \mathrm{~T}$ & 0.9980 & 0.0010 \\
\hline Neat $[$ bmim $]\left[\mathrm{BF}_{4}\right]$ & $E_{T}^{N}=0.7743-0.0026 \mathrm{~T}+1.1821 \times 10^{-5} \mathrm{~T}^{2}$ & 0.9997 & 0.0007 \\
\hline Equimolar aqueous [bmim] $\left[\mathrm{BF}_{4}\right]$ & $E_{T}^{N}=0.8694-0.0028 \mathrm{~T}+1.8940 \times 10^{-5} \mathrm{~T}^{2}$ & 0.9968 & 0.0019 \\
\hline Neat water & $E_{T}^{N}=0.9806-0.0010 \mathrm{~T}$ & 0.9998 & 0.0003 \\
\hline \multicolumn{4}{|c|}{$\pi^{*}$} \\
\hline Neat $[\mathrm{bmim}]\left[\mathrm{BF}_{4}\right]$ & $\pi^{*}=1.0647-0.0009 \mathrm{~T}$ & 0.9999 & 0.0001 \\
\hline Equimolar aqueous [bmim] $\left[\mathrm{BF}_{4}\right]$ & $\pi^{*}=1.1192-0.0009 \mathrm{~T}$ & 0.9997 & 0.0001 \\
\hline Neat water & $\pi^{*}=1.3467$ & 0.9999 & 0.0000 \\
\hline \multicolumn{4}{|c|}{$a$} \\
\hline Neat $[\mathrm{bmim}]\left[\mathrm{BF}_{4}\right]$ & $\alpha=0.8057-0.0042 \mathrm{~T}+2.3393 \times 10^{-5} \mathrm{~T}^{2}$ & 0.9995 & 0.0013 \\
\hline Equimolar aqueous [bmim] $\left[\mathrm{BF}_{4}\right]$ & $\alpha=0.9442-0.0047 \mathrm{~T}+3.7226 \times 10^{-5} \mathrm{~T}^{2}$ & 0.9936 & 0.0038 \\
\hline Neat water & $\alpha=0.9610-0.0020 \mathrm{~T}$ & 0.9998 & 0.0006 \\
\hline \multicolumn{4}{|c|}{$\beta$} \\
\hline Neat $[\mathrm{bmim}]\left[\mathrm{BF}_{4}\right]$ & $\beta=0.3846-0.0002 \mathrm{~T}$ & 0.9999 & 0.0000 \\
\hline Equimolar aqueous $[\mathrm{bmim}]\left[\mathrm{BF}_{4}\right]$ & $\beta=0.3483-0.0002 \mathrm{~T}$ & 0.9999 & 0.0007 \\
\hline Neat water & $\beta=0.1416$ & 0.9998 & 0.0003 \\
\hline
\end{tabular}

\section{References}

1. Fletcher, K. A., \& Pandey, S. (2002). Effect of water on the solvatochromic probe behavior within room-temperature ionic liquid 1-butyl-3-methylimidazolium hexafluorophosphate. Applied spectroscopy, 56(2), 266-271. https:// doi.org/ 10.1366/ 0003702021954539

2. Pandey, S., Fletcher, K. A., Baker, S. N., \& Baker, G. A. (2004). Correlation between the fluorescent response of microfluidity probes and the water content and viscosity of ionic liquid and water mixtures. Analyst, 129(7), 569-573. https://doi.org/ 10.1039/B402145M

3. Fletcher, K. A., \& Pandey, S. (2002). Solvatochromic probe behavior within binary room-temperature ionic liquid 1-butyl-3-methyl imidazolium hexafluorophosphate plus 


\section{Thermosolvatochromism}

ethanol solutions. Applied spectroscopy, 56(11), 1498-1503.https://doi.org/ 10.1366/00037020260377823

4. Fletcher, K. A., \& Pandey, S. (2003). Solvatochromic probe behavior within ternary room-temperature ionic liquid 1-butyl-3-methylimidazolium hexafluorophosphate+ ethanol+ water solutions. The Journal of Physical Chemistry B, 107(48), 13532-13539. https://doi.org/10.1021/jp0276754

5. Fletcher, K. A., Baker, S. N., Baker, G. A., \& Pandey, S. (2003). Probing solute and solvent interactions within binary ionic liquid mixtures. New Journal of Chemistry, 27(12), 1706-1712. https://doi.org/10.1039/B305965K

6. Ali, M., Sarkar, A., Pandey, M. D., \& Pandey, S. (2006). Efficient precipitation of dyes from dilute aqueous solutions of ionic liquids. Analytical sciences, 22(8), 10511053. https://doi.org/10.2116/analsci.22.1051

7. Sarkar, A., \& Pandey, S. (2006). Solvatochromic absorbance probe behavior and preferential solvation in aqueous 1-butyl-3-methylimidazolium tetrafluoroborate. Journal of Chemical \& Engineering Data, 51(6), 2051-2055. https://doi.org/ 10.1021/je0601560

8. Ali, M., Sarkar, A., Tariq, M., Ali, A., \& Pandey, S. (2007). Dilute aqueous 1-butyl-3methylimidazolium hexafluorophosphate: properties and solvatochromic probe behavior. Green Chemistry, 9(11), 1252-1258. https://doi.org/10.1039/b704843b.

9. Ali, M., Baker, G. A., \& Pandey, S. (2008). Dye redissolution after precipitation with a water-miscible ionic liquid. Chemistry letters, 37(3), 260-261. https://doi.org/ 10.1246/cl.2008.260

10. Sarkar, A., Trivedi, S., \& Pandey, S. (2008). Unusual solvatochromism within 1butyl-3-methylimidazolium hexafluorophosphate+ poly (ethylene glycol) mixtures. The Journal of Physical Chemistry B, 112(30), 9042-9049. https://doi.org/ 10.1021/ jp802833f

11. Sarkar, A., Trivedi, S., Baker, G. A., \& Pandey, S. (2008). Multiprobe spectroscopic evidence for "hyperpolarity" within 1-butyl-3-methylimidazolium hexafluorophosphate mixtures with tetraethylene glycol. The Journal of Physical Chemistry B, 112(47), 14927-14936. https://doi.org/10.1021/jp804591q

12. Trivedi, S., Sarkar, A., \& Pandey, S. (2009). Solvatochromic absorbance probe behavior within 1-butyl-3-methylimidazolium hexafluorophosphate+ propylene carbonate: Preferential solvation or solvent-solvent interaction?. Chemical Engineering Journal, 147(1), 36-42. https://doi.org/10.1016/j.cej.2008.11.014

13. Sarkar, A., Ali, M., Baker, G., Tetin, S., Ruan, Q. \& Pandey, S. (2009). Multiprobe Spectroscopic Investigation of Molecular-level Behavior within Aqueous 1-Butyl-3- 
methylimidazolium Tetrafluoroborate, The Journal of Physical Chemistry B, 113 (10), 3088-3098. https://doi.org/10.1021/jp8098297

14. Sarkar, A., Ali, M., Baker, G. A., Tetin, S. Y., Ruan, Q., \& Pandey, S. (2009). Multiprobe spectroscopic investigation of molecular-level behavior within aqueous 1butyl-3-methylimidazolium tetrafluoroborate. The Journal of Physical Chemistry $B$, 113(10), 3088-3098. https://doi.org/10.1021/jp901338xJ

15. Mele, A., Tran, C. D., \& De Paoli Lacerda, S. H. (2003). The Structure of a Room-Temperature lonic Liquid with and without Trace Amounts of Water: The Role of C-H...O and C-H...F Interactions in 1-n-Butyl-3-Methylimidazolium Tetrafluoroborate. Angewandte Chemie, 115(36), 4500-4502. https:// 10.1002/anie.200351783

16. Saha, S., \& Hamaguchi, H. O. (2006). Effect of water on the molecular structure and arrangement of nitrile-functionalized ionic liquids. The Journal of Physical Chemistry B, 110(6), 2777-2781. https://doi.org/10.1021/jp053817t

17. Cammarata, L., Kazarian, S. G., Salter, P. A., \& Welton, T. (2001). Molecular states of water in room temperature ionic liquids. Physical Chemistry Chemical Physics, 3(23), 5192-5200. https://doi.org/10.1039/B106900D

18. Köddermann, T., Wertz, C., Heintz, A., \& Ludwig, R. (2006). The association of water in ionic liquids: a reliable measure of polarity. Angewandte Chemie International Edition, 45(22), 3697-3702. https://doi.org/10.1002/anie.200504471

19. Tokuda, H., Baek, S. \& Watanabe, M. (2005). Room-Temperature Ionic LiquidOrganic Solvent Mixtures: Conductivity and Ionic Association. Electrochemistry, 73(8), 620-622. https://doi.org/10.5796/electrochemistry.73.620

20. Bowers, J., Butts, C. P., Martin, P. J., Vergara-Gutierrez, M. C., \& Heenan, R. K. (2004). Aggregation behavior of aqueous solutions of ionic liquids. Langmuir, 20(6), 2191-2198. https://doi.org/10.1021/la035940m

21. Reichardt, C. (1992). Solvatochromism, thermochromism, piezochromism, halochromism, and chiro-solvatochromism of pyridinium N-phenoxide betaine dyes. Chemical Society Reviews, 21(3), 147-153. https://doi.org/10.1039/CS9922100147

22. Silva, P. L., Bastos, E. L., \& El Seoud, O. A. (2007). Solvation in binary mixtures of water and polar aprotic solvents: theoretical calculations of the concentrations of solvent- water hydrogen-bonded species and application to thermosolvatochromism of polarity probes. The Journal of Physical Chemistry B, 111(22), 6173-6180. DOI: 10.1021/jp068596|

23. Tada, E. B., Silva, P. L., \& El Seoud, O. A. (2003). Thermo-solvatochromism of zwitterionic probes in aqueous alcohols: effects of the properties of the probe and the alcohol. Physical Chemistry Chemical Physics, 5(24), 5378-5385. https://doi.org/ 10.1039/B308550C 


\section{Thermosolvatochromism}

24. Martins, C. T., Lima, M. S., Bastos, E. L., \& El Seoud, O. A. (2008). Thermo-Solvatochromism of Merocyanine Polarity Probes-What Are the Consequences of Increasing Probe Lipophilicity through Annelation?. European Journal of Organic Chemistry, 2008(7), 1165-1180.https://doi.org/10.1002/ ejoc. 200700805

25. Martins, C. T., Lima, M. S., \& El Seoud, O. A. (2006). Thermosolvatochromism of merocyanine polarity indicators in pure and aqueous solvents: relevance of solvent lipophilicity. The Journal of Organic Chemistry, 71(24), 9068-9079. https://doi.org/ 10.1021/j0061533e

26. Kessler, M. A., \& Wolfbeis, O. S. (1989). ET (33), a solvatochromic polarity and micellar probe for neutral aqueous solutions. Chemistry and physics of lipids, 50(1), 5156. https://doi.org/10.1016/0009-3084(89)90025-X

27. Kamlet, M. J., Abboud, J. L., \& Taft, R. W. (1977). The solvatochromic comparison method. 6. The. $\pi^{*}$ scale of solvent polarities. Journal of the American Chemical Society, 99(18), 6027-6038. https://doi.org/10.1021/ja00460a031

28. Muldoon, M. J., Gordon, C. M., \& Dunkin, I. R. (2001). Investigations of solvent-solute interactions in room temperature ionic liquids using solvatochromic dyes. Journal of the Chemical Society, Perkin Transactions 2, (4), 433-435. https://doi.org/10.1039/B101449H

29. Kamlet, M. J., Abboud, J. L. M., Abraham, M. H., \& Taft, R. W. (1983). Linear solvation energy relationships. 23. A comprehensive collection of the solvatochromic parameters, $\Pi^{*}, \alpha$, and $\beta$, and some methods for simplifying the generalized solvatochromic equation. The Journal of Organic Chemistry, 48(17), 2877-2887.https:// doi.org/10.1021/jo00165a018

30. Baker, S. N., Baker, G. A., \& Bright, F. V. (2002). Temperature-dependent microscopic solvent properties of 'dry'and 'wet'1-butyl-3-methylimidazolium hexafluorophosphate: correlation with ET (30) and Kamlet-Taft polarity scales. Green Chemistry, 4(2), 165-169. https://doi.org/10.1039/B111285F

31. Li, W., Zhang, Z., Han, B., Hu, S., Xie, Y., \& Yang, G. (2007). Effect of water and organic solvents on the ionic dissociation of ionic liquids. The Journal of Physical Chemistry B, 111(23), 6452-6456. https://doi.org/10.1021/jp071051m

32. Martins, C. T., Sato, B. M., \& Seoud, O. A. E. (2008). First study on the thermosolvatochromism in aqueous 1-(1-butyl)-3-methylimidazolium tetrafluoroborate: a comparison between the solvation by an ionic liquid and by aqueous alcohols. The Journal of Physical Chemistry B, 112(28), 8330-8339. https://doi.org/10. 1021/jp8017474 
doi:10.31674/book.2020.macbs

\title{
Role of tDMRT1, Sox9a, Cyp19a1 and Foxl2 in the sex-determining system of Oreochromis niloticus: An Overview
}

\author{
Adity Sarbajna
}

Assistant Professor, Department of Zoology, Surendranath College, Kolkata, India

Corresponding Author's E-mail: aditymukhopadhyay@gmail.com

\begin{abstract}
The Nile tilapia, a gonochoristic teleost fish with $X X / X Y$ sex-determining system, provides an excellent model for studying gonadal sex differentiation. The Nile tilapia gonads rise as a pair to form the genital ridge composed of primordial germ cells and surrounded by connective tissues. The gonads grow to differentiate into male and female structures with the proliferation of the primordial germ cells. Quantitative real time RT-PCR is used to determine the precise timing of gonadal expression of genes thought to be associated with gonadal sex differentiation in vertebrates. It is evident from various studies that the sex-specific expression of foxl2 and cyp19al in XX gonads and dmrt1 in XY gonads during early gonadal differentiation (5-6 dah) is critical for undifferentiated gonads to differentiate in either the ovary or testis in Nile tilapia. Characterization of gonadal trancriptomes from Nile tilapia reveals differentially expressed genes. Both estrogen and androgen receptors are found to be expressed in $X X$ gonads, but only estrogen receptors are expressed in $X Y$ gonads at 5 dah. This forms the basis of exogenous steroid treatment induced $X X-X Y$ sex reversal in this fish. Recent studies have identified the role of miRNA-mediated post transcriptional regulation in differentiation of ovary and testis in Nile Tilapia. Different expression pattern of miRNA is observed during development of testis and ovary which ascertain their role in the regulation of the ovarian and testicular development and function.
\end{abstract}

Keywords: Nile tilapia, Sex Differentiation, tDMRT1, Sox9a, Cyp19a1, Fox/2

\section{Introduction}

Sex determination, unlike many developmental processes, is characterized by a lack of conservation throughout the vertebrates. Although two sex-determining genes, SRY/Sry [1] and dmy [2, 3] have been identified in mammals and a teleost fish, the medaka Oryzias latipes, respectively, their gene structures are entirely different. Furthermore, dmy was found to be present only in two of more than 20 closely related species of medaka. Thus, the mechanisms by which sex is determined are extremely diverse in vertebrates. In contrast, factors operating during gonadal sex 
differentiation appear to be relatively conserved. For example, Sox9 has been implicated in testicular differentiation in mammals as one of the immediate gene products after SRY [4]. It has also been implicated in testicular development in birds $[5,6]$. Dmrt1 and amh reportedly are involved in testicular differentiation in several vertebrate species [7-10]. Another good example of a conserved mechanism involved in sex differentiation is the important role of estrogens in ovarian differentiation in non-mammalian vertebrates including fish [11, 12], amphibians [13, 14], reptiles [15], and birds [9]. In contrast, there has been a controversy regarding the role of androgen or steroid receptors in the regulation of gonadal sex differentiation. However, the roles of these genes and factors in early gonadal sex differentiation do not appear to always be the same among different vertebrate groups. For example, in eutherian mammals, estrogens do not play an important role in early ovarian differentiation. It has also been reported that sox9 showed relatively strong expression at equivalent levels in both male and female gonads during the early sex differentiation of fish [16]. Thus, it is still too early to make any conclusions regarding the conserved and divergent mechanisms of sex determination and gonadal sex differentiation in vertebrates.

\section{Gonadal Sex Differentiation}

The Nile tilapia (Oreochromis niloticus) is a gonochoristic teleost with a stable XXIXY sex-determination system. In this fish, all-female $(X X)$ or all-male $(X Y)$ broods have been obtained by artificial fertilization of normal eggs $(X X)$ and sex-reversed male sperm (XX), or normal eggs $(X X)$ and super male sperm (YY), respectively. The morphological sexual dimorphism during gonadal differentiation consisted of changes in germ cell number and histogenesis (Figs. 1, 2). Primordial germ cells (PGCs) migrated into the gonadal anlagen 3 days after hatching (dah), 7 days after fertilization $[17,18]$. Thereafter, the germ cell numbers did not significantly change in either sex from 5 to 8 dah. After 8 dah, however, the XX female germ cells continued to proliferate, whereas the germ cell numbers did not change from 9 to 14 dah in XY male gonads (Fig. 1). As described in a previous report [17], the number of germ cells in $X Y$ male gonads increased again after 14 dah, but spermatogenesis was not observed until 70 dah. The formation of the ovarian cavity or the intratesticular efferent duct occurred between 20 and 25 dah in the $X X$ and $X Y$ gonads, respectively. Figure 2 shows the gonadal differentiation in tilapia. In $X Y$ gonads, the medullary cell mass derived from the germinal epithelium, neighboured the germ-cell-surrounding cells and developed into a cord-like structure as the intra-testicular efferent duct. Although no medullary cell mass developed in the XX gonads, an ovarian cavity was formed by the extension of both tips of the gonads [19]. 


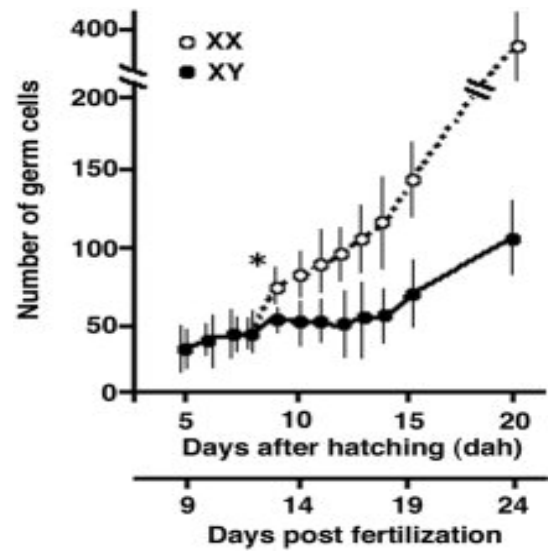

Figure 1: Changes in germ cell number during gonadal differentiation in Tilapia. Germ cell numbers for both sexes were counted daily in five to six individuals using histological sections. Germ cell numbers are represented as means +/- SE. ${ }^{*} P$ $<0.05$, as compared between $X Y$ and $X X$ fry. The open and closed circles and the bars indicate the means +/- SE of XX females and $X Y$ males, respectively.

\section{tDMRT1}

Around 25 dah, when the formation of the intra-testicular efferent duct anlagen was observed, tDMRT1 expression was found in the Sertoli cells, medullary cell mass and epithelial cells of the anlagen of the efferent duct (Fig. 2)[18]. From the localization of tDMRT1-positive cells, it appears that some portion of the tDMRT1-positive medullary cell mass neighbouring the Sertoli cells differentiates into the precursor cell mass of the efferent duct, and onward into the anlagen of the intra-testicular efferent duct. In mature fish, the specific expression of tDMRT1was localized only in the Sertoli and epithelial cells of the intra-testicular efferent duct in the mature testes and was undetectable in the ovaries.

\section{Sox9a}

Although Sox9a is expressed in the germ-cell-surrounding cells, Sox9a expression shows no difference between the sexes until 25 dah. The first signs of the sexual dimorphic expression of Sox9a are observed at 25 dah, when sex differences in histological architecture begins to be seen, such as the incipient formation of the intratesticular efferent duct and the ovarian cavity in the males and the females, respectively [17]. The localization of Sox9a showed sex differences at this stage. In the XY gonad, signals for Sox9a are seen in the germ-cell-surrounding cells and the medullary cell mass. In the XX gonad, signals are seen in the germ-cell-surrounding cells and interstitial cells in the tip of the gonad. After 25 dah, Sox9a expression is seen specifically in the germ-cell-surrounding cells of the male gonads. In contrast to tDMRT1, however, Sox9a was not expressed in the epithelial cells of the efferent duct in the testis. Thus tDMRT1 is expressed in XY gonads specifically before the appearance of any morphological sex differences, and that Sox9a is expressed in XY gonads specifically after the appearance of sex differences in histological architecture, such as the formation of intra-testicular efferent duct or ovarian cavity. In mature gonads, Sox9a is expressed in males but notfemales [20]. 


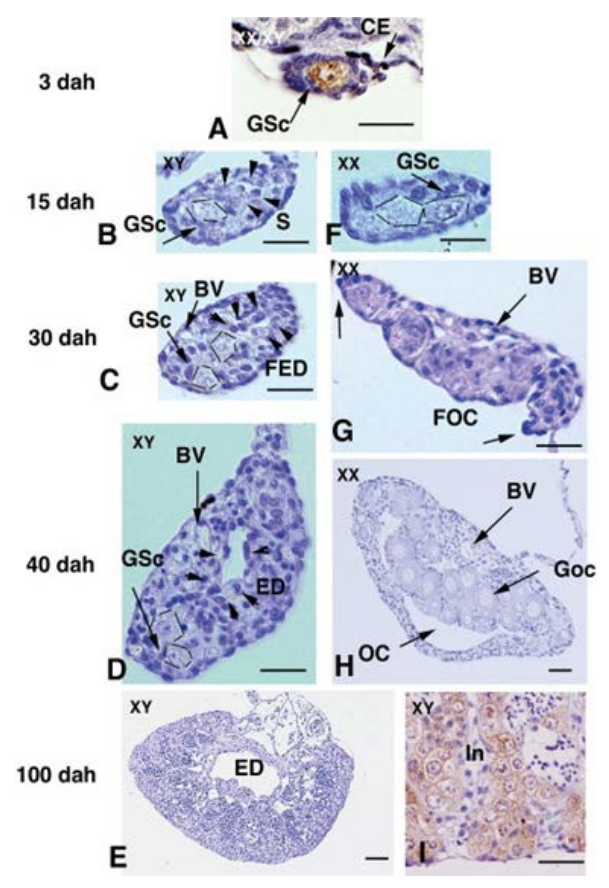

Figure 2: Gonadal differentiation in Tilapia. A: Gonad at 3 days after hatching (dah). The gonadal anlagen were formed at 3 dah. CE, coelomic epithelium; Gsc, germ-cell-surrounding cell. B-E, I:XY gonads. F-H: XX gonads. Dotted line, gonial germ cell; $\mathrm{S}$, medullary cell mass; BV, blood vessel; FOC, formation of ovarian cavity; FED, formation of efferent duct; Goc, growing oocyte; OC, ovarian cavity; ED, efferent duct; In interstitium A and I: the germ cells were stained with anti-vasa antibody [18]. Scale bars $20 \mathrm{~m}$ in $\mathrm{A}-\mathrm{H}, 30 \mathrm{~m}$ in I.

\section{Cyp19a1}

Even though the tilapia gonad remains morphologically undifferentiated until $25 \mathrm{~d}$ after hatching (dah), the female-specific expression of Cyp19a1, encoding aromatase that catalyzes the conversion of androgen to estrogen, starts from around 5 dah, before the onset of morphological differentiation of the ovary. Cyp19a1 was found to encode the fish ovarian type aromatase, involved in the production of estrogens in the fish gonad [21].

\section{Foxl2}

There have been several studies implicating the forkhead $(\mathrm{FH})$ transcription factor, Foxl2, in ovarian development, granulosa cell differentiation, and thus the proper maintenance of ovarian function [22, 23]. It is the earliest known sex dimorphic marker, expressed in the somatic cells during early development and later in granulosa cells surrounding the oocytes [21]. A number of studies have provided information on varying ranges of phenotypes, where Foxl2 was either mutated or knocked out, demonstrating its role in ovarian differentiation. Furthermore, the preliminary data on the quantitative expression of Foxl2 also corroborated its positive correlation with the expression patterns of aromatase from as early as 5 dah [24] in the Nile tilapia. 


\section{Conclusion}

The genetic mechanisms triggering sex determination appear to be diverse in nonmammalian vertebrates. The undifferentiated gonads of teleosts differentiate into testes or ovaries in a similar way to other vertebrates. Sex differentiation progresses under genetic control together with the effects of various environmental factors. Considerable changes in the abundance of transcripts occur in the gonads of the Nile tilapia during the course of sex determination and differentiation. Increases in the expression of fox $\mid 2$ and cyp19a1 in XX gonads from 5 dah suggest an important role for Foxl2 and Cyp19a1 in ovarian differentiation. Dmrt1 exhibited a male specific expression in XY gonads from 6 dah onward, suggesting an important role for Dmrt1 in testicular differentiation. Thus, the differential expression of genes occurring in XX and $X Y$ gonads during the period 5-6 dah is critical for undifferentiated gonads to differentiate into either the ovary or testis in the Nile tilapia. Whether any genes (sex-determining gene?) are expressed in either gonad prior to this period is an important questions yet to be answered.

\section{References}

1. Sinclair, A. H., Berta, P., Palmer, M. S., Hawkins, J. R., Griffiths, B. L., Smith, M. J., ... \& Goodfellow, P. N. (1990). A gene from the human sex-determining region encodes a protein with homology to a conserved DNA-binding motif. Nature, 346(6281), 240244.

2. Matsuda, M., Nagahama, Y., Shinomiya, A., Sato, T., Matsuda, C., Kobayashi, T., ... \& Hori, H. (2002). DMY is a Y-specific DM-domain gene required for male development in the medaka fish. Nature, 417(6888), 559-563.

3. Nanda, I., Kondo, M., Hornung, U., Asakawa, S., Winkler, C., Shimizu, A., ... \& Schmid, M. (2002). A duplicated copy of DMRT1 in the sex-determining region of the $Y$ chromosome of the medaka, Oryzias latipes. Proceedings of the National Academy of Sciences, 99(18), 11778-11783.

4. Kanai, Y., Hiramatsu, R., Matoba, S., \& Kidokoro, T. (2005). From SRY to SOX9: mammalian testis differentiation. Journal of biochemistry, 138(1), 13-19.

5. Takada, S., Ota, J., Kansaku, N., Yamashita, H., Izumi, T., Ishikawa, M., ... \& Fujiwara, S. I. (2006). Nucleotide sequence and embryonic expression of quail and duck Sox9 genes. General and comparative endocrinology, 145(2), 208-213.

6. Vaillant, S., Magre, S., Dorizzi, M., Pieau, C., \& Richard-Mercier, N. (2001). Expression of AMH, SF1, and SOX9 in gonads of genetic female chickens during sex reversal induced by an aromatase inhibitor. Developmental dynamics: an official publication of the American Association of Anatomists, 222(2), 228-237. 
7. Bratuś, A., \& Słota, E. (2006). DMRT1/Dmrt1, the sex determining or sex differentiating gene in Vertebrata. Folia Biologica, 54(3-4), 81-86.

8. Behringer, R. R., Finegold, M. J., \& Cate, R. L. (1994). Müllerian-inhibiting substance function during mammalian sexual development. Cell, 79(3), 415-425.

9. Smith, C.A., \& Sinclair, A. H. (2004). Sex determination: insights from the chicken. Bioessays, 26(2), 120-132.

10. Shoemaker, C., Ramsey, M., Queen, J., \& Crews, D. (2007). Expression of Sox9, Mis, and Dmrt1 in the gonad of a species with temperature-dependent sex determination. Developmental dynamics: an official publication of the American Association of Anatomists, 236(4), 1055-1063.

11. Devlin, R. H., \& Nagahama, Y. (2002). Sex determination and sex differentiation in fish: an overview of genetic, physiological, and environmental influences. Aquaculture, 208(3-4), 191-364.

12. Yamamoto, T. O. (1969). 3 Sex Differentiation. In Fish physiology (Vol. 3, pp. 117175). Academic Press.

13. Hayes, T. B. (1998). Sex determination and primary sex differentiation in amphibians: genetic and developmental mechanisms. Journal of experimental zoology, 281(5), 373-399.

14. Miyata, S., \& Kubo, T. (2000). In vitro effects of estradiol and aromatase inhibitor treatment on sex differentiation in Xenopus laevis gonads. General and comparative endocrinology, 119(1), 105-110.

15. Pieau, C., \& Dorizzi, M. (2004). Oestrogens and temperature-dependent sex determination in reptiles: all is in the gonads. Journal of Endocrinology, 181(3), 367377.

16. Nakamoto, M., Suzuki, A., Matsuda, M., Nagahama, Y., \& Shibata, N. (2005). Testicular type Sox9 is not involved in sex determination but might be in the development of testicular structures in the medaka, Oryzias latipes. Biochemical and biophysical research communications, 333(3), 729-736.

17. Kobayashi, T., Kajiura-Kobayashi, H., \& Nagahama, Y. (2000). Differential expression of vasa homologue gene in the germ cells during oogenesis and spermatogenesis in a teleost fish, tilapia, Oreochromis niloticus. Mechanisms of Development, 99(1-2), 139-142.

18. Kobayashi, T., Kajiura-Kobayashi, H., \& Nagahama, Y. (2002). Two isoforms of vasa homologs in a teleost fish: their differential expression during germ cell 
differentiation. Mechanisms of development, 111(1-2), 167-171.

19. Nakamura, M., Kobayashi, T., Chang, X. T., \& Nagahama, Y. (1998). Gonadal sex differentiation in teleost fish. Journal of Experimental Zoology, 281(5), 362-372.

20. Kobayashi, T., Kajiura-Kobayashi, H., Guan, G., \& Nagahama, Y. (2008). Sexual dimorphic expression of DMRT1 and Sox9a during gonadal differentiation and hormone-induced sex reversal in the teleost fish Nile tilapia (Oreochromis niloticus). Developmental dynamics: an official publication of the American Association of Anatomists, 237(1), 297-306.

21. Yao, H. H. C. (2005). The pathway to femaleness: current knowledge on embryonic development of the ovary. Molecular and cellular endocrinology, 230(1-2), 87-93.

22. Cocquet, J., De Baere, E., Gareil, M., Pannetier, M., Xia, X., Fellous, M., \& Veitia, R. A. (2003). Structure, evolution and expression of the FOXL2 transcription unit. Cytogenetic and genome research, 101(3-4), 206-211.

23. Loffler, K. A., Zarkower, D., \& Koopman, P. (2003). Etiology of ovarian failure in blepharophimosis ptosis epicanthus inversus syndrome: FOXL2 is a conserved, earlyacting gene in vertebrate ovarian development. Endocrinology, 144(7), 3237-3243.

24. Ijiri, S., Kaneko, H., Kobayashi, T., Wang, D. S., Sakai, F., Paul-Prasanth, B., ... \& Nagahama, Y. (2008). Sexual dimorphic expression of genes in gonads during early differentiation of a teleost fish, the Nile tilapia Oreochromis niloticus. Biology of reproduction, 78(2), 333-341. 
doi:10.31674/book.2020.macbs

\title{
Introducing a New Family of Fluorophores: Keto- tetrahydrocarbazole
}

\author{
Amrit Krishna Mitra \\ Assistant Professor [West Bengal Education Service], Department of Chemistry \\ Government General Degree College, Singur, Hooghly, West Bengal, India \\ Corresponding Author's E-mail: amritsepistles@gmail.com
}

\begin{abstract}
The primary aim of this research venture is the synthesis and photophysical characterizations of different fluorophores based on 1-keto-1,2,3,4-tetrahydrocarbazole skeleton. Several such molecules have been designed that can act as fluorosensors of immediate micro-environments. The emissive properties of such fluorophores are considerably solvent sensitive, although their absorption spectra are relatively less sensitive to the nature of the solvents. Various analyses suggest that the hydrogen bond donating ability of the solvents is chiefly responsible for controlling the fluorescence spectral shifts of such derivatives. Sensitivity towards homogeneous solvents of varied nature, effect of binary mixtures, competence towards sensing the micro-heterogeneous environments of different micelles, reverse micelles and $\beta$-cyclodextrin add significance to this family of fluorophores. Significant interactions with albumin proteins and photo induced electron transfer from aliphatic or aromatic amines indicate the probable impending use of such molecules as potential drugs. Suitable synthetic exploration generates new derivatives having a-hydroxy acetic acid moiety keeping the chromophoric unit intact. Acid functionality thus generated can be tagged with biomolecules leading to the development of probable synthetic bio-markers.
\end{abstract}

Keywords: Keto-tetrahydrocarbazole; Fluorophore; Fluorosensor; Serum albumin; Micelles; Cyclodextrins; Fluorescence quenching; Fischer Indole Cyclization; JappKlingemann

\section{Introduction}

Designing and characterizations of small molecule environment sensitive fluorophores are extremely significant in the viewpoint of bio-chemical and bio-physical studies [1]. They are extremely precious owing to their capability to probe micro-environments which can decipher bulk information in the study of molecular biology, drug discovery, material science, tissue diagnostics, environmental indicators, enzyme substrates and cellular staining agents [2]. Although numerous fluorophores [3] are known in the form of coumarins, fluoresceins, cyanines, oxazines, pyrenes, quinines, bodipy dyes etc., the quest for newer ones is still on as they are extremely essential to visualize a biochemical process.

This research venture involves synthesis and photo-physical studies of a new family of fluorophores having keto-tetrahydrocarbazole (KTHC) framework. The origin of this 
research work dates back to approximately ten years. There has been a surprising observation of Chakraborty et al (at Calcutta School of Tropical Medicine) while synthesising several methoxy and methylenedioxy derivatives of ketotetrahydrocarbazole in the viewpoint that, they emit fluorescence [4]. This observation has been the backbone of this research work and demanded exhaustive photophysical and photobiological studies of methoxy and methylenedioxy derivatives of ketotetrahydrocarbazole [MDKTHC].

It is worthwhile to mention that keto-tetrahydrocarbazoles are important synthetic precursors to obtain biologically active carbazole derivatives. Several members of ketotetrahydrocarbazole family show promising synthetic importance as intermediates for the synthesis of naturally occurring, biologically active [5] carbazole alkaloids and carbazoloquinones (Figure 1). Prominent biological activities of carbazole alkaloids have always been an inspiration for us to study the growth and development of ketotetrahydrocarbazole family as the members have the potentiality to act as bio-active units.

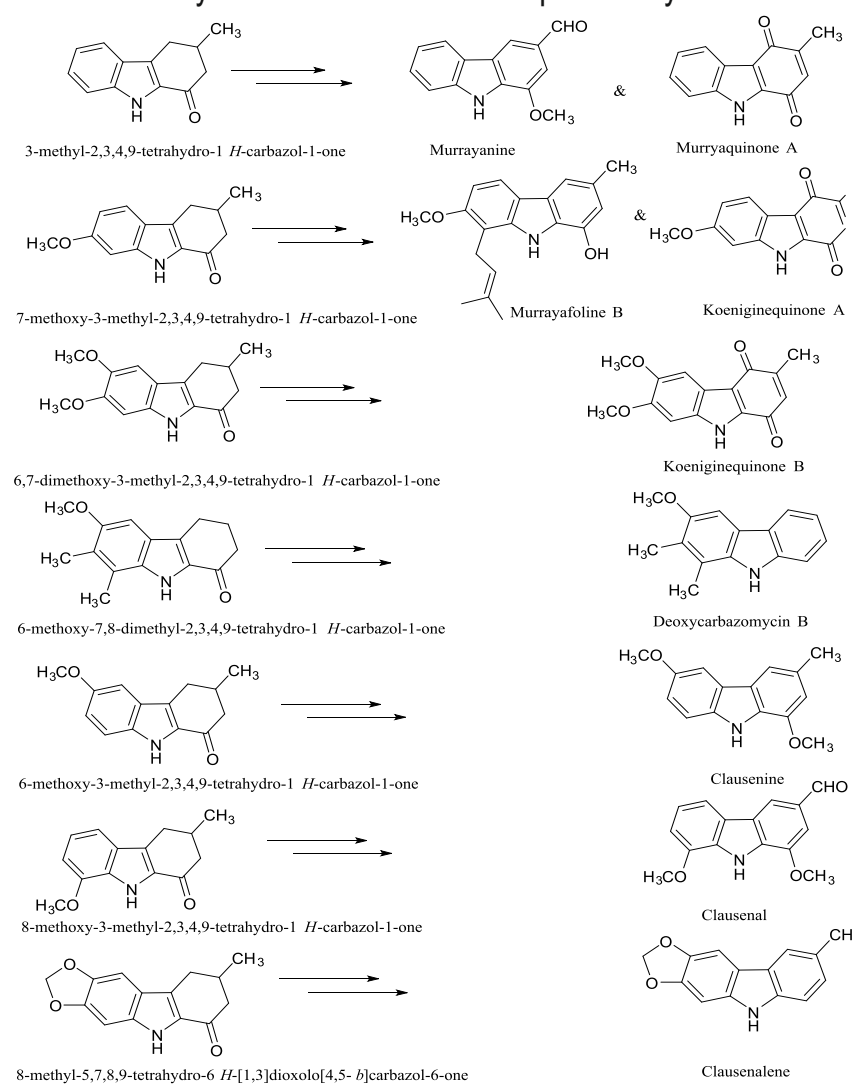

Figure 1: Members of 1-keto-1,2,3,4-tetrahydrocarbazole family as important synthetic intermediates for the efficient synthesis of corresponding bio-active carbazole derivatives. 


\section{Instrumentations and Methods}

Jasco V-650 spectrophotometer and Horiba Jobin-Yvon Fluoromax-3 have been used for absorbance and fluorescence measurements respectively. In all measurements, the sample concentration has been maintained in the range of $\sim 10^{-6} \mathrm{M}$ in order to avoid aggregation and reabsorption effects. Experiments have been carried out at an ambient temperature of $25^{\circ} \mathrm{C}$, unless otherwise specified. Only freshly prepared air-equilibrated solutions have been used for spectroscopic measurements. Fluorescence lifetimes have been measured using a time-correlated single-photon-counting (TCSPC) spectrophotometer (Horiba Jobin-Yvon Single Photon Counting Controller Fluorohub). The sample has been excited at $340 \mathrm{~nm}$ using an LED to trigger the fluorescence of MDKTHC, and the signals have been collected at a magic angle of $54.7^{\circ}$. The lifetime is obtained using deconvolution technique which is based on a convolution integral. We have used IBH DAS 6.2 data analysis software in which reduced $x^{2}$ and weighted residuals serve as parameters for goodness of fit. Nanosecond flash photolysis set-up (Applied Photophysics) containing Nd:YAG (Lab series, Model Lab 150, Spectra Physics) laser has been used for the measurement of transient absorption spectra. The sample has been excited at $355 \mathrm{~nm}$ (FWHM = $8 \mathrm{~ns}$ ) using Nd-YAG laser (Lab series, Model Lab 150, Spectra Physics). Transient species in solution have been monitored through absorption of light from a pulsed xenon lamp (150 W) at right angle to the laser beam. All the data have been analysed fitted and plotted by the software Origin ${ }^{\circledR}$ 8.0 Pro. All experiments have been carried out using quartz cuvettes of $1 \mathrm{~cm}^{2}$ cross-sections purchased from HellmaAnalytics.

\section{Synthesis of various fluorophores based on 1-keto-1,2,3,4-tetrahydrocarbazole skeleton}

Out of many sophisticated methods [5, 6], here we have followed Japp-Klingemann [7, 8] reaction to obtain desired hydrazones and then Fischer Indole Cyclization [9] to achieve the said skeleton(Figure 2).<smiles>[R]c1cc(NN=C2CCC([R5])CC2=O)c([R2])c([R3])c1[R]</smiles>

$$
\underset{\text { Cyclisation }}{\stackrel{\text { Fischer Indole }}{\longrightarrow}}
$$

Substituents

$\mathrm{R}_{1}=\mathrm{OCH}_{3} ; \mathrm{R}_{2}, \mathrm{R}_{3}, \mathrm{R}_{4}, \mathrm{R}_{5}=\mathrm{H}$

$\mathrm{R}_{1}, \mathrm{R}_{3}=\mathrm{OCH}_{3} ; \mathrm{R}_{2}, \mathrm{R}_{4}, \mathrm{R}_{5}=\mathrm{H}$

$\mathrm{R}_{3}=\mathrm{OCH}_{3} ; \mathrm{R}_{1}, \mathrm{R}_{2}, \mathrm{R}_{4}, \mathrm{R}_{5}=\mathrm{H}$

$\mathrm{R}_{4}=\mathrm{OCH}_{3} ; \mathrm{R}_{1}, \mathrm{R}_{2}, \mathrm{R}_{3}, \mathrm{R}_{5}=\mathrm{H}$

$\mathrm{R}_{1}, \mathrm{R}_{4}=\mathrm{OCH}_{3} ; \mathrm{R}_{2}, \mathrm{R}_{3}, \mathrm{R}_{5}=\mathrm{H}$

$\mathrm{R}_{2}, \mathrm{R}_{3}=\mathrm{OCH}_{3} ; \mathrm{R}_{1}, \mathrm{R}_{4}, \mathrm{R}_{5}=\mathrm{H}$

$\mathrm{R}_{2}, \mathrm{R}_{3}=\mathrm{OCH}_{3} ; \mathrm{R}_{1}, \mathrm{R}_{4}=\mathrm{H} ; \mathrm{R}_{5}=\mathrm{CH}_{3}$

$\mathrm{R}_{1}, \mathrm{R}_{2}, \mathrm{R}_{3}=\mathrm{OCH}_{3} ; \mathrm{R}_{4}, \mathrm{R}_{5}=\mathrm{H}$

$\mathrm{R}_{2}=\mathrm{OCH}_{3} ; \mathrm{R}_{1}, \mathrm{R}_{5}=\mathrm{H} ; \mathrm{R}_{3}, \mathrm{R}_{4}=\mathrm{CH}_{3}$

$\mathrm{R}_{2}, \mathrm{R}_{3}=\mathrm{OCH}_{2} \mathrm{O} ; \mathrm{R}_{1}, \mathrm{R}_{4}=\mathrm{H} ; \mathrm{R}_{5}=\mathrm{CH}_{3}$<smiles>[R9]c1c([R9])c(Br)c2c3c([nH]c2c1[R])C(=O)CC([R9])C3</smiles>

Products

5-methoxy-2,3,4,9-tetrahydro-1 $H$-carbazol-1-one

5,7-dimethoxy-2,3,4,9-tetrahydro-1 $H$-carbazol-1-one

7-methoxy-2,3,4,9-tetrahydro-1 $H$-carbazol-1-one

8-methoxy-2,3,4,9-tetrahydro-1 $H$-carbazol-1-one

5,8-dimethoxy-2,3,4,9-tetrahydro-1 $H$-carbazol-1-one

6,7-dimethoxy-2,3,4,9-tetrahydro-1 $H$-carbazol-1-one

6,7-dimethoxy-3-methyl-2,3,4,9-tetrahydro-1 $H$-carbazol-1-one

5,6,7-trimethoxy-2,3,4,9-tetrahydro-1 $H$-carbazol-1-one

6-methoxy-7,8-dimethyl-2,3,4,9-tetrahydro-1 $H$-carbazol-1-one

8-methyl-5,7,8,9-tetrahydro-6 $H$-[1,3]dioxolo[4,5- $b]$ carbazol-6-one

Abbreviated names
MTC
KTHC-57
MTCO-7
MTCO-8
KTHC-58
KTHC-67
DMMTCO
TTCO
MDTCO-6
MTDCO

Figure 2: Various fluorophores based on methoxy derivatives of 1-keto-1,2,3,4tetrahydrocarbazole. 
Inspired by these studies, we have made a foray into the synthesis of some new fluorophores having $\alpha$-hydroxy acetic acid moiety (marked blue) in place of methoxy group at $\mathrm{C}_{6}$ position of keto-tetrahydrocarbazole skeleton as the acid moiety has the potentiality to be tagged with bio-molecules through functional group interconversion. To check the feasibility of this hypothesis, we have tagged an amino acid derivative, ethyl 4aminobenzoate (benzocaine) (marked red) with these fluorophores (Figure 3). These compounds are represented in Figure 3. Detailed photophysical studies of the fluorophores having acid functionality and their tagged derivatives have been performed in homogeneous and microheterogeneous media $[10,11]$.

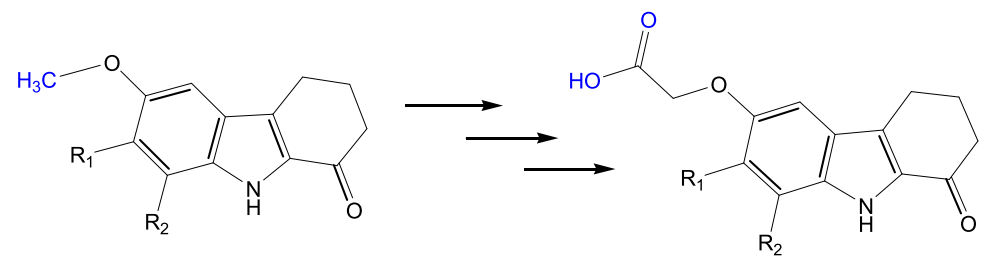

2-((1-oxo-2,3,4,9-tetrahydro-1H-carbazol-6-yl)oxy)acetic acid

2-((7,8-dimethyl-1-oxo-2,3,4,9-tetrahydro-1H-carbazol-6-yl)oxy)acetic acid

2-((7-methyl-1-oxo-2,3,4,9-tetrahydro-1H-carbazol-6-yl)oxy)acetic acid

2-((8-methyl-1-oxo-2,3,4,9-tetrahydro-1H-carbazol-6-yl)oxy)acetic acid

2-((7-methoxy-1-oxo-2,3,4,9-tetrahydro-1H-carbazol-6-yl)oxy)acetic acid

$$
\begin{array}{ll}
R_{1}=\mathrm{H}, & R_{2}=\mathrm{H} \\
R_{1}=\mathrm{CH}_{3}, & R_{2}=\mathrm{CH}_{3} \\
R_{1}=\mathrm{CH}_{3}, & R_{2}=\mathrm{H} \\
R_{1}=\mathrm{H}, & R_{2}=\mathrm{CH}_{3} \\
R_{1}=\mathrm{OCH}_{3}, & \mathrm{R}_{2}=\mathrm{H}
\end{array}
$$

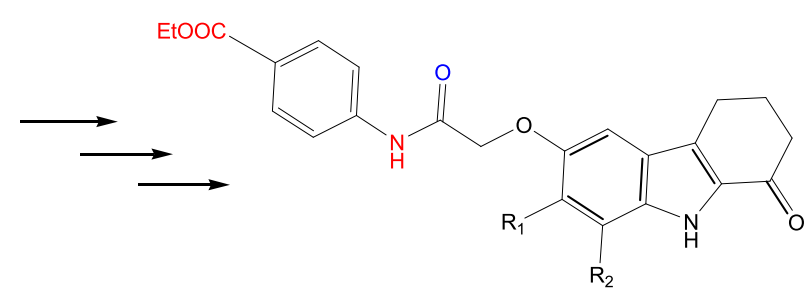

ethyl 4-(2-((7,8-dimethyl-1-oxo-2,3,4,9-tetrahydro-1H-carbazol-6-yl)oxy)acetamido)benzoate

$$
R_{1}, R_{2}=\mathrm{CH}_{3}
$$

Figure 3: Synthetic expansions of MDKTHC through functional group interconversions.

\section{Spectroscopic investigations of MDKTHC in homogeneous solvents}

In this research venture, rigorous photophysical studies of methoxy derivatives of ketotetrahydrocarbazoles (MDKTHC) have been performed in solvents of varied nature in order to predict the fundamental solvation dynamics to estimate the enhancement of electric dipole moment of molecules in the excited states, hydrogen-bond interactions, assessing the micro-environmental features of biochemical systems and many others $[10,11,14-20]$. Throughout our spectroscopic investigations, lots of solvents have been used, e.g. benzene (Bz), toluene (Tol), 1,4-dioxane (DOX), ethyl acetate (EtAc), tetrahydrofuran (THF), acetonitrile (ACN), dimethylformamide (DMF), dimethyl sulfoxide (DMSO), water $(\mathrm{HOH})$, methanol $(\mathrm{MeOH})$, ethanol (EtOH), n-butanol $(\mathrm{BuOH})$, n-hexanol $(\mathrm{HxOH})$, n-octanol $(\mathrm{OcOH}), \mathrm{n}$-decanol $(\mathrm{DcOH})$, n-dodecanol (DdOH), etc. The MDKTHC have absorption spectra (Figure 4) in similar region and have almost similar absorbance 
320-345 nm; however, absorption spectra are hardly solvent dependent. High molar absorption coefficients $\left(>10^{4}\right)$ indicate $\pi$ to $\pi^{*}$ transition in all the solvents. MDKTHC emit fluorescence (Figure 4) with large stokes shifts with respect to corresponding absorption spectrum. With increasing $E_{T}(30)$ value of the solvent, greater will be the emission maximum shifted towards the red end of the spectrum indicating that the excited state is much more sensitive towards the nature of the surrounding solvent molecules. Quantum yields and lifetimes of MDKTHC generally increase in the aprotic solvents as the $E_{T}(30)$ value of the solvent increases. However, no such trend, depending on a particular solvent parameter, is observed in the case of protic solvents. When it comes to long chain alcohols, fluorescence decay profiles are better fitted in a bi-exponential decay equation as MDKTHC are differentially solvated to polar head groups and the hydrophobic tail regions of such alcohols (Table 1).
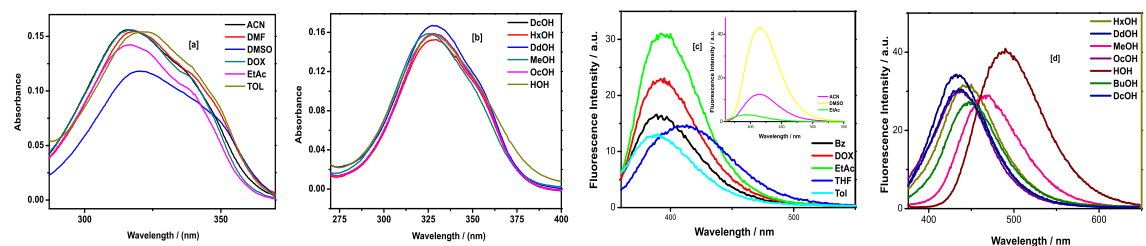

Figure 4: Absorption and emission spectra of a representative of MDKTHC (10-6 M) $(a, c)$ aprotic solvents $(b, d)$ protic solvents respectively.

Table 1: Wavelengths of absorption maximum $\left(\lambda_{\mathrm{abs}} \mathrm{nm}\right)$ and emission maximum $\left(\lambda_{f \mathrm{~nm}}\right)$, quantum yield $\left(\phi_{f}\right)$, fluorescence lifetime $(\tau)$, radiative decay constant $\left(\mathrm{k}_{\mathrm{f}}\right)$ and non-radiative decay constant $\left(\mathrm{k}_{\mathrm{n}}\right)$ of a representative of MDKTHC in different solvents.

\begin{tabular}{|c|c|c|c|c|c|c|c|c|c|c|c|c|c|c|c|c|c|c|c|}
\hline Solvents & $\begin{array}{c}\lambda_{\mathrm{abs} s} \\
\mathrm{hmm}\end{array}$ & $\begin{array}{l}\lambda_{\mathrm{A} /} \\
\mathrm{nm}\end{array}$ & $f$ & $\begin{array}{l}a_{1} \\
\text { (a) } \\
2\end{array}$ & $\begin{array}{c}\tau \\
\substack{1 \\
(\tau) / 1 \\
2}\end{array}$ & $\begin{array}{l}\tau_{x y /} / \\
\mathrm{ns}\end{array}$ & $x$ & $\begin{array}{l}k_{r} \times x \\
10^{-7} \\
s^{-1}\end{array}$ & $\begin{array}{l}\mathrm{k}_{\mathrm{nr}} \times x \\
10^{-7} / \mathrm{s}^{-}\end{array}$ & Solvents & $\lambda_{\operatorname{mab} / \mathrm{am}}$ & $\begin{array}{l}\lambda_{\mathrm{A} /} \\
\mathrm{nm}\end{array}$ & $f$ & $\mathrm{a}_{1}{ }_{2}(\mathbf{a})$ & $\begin{array}{l}\tau(\tau) / \\
\begin{array}{c}\tau(\tau) / \\
n \\
n s\end{array}\end{array}$ & $\begin{array}{l}\tau_{\mathrm{z} y} / \\
\mathrm{ns}\end{array}$ & $x$ & $\begin{array}{l}\mathrm{k}_{\mathrm{r}} \times \\
10^{-7} \\
\mathrm{~s}^{-1}\end{array}$ & $\begin{array}{ll}k_{\text {arr }} \times x \\
10^{-7} / s^{-}\end{array}$ \\
\hline $\mathrm{BZ}$ & 321 & 391 & 0.04 & 1 & 0.35 & 0.35 & 1.07 & 11.42 & 274.28 & $\mathrm{OH}$ & 326 & 466 & 0.08 & 1 & 0.86 & 0.86 & 1.09 & 9.30 & 106.97 \\
\hline DOX & 317 & 391 & 0.05 & 1 & 0.43 & 0.43 & 1.43 & 11.62 & 220.93 & & 329 & 448 & 0.07 & 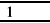 & 0.65 & 0.65 & 1.07 & $\begin{array}{ll}10.76 \\
\end{array}$ & $\begin{array}{l}143.07 \\
\end{array}$ \\
\hline EtAc & 317 & 393 & 0.07 & 1 & 0.64 & 0.64 & 1.06 & \begin{tabular}{ll|}
10.93 \\
\end{tabular} & 145.31 & $\mathrm{DcOH}$ & 329 & 434 & 0.09 & $\begin{array}{l}0.32 \\
(0.68)\end{array}$ & $\begin{array}{l}0.34 \\
(0.99)\end{array}$ & $\begin{array}{l}.78 \\
\end{array}$ & 1.02 & 11.53 & 116.66 \\
\hline $\mathrm{ACN}$ & 317 & 415 & 0.26 & 1 & 1.15 & 1.15 & 1.00 & 22.60 & 64.34 & $\mathrm{HxOH}$ & 329 & 442 & 0.08 & $\begin{array}{l}0.21 \\
(0.79)\end{array}$ & $\begin{array}{l}0.22 \\
(0.92)\end{array}$ & 0.77 & 0.99 & \begin{tabular}{|l|l|}
10.38 \\
\end{tabular} & 119.48 \\
\hline DMF & 317 & 407 & 0.14 & 1 & 1.07 & 1.07 & 0.99 & \begin{tabular}{|l|l|}
13.08 \\
\end{tabular} & 80.37 & DdOH & 327 & 432 & 0.09 & $\begin{array}{l}0.48 \\
(0.52)\end{array}$ & $\begin{array}{l}0.36 \\
(1.29)\end{array}$ & 0.84 & 1.01 & 10.71 & 108.33 \\
\hline DMSO & 320 & 414 & 0.32 & 1 & 2.58 & 2.58 & 0.99 & \begin{tabular}{l|l|l}
12.40 \\
\end{tabular} & 26.35 & $\mathrm{OcOH}$ & 329 & $\begin{array}{l}438 \\
\end{array}$ & 0.07 & $\begin{array}{l}0.28 \\
(0.72)\end{array}$ & $\begin{array}{l}0.34 \\
(1.32)\end{array}$ & 1.06 & 1.17 & 6.60 & 87.73 \\
\hline THF & 320 & 410 & 0.05 & 1 & 0.79 & 0.79 & 1.22 & 6.32 & 120.25 & HоH & 329 & 489 & 0.13 & & 1.83 & 1.83 & 0.99 & 7.10 & 47.54 \\
\hline
\end{tabular}

Now monitoring the bathochromic shift in the emission spectrum of MDKTHC with the increase in solvent polarity, we have paid interest to measure the enhancement of dipole moment in excited state using Lippert-Mataga method [12]. Now to measure individual contributions of different modes of solute-solvent interactions, Kamlet-Taft Solvatochromic Comparison Method (KTSCM) has been used [13]. The values obtained for a representative of MDKTHC using benzene as the reference solvent are given in relations below.

$$
\bar{v}=25380-1752 \pi^{*}-3200 \alpha-838 \beta \quad \bar{v}=25641-585 \pi^{*}-3135 \alpha-846 \beta
$$

The negative sign of the coefficients indicates the bathochromic shift of the emission maximum of MDKTHC with increase in solvent polarity, ability of $\mathrm{H}$-bond donor acidity and ability of $\mathrm{H}$-bond acceptor basicity of the solvent respectively. The relative magnitudes indicate that HBD acidity of the solvent plays a major role in governing the photophysics of these compounds. 


\section{Spectroscopic investigations of microheterogeneity in various binary mixtures probed by MDKTHC}

\section{Water-acetonitrile and Water-ethanol mixture}

Figure 5 represents the fluorescence of $10 \mu \mathrm{M}$ of a representative of MDKTHC in wateracetonitrile and water-ethanol mixtures with gradual increase in mole fraction of water from 0 to 1.0. In pure acetonitrile, $\lambda_{\max }^{\mathrm{em}}$ of this derivative is found around $408 \mathrm{~nm}$, however with the slightest increase of water in the mixture of water-acetonitrile, we observe a drop in fluorescence intensity with substantial red-shift upto a mole fraction of 0.3 . With further increase in water, the fluorescence intensity is enhanced with a significant red-shift reaching a maximum around 0.7 and then followed by a decrease till the mole fraction becomes 1.0. Thus this particular fluorophore can sense even the slight variation of composition of these binary mixtures [16].
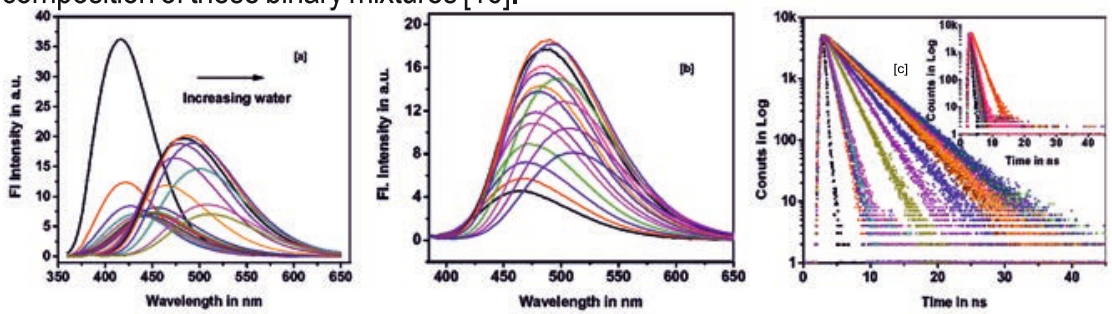

Figure 5: Fluorescence intensity of a representative of MDKTHC $(10 \mu \mathrm{M})$ with increasing mole fraction of water from 0 to 1 in (a) acetonitrile-water and (b) ethanol-water binary mixtures. (c) Time-resolved decay profiles of a representative of MDKTHC $(10 \mu \mathrm{M})$ with increasing mole fraction of water from 0.3 to 1.0 in acetonitrile-water binary mixture. The inset of the figure shows the decay profiles for increase in mole fraction from 0 to 0.3 .

\section{DMSO-water binary mixture}

Emission profile of a representative of MDKTHC shows appreciable change as the percentage of water increases. As the percentage of water increases ( $0 \%$ to $100 \%)$, a systematic bathochromic shift ( $47 \mathrm{~nm}$ ) is observed from $415 \mathrm{~nm}$ to $462 \mathrm{~nm}$ (Figure 6).
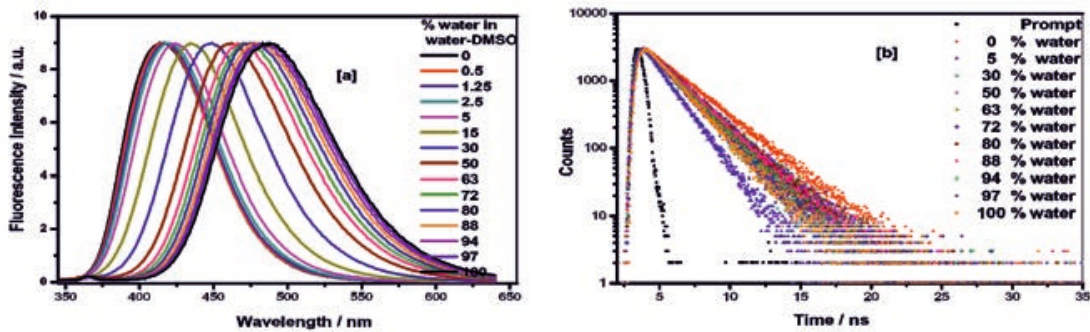

Figure 6: (a) Emission profile and (b) Corresponding fluorescence decay profiles of a representative of MDKTHC $\left(10^{-6} \mathrm{M}\right)$ in DMSO-water binary mixture.

It is obvious from Figure 6 (b) that on addition of $\sim 5 \%$ water, lifetime obtained from the analysis of corresponding decay profile decreases abruptly from $2.58 \mathrm{~ns}$ to $1.47 \mathrm{~ns}$. As the water proportion increases up to $63 \%$, increment in lifetime is observed (1.90 ns for 
$30 \%, 2.20$ ns for $50 \%$ and 2.21 ns for $63 \%$ water proportions respectively). Lifetime of a representative of MDKTHC again falls systematically with increase in water concentration ( 2.19 ns for $72 \%, 2.14$ ns for $80 \%, 2.12$ ns for $88 \%, 2.0$ ns for $94 \%, 1.89$ ns for $97 \%$ and 1.82 ns for $100 \%$ water proportions respectively). Rapid rearrangement of water's hydrogen bonding network is responsible for this sort of fluctuation in lifetime and most importantly MDKTHC can sense it [18].

\section{Modifications observed in the photophysical responses of MDKTHC in presence of micelles, reverse micelles and $\beta$-cyclodextrin environments}

On addition of surfactants like sodium dodecyl sulphate (SDS), cetyl trimethylammonium bromide (CTAB) and Triton X-100 (TX-100), the nature of absorption spectra of MDKTHC remain practically unchanged except a small increase in absorbance while significant enhancement in emission intensity (fluorescence lifetime also increases) is observed coupled with a hypsochromic shift (Figure 7). Prominent change in the fluorescence emission spectra is observed when the surfactant concentration is around CMC. MDKTHC reside in the micelle-water interfacial region and do not penetrate deep into the less polar micellar core [15,18,19].
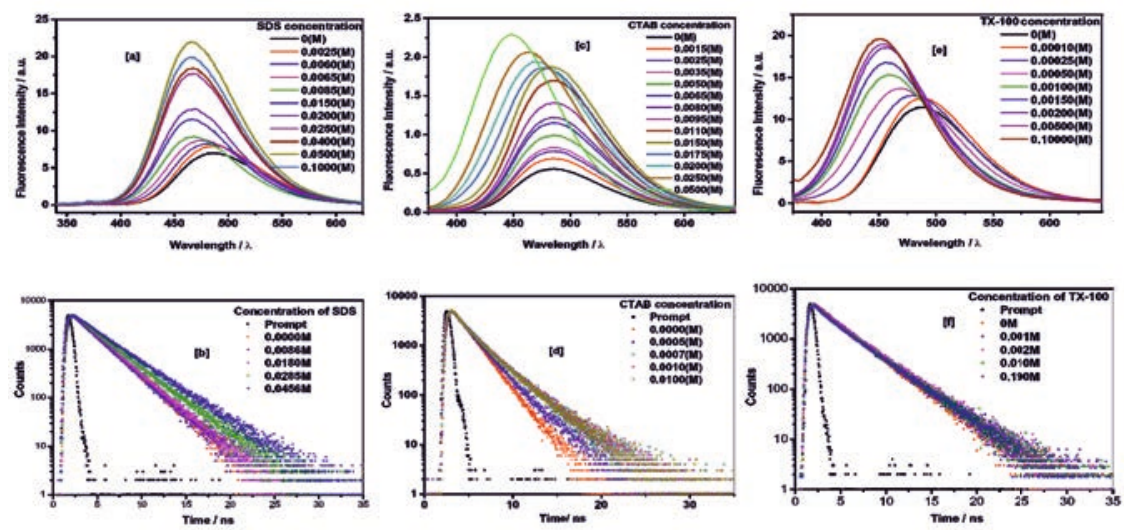

Figure 7: Fluorescence emission spectra $(a, c, e)$ of a representative of MDKTHC(10-6 M) in aqueous SDS, CTAB and TX-100 solutions respectively. Corresponding Fluorescence decay profiles are also shown $(b, d, f)$.

\section{Constrained photophysics of MDKTHC within $\beta-C D$ nanocavity}

Barring a small increase in absorbance values, an increasing concentration of $\beta-C D$ is found to introduce no significant changes on the absorption profile of MDKTHC. Whereas, emission profiles show more dramatic modifications with increasing $\beta-C D$ concentration in terms of a marked intensity enhancement coupled with a prominent blue shift of the emission maxima indicating formation of inclusion complex between the host $\beta-C D$ and the guest MDKTHC (Figure 8). Confinement imposed by the formation of inclusion complex is significantly imparting rigidity to the entire molecular framework of 
MDKTHC and in so doing, arresting the vibrational and rotational degrees of freedom that in turn results in diminution of non-radiative decay of the fluorophores producing consequentenhancement of fluorescence intensity $[15,18,19]$.
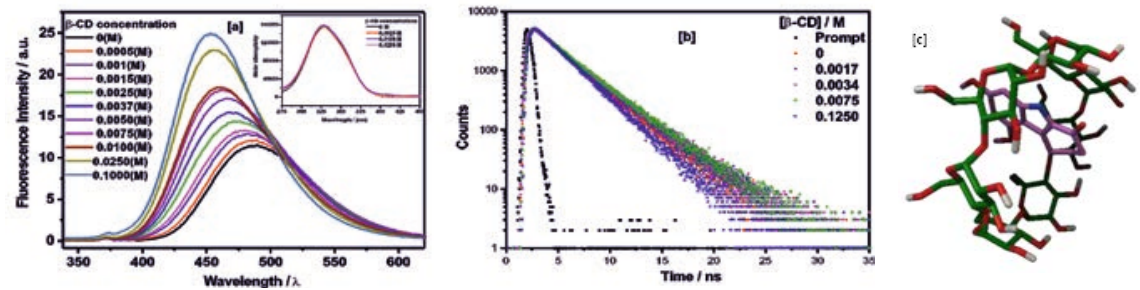

Figure 8: (a) Fluorescence emission spectra [absorption spectra shown as inset] and (b) fluorescence decay profiles of a representative of $\operatorname{MDKTHC}\left(10^{-6} \mathrm{M}\right)$ in aqueous $\beta$-Cyclodextrin solutions. (c) Corresponding Molecular docking representation in $\beta$-Cyclodextrin environment.

\section{MDKTHC in AOT/H ${ }_{2} \mathrm{O} / \mathrm{n}$-heptane reverse micelles}

Among many different surfactants, sodium dioctylsulfosuccinate (AOT) is the most widely studied one as it readily forms spherical monodispersed nanopool in a range of non-polar solvents without any co-surfactant, and is capable of solubilizing a large amount of water inside. Varying the amount of water, one can vary the size of the water pool $\left(\mathrm{w}_{0}=\right.$ $\left.\left[\mathrm{H}_{2} \mathrm{O}\right] /[\mathrm{AOT}]\right)$. In $n$-heptane, MDKTHC exhibits very weak fluorescence. In RMs $\mathrm{w}_{0}=1$ in $0.1 \mathrm{M} \mathrm{AOT} / \mathrm{H}_{2} \mathrm{O} / \mathrm{n}$-heptane microemulsion we observe an intense fluorescence around $407 \mathrm{~nm}$. Figure 9 shows the variation of fluorescence emission of a representative of MDKTHC with increase in the size of the RMs from 1 to 35 , the inset of the figure reflects the absorption spectra of a representative of MDKTHC for some selected $\mathrm{w}_{0}$.
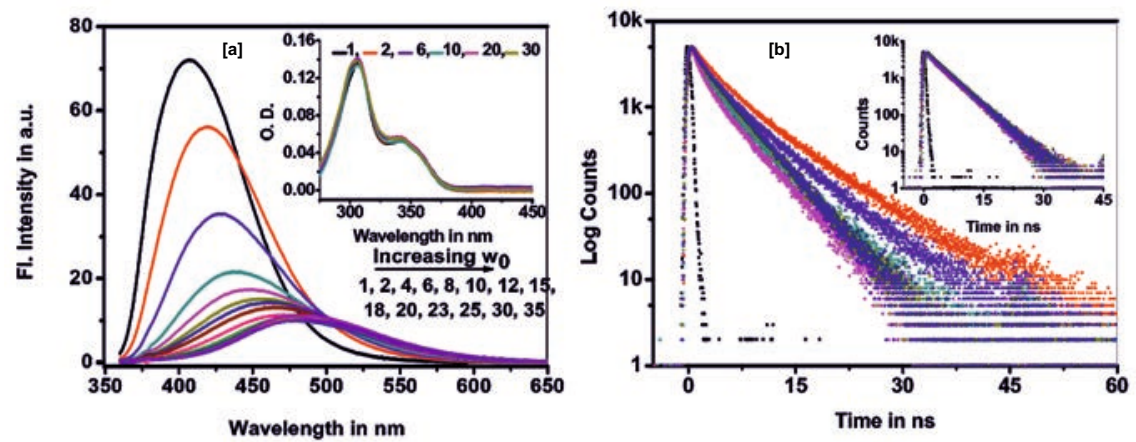

Figure 9: (a) Fluorescence emission spectra of a representative of MDKTHC $(10 \mu \mathrm{M})$ in $0.1 \mathrm{M} \mathrm{AOT} / \mathrm{H}_{2} \mathrm{O} / \mathrm{n}$-heptane RMs with variation of $\mathrm{w}_{0}$. The inset shows the absorption spectra in selective $\mathrm{w}_{0}$. (b) Time-resolved fluorescence decays of a representative of MDKTHC (10 $\mu \mathrm{M})$ in different $\mathrm{w}_{0}$.

Figure 10 (a) shows the time-resolved profiles of a representative of MDKTHC in $w_{0}=6$ at different selective emission wavelength displaying a distinct wavelength dependence. 
The evolution of the emission spectra with time is an indication of two distinct excited state phenomena, solvation dynamics or evolution of a new species. To differentiate between the two dynamic processes, we perform area normalization technique as suggested by Koti et al. TRANES is a unique method for determination of the number of emitting species in singlet excited state [21]. Figure10b shows the TRANES of a representative of MDKTHC in $\mathrm{w}_{0}=6$, showing a distinct iso-emissive point at $22220 \mathrm{~cm}^{-1}$. The iso-emissive point in the area normalized spectra is an indication of emission from two distinct species of a representative of MDKTHC inside the confined RMs. This suggests that, the growth at the red end of the time-resolved spectra is the generation of h-bonded MDKTHC with a longer lifetime [16].
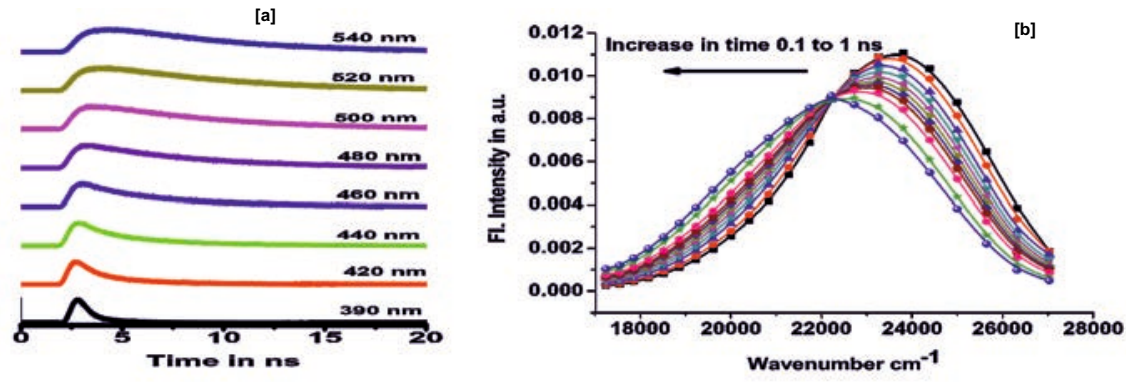

Figure 10: (a) Fluorescence emission decays of a representative of MDKTHC in 0.1M AOT/H2O/n-heptane RMs $\mathrm{w}_{0}=6$ at $390,420,440,460,480,500,520$ and $540 \mathrm{~nm}$ respectively. (b) Time resolved area normalized emission spectra (TRANES) of a representative of MDKTHC $(10 \mu \mathrm{M})$ in in $0.1 \mathrm{M} \mathrm{AOT} / \mathrm{H}_{2} \mathrm{O} / \mathrm{n}$-heptane RMs $\mathrm{w}_{0}=6$ between time 0.1 and $1 \mathrm{~ns}$. The arrow indicates an increase in time interval of $0.1 \mathrm{~ns}$.

\section{Spectroscopic investigation of the interaction of MDKTHC with aromatic and aliphatic amines}

On gradual addition of DMA or TEA, there is no observable change in the absorption spectra of MDKTHC. This excludes the possibility of any ground state complex formation. However the fluorescence intensity of MDKTHC is found to quench on gradual increase in concentration of DMA or TEA. The extent of steady-state fluorescence quenching is calculated using the Stern-Volmer (SV) relationship. For example, fluorescence quenching experiments of MDKTHC with DMA in (a) ACN, (b) DMSO and (c) EtOH have been performed and the results are listed in the Table 2. The order of Ksv can be explained primarily based on viscosity of the solvent, as the quenching process is a diffusion-controlled phenomenon. More is the viscosity of the solvent less is the encounter between MDKTHC and DMA $[14,19]$.

Table 2: Stern-Volmer constants for the quenching of a representative of MDKTHC with DMAin three solvents

\begin{tabular}{|l|l|l|l|}
\hline Solvent & ACN & DMSO & EtOH \\
\hline $\mathrm{K}_{\mathrm{sv}} /[\mathrm{M}]$ & 17.066 & 9.156 & 12.119 \\
\hline
\end{tabular}


Besides fluorescence quenching study in homogeneous medium, we have also performed similar experiments with TEA in micro-heterogeneous medium [18].

\section{Interactions of MDKTHC with serum albumins}

Gradual addition of the proteins results in a slight increase in the absorbance with no significant change in wavelength. Room temperature emission spectrum of MDKTHC in PBS gets remarkably modified showing a radical increase in the emission yield with an associated blue shift indicating that in the protein media a lowering in the polarity of the microenvironment around the probe is observed (Figure11).
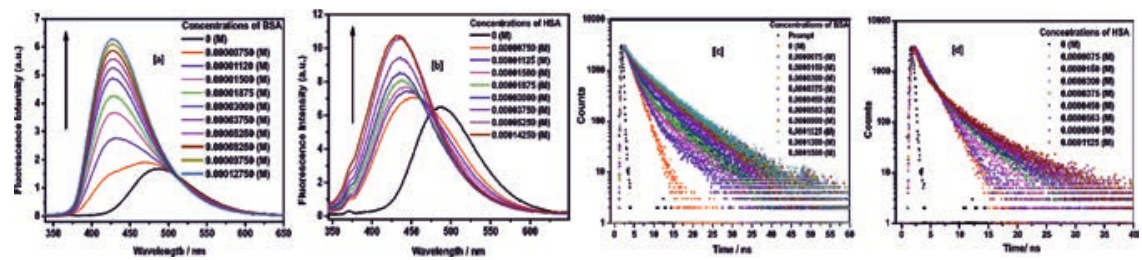

Figure 11: Fluorescence emission spectra $(a, b)$ and corresponding fluorescence decay profiles $(c, d)$ of a representative of MDKTHC $\left(10^{-6} \mathrm{M}\right)$ in presence of different concentrations of (a) BSAand (b) HSA.

We have used circular dichroism (CD) spectroscopy to study the conformational aspects of proteins upon binding with MDKTHC-based dyes and fluorescence anisotropy study to assess the degree of restrictions imparted by the micro-environments of serum albumins.

In order to locate the probable position of the probe, in the serum albumin environments, we have paid interest in the FRET study with the present systems. Again, to speculate the triplet excited state interaction between MDKTHC and albumin proteins (BSA \& HSA) laser flash-photolysis experiments have been carried out. Molecular docking experiments have also been performed to support the conclusions obtained from steady state experiments [19].

\section{Astepping stone towards the development of new fluorescent markers}

We have synthesized several fluorophores having carboxylic acid functionality using the following methodology [Figure 12] and have performed their detailed photophysical responses in various homogeneous and micro-heterogeneous environments [10,11]. Excited state spectral possessions (quantum yield, lifetime and wavelength of fluorescence maximum, $\lambda_{\text {max }}$ ) of keto-tetrahydrocarbazoles having acid functionality are markedly sensitive to polarity and the $\mathrm{H}$-bonding nature of its immediate local environment. Protic solvents have been found to play an influential role in the excited state photophysics of these fluorophores. To prove the special sensitivity of the molecules for hydrogen bonding, we have carried out thorough investigations namely solvent variation, Kamlet-Taft solvatochromic comparison method, calculation of dipole moment, free energy of solvation, reorganization energy etc. Such special affinity for hydrogen bonding makes the molecules suitable sensors of their immediate microenvironment. 
Motivated by these studies, we have synthesized several benzocaine tagged derivatives of such fluorophores and have performed their photophysical responses in several homogeneous and micro-heterogeneous environments as well. Distinct differences in the spectral responses of these tagged derivatives with respect to original fluorophores having acid functionality clearly indicates the worth of such experimentation and consequently this concept leads to the development of new synthetic bio-marker [11].

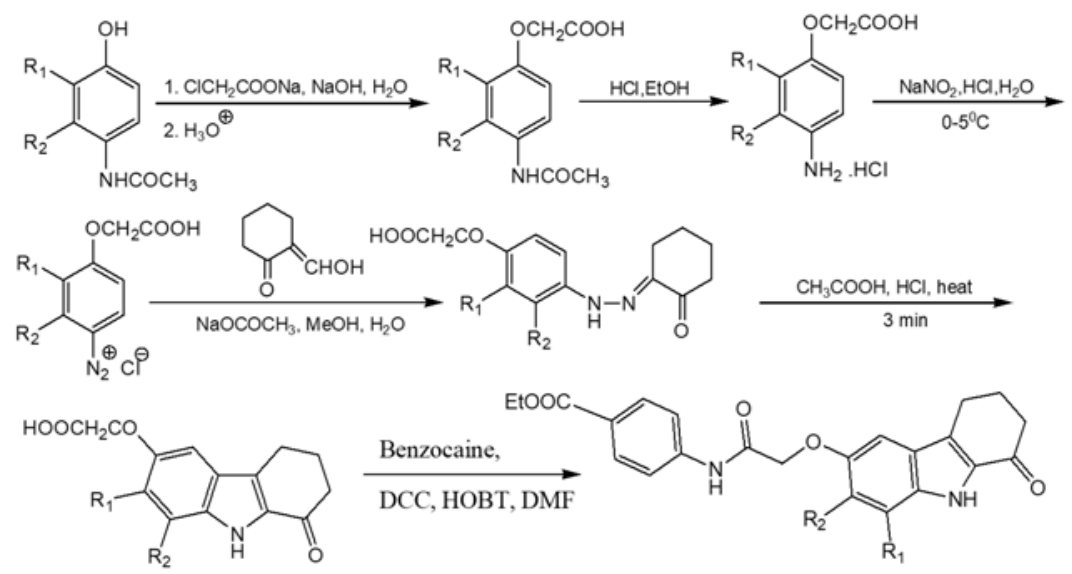

Figure 12: Synthesis of Keto-tetrahydrocarbazole based fluorophores having a-hydroxy acetic acid moiety and their benzocaine tagged derivatives.

\section{Conclusion}

Primary objective of this research venture has been to explore photophysical studies of some newly synthesized fluorophores based on 1-keto-1,2,3,4-tetrahydrocarbazole framework in solution phase and also to study their interactions with other small molecules and biological macromolecules. Such studies have the potential to endeavour better understanding on the properties of those molecules and may also divulge newer applications. Photophysics of such fluorophores have been interesting so far. Our journey is going on to establish this new family of fluorophores a potential bio-marker.

\section{Acknowledgement}

The author acknowledges Prof. Samita Basu of Saha Institute of Nuclear Physics, Kolkata and Dr. Chandan Saha of Calcutta School of Tropical Medicine for supervising the project. The author is also thanking Dr. Sujay Ghosh, Dr. Manas Kumar Sarangi and Dr. Suchandra Chakraborty for extending their help in making this project successful.

\section{References}

1. Lakowicz, J. R. (2006). Principles of Fluorescence Spectroscopy. Springer Science. New York, 158-204. 
2. Loving, G. S., Sainlos, M., \& Imperiali, B. (2010). Monitoring protein interactions and dynamics with solvatochromic fluorophores. Trends in biotechnology, 28(2), 73-83.

3. Venkatraman, P., Nguyen, T. T., Sainlos, M., Bilsel, O., Chitta, S., Imperiali, B., \& Stern, L. J. (2007). Fluorogenic probes for monitoring peptide binding to class II MHC proteins in living cells. Nature chemical biology, 3(4), 222-228.

4. Chakraborty, S., Chattopadhyay, G., \& Saha, C. (2011). Montmorillonite-KSF induced Fischer indole cyclization under microwave towards a facile entry to 1-keto-1, 2, 3, 4-tetrahydrocarbazoles.

5. Knölker, H. J., \& Fröhner, W. (1999). Transition metal complexes in organic synthesis, part 54. Improved total syntheses of the antibiotic alkaloids carbazomycin A and B. Tetrahedron letters, 40(38), 6915-6918.

6. Knölker, H. J., \& Reddy, K. R. (2002). Isolation and synthesis of biologically active carbazole alkaloids. Chemical reviews, 102(11), 4303-4428.

7. Saha, C., Chakraborty, A., \& Chowdhury, B. K. (1996). A new synthesis of 4deoxycarbazomycin B and its antimicrobial properties. Indian journal of chemistry. Sect. B: Organic chemistry, including medical chemistry, 35(7), 677-680.

8. He, W., Zhang, B. L., Li, Z. J., \& Zhang, S. Y. (2005). PTC-Promoted Japp-Klingmann Reaction for the Synthesis of Indole Derivatives. Synthetic communications, 35(10), 1359-1368.

9. Robinson, B. (1963). The Fischer Indole Synthesis. Chemical reviews, 63(4), 373401.

10. Mitra, A. K., Ghosh, S., Chakraborty, S., Basu, S., \& Saha, C. (2013). Synthesis and spectroscopic exploration of carboxylic acid derivatives of 6-hydroxy-1-keto-1, 2, 3, 4-tetrahydrocarbazole: hydrogen bond sensitive fluorescent probes. Journal of luminescence, 143, 693-703.

11. Mitra, AK., Ghosh. S., Sarangi. MK., Sau, A., Saha, C., Basu, S. (2014). Influence of microheterogeneity on the solution phase photophysics of a newly synthesised, environment sensitive fluorophore 2-((7,8-dimethyl-1-oxo-2,3,4,9-tetrahydro-1Hcarbazol-6-yl)oxy)acetic acid and its tagged derivative. Journal of Photochemistry and Photobiology A: Chemistry, 296 (2014), 66-79.

12. Lippert, E. V. (1957). Spektroskopische Bestimmung des Dipolmomentes aromatischer Verbindungen im ersten angeregten Singulettzustand. Zeitschrift für Elektrochemie, Berichte der Bunsengesellschaft für physikalische Chemie, 61(8), 962975.

13. Abboud, J. L., Kamlet, M. J., \& Taft, R. W. (1977). Regarding a generalized scale of 
solvent polarities. Journal of the American Chemical Society, 99(25), 8325-8327.

14. Mitra, A. K., Ghosh, S., Chakraborty, S., Sarangi, M. K., Saha, C., \& Basu, S. (2012). Photophysical properties of an environment sensitive fluorophore 1-keto-6, 7dimethoxy-1, 2, 3, 4-tetrahydrocarbazole and its excited state interaction with $\mathrm{N}, \mathrm{N}$ dimethylaniline: A spectroscopic investigation. Journal of Photochemistry and Photobiology A: Chemistry, 240, 66-74.

15. Mitra, A. K., Ghosh, S., Sarangi, M. K., Chakraborty, S., Saha, C., \& Basu, S. (2014). Photophysics of a solvent sensitive keto-tetrahydrocarbazole based fluorophore and its interaction with triethylamine: a spectroscopic inquest under surfactant and $\beta-C D$ confinement. Journal of Molecular Structure, 1074, 617-628.

16. Sarangi, M. K., Mitra, A. K., Sengupta, C., Ghosh, S., Chakraborty, S., Saha, C., \& Basu, S. (2013). Hydrogen bond sensitive probe 5-methoxy-1-keto-1, 2, 3, 4-tetrahydro carbazole in the microheterogeneity of binary mixtures and reverse micelles. The Journal of Physical Chemistry C, 117(5), 2166-2174.

17. Ghosh, S., Mitra, A. K., Saha, C., \& Basu, S. (2013). Tuning the solution phase photophysics of two de novo designed hydrogen bond sensitive 9-methyl-2, 3, 4, 9tetrahydro-1 H-carbazol-1-one derivatives. Journal of fluorescence, 23(6), 1179-1195.

18. Mitra, A. K., Ghosh, S., Sau, A., Saha, C., \& Basu, S. (2015). Solution phase photophysics of 5, 7-dimethoxy-2, 3, 4, 9-tetrahydro-1H-carbazol-1-one: Analysing the lineaments of a new fluorosensor to probe different micro-environments. Journal of Luminescence, 167, 233-248.

19. Mitra, A. K., Sau, A., Bera, S. C., Chakraborty, S., Saha, C., \& Basu, S. (2015). Monitoring the Competence of a New Keto-tetrahydrocarbazole Based Fluorosensor Under Homogeneous, Micro-Heterogeneous and Serum Albumin Environments. Journal of fluorescence, 25(6), 1931-1949.

20. Ghosh, S., Mitra, A. K., Basu, S., Chakraborty, S., \& Saha, C. (2014). 5, 6, 7, 9Tetrahydro-[1, 3] dioxolo [4, 5-h] carbazol-8-one: A solvatochromic PET-acceptor fluorescent probe. Journal of /uminescence, 153, 296-303.

21. Kumar, C. V., \& Buranaprapuk, A. (1997). Site-Specific Photocleavage of Proteins. Angewandte Chemie International Edition in English, 36(19), 2085-2087. 


\title{
Synthesis of Mixed Ligand Complexes of Ruthenium with 2,3,5,6-Tetrakis-(2-Pyridyl) Pyrazine Ligands: An Overview
}

\author{
Chhandasi GuhaRoy Sarkar \\ Department of Chemistry, Hooghly Mohsin College, West Bengal, India \\ Corresponding Author's E-mail: chhandasi_guharoy@yahoo.co.in
}

\begin{abstract}
The chapter reviews the synthesis of ruthenium complexes with 2,3,5,6-tetrakis-(2pyridyl)pyrazine (tppz) ligand. It summarizes the applications and importance of tppz and its suitability in binding with the ruthenium centre. The synthetic methods are discussed since it presents the initial hurdle for any application based experiments. It is found that the ruthenium-tppz complexes can be synthesized under simple reaction conditions and thus they generate a scope of varied industrial, chemical and biological applications.
\end{abstract}

Keywords: Ruthenium, 2,3,5,6-tetrakis-(2-pyridyl)pyrazine, Synthesis

\section{Introduction}

The review summarizes the synthesis of ruthenium-2,3,5,6-tetrakis-(2-pyridyl)pyrazine (tppz) complexes. The importance of the synthetic methods lies in the fact that simple synthesis is of utmost necessity for widespread applications of a particular complex. In this chapter ruthenium-tppz complexes published during the period 2000-2020 has been referred. A comprehensive list of reaction conditions has been presented as far as possible.

\section{Properties of 2,3,5,6-tetrakis-(2-pyridyl)pyrazine(tppz)}

There has been a sustained interest over the coordination chemistry of transition metal complexes with nitrogen-containing ligands. Transition metal complexes with nitrogen-containing ligands find application in a variety of biological and industrial processes. [1-3] Among these ligands, pyridinederived polydentate ligands are of major importance and one of the interesting ligands of this kind 2,3,5,6tetrakis-(2-pyridyl)pyrazine (Figure 1). This ligand is<smiles>c1ccc(-c2nc(-c3ccccn3)c(-c3ccccn3)nc2-c2ccccn2)nc1</smiles>

Figure 1: 2,3,5,6-tetrakis(2-pyridyl)pyrazine (tppz) a potential $\mathrm{N}, \mathrm{N}, \mathrm{N}$-donor which binds to the metal center forming a stable five-membered 


\section{2,3,5,6-tetrakis-(2-pyridyl) pyrazine complexes of ruthenium}

chelate ring. [2, 4-12] Synthesis of tppz complexes is very important because of their useful photophysical and magnetic properties [13], preparation of carbon-supported catalysts [14], synthesis of supramolecular compounds [9,15], coordination polymers [16], molecular sensors [17], molecular wires [18], and finally in biochemical studies such as the investigation of DNA- and BSA-binding [4]. The synthesis of 2,3,5,6-tetrakis(2-pyridyl)pyrazine was first reported in 1959. [19] It possesses a variety of coordination modes (Figure 2): bidentate, (I, II) [20,21] terdentate, (III) [22] bis-bidentate, (IV, V)

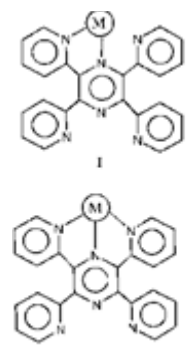

III

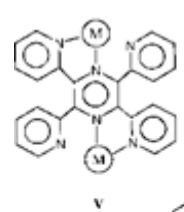

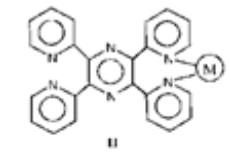

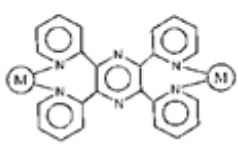

w

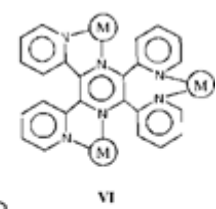

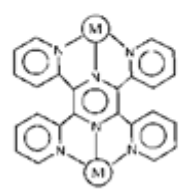

vil

Figure 2: Probable Binding Modes of 2,3,5,6-tetrakis-(2-pyridyl)pyrazine (tppz) [11] $[21,23]$ tris-bidentate $(\mathrm{VI})[21]$ and bis-terdentate. (VII) $[24,25]$. So, the use of tppz as bridging ligand has attracted considerable research interest in recent years. The bridging ligand mediates intermetallic electronic communication occurring through $\pi-$ orbitals either by electron-transfer or hole-transfer mechanisms [26,27]. Thus, it is a 'non-innocent' ligand, sensitive to oxidation and reduction. It is intriguing to note that although tppz is non-planar in bridging coordination mode, it allows considerable electronic communication. The present review presents the reaction procedures of 2,3,5,6-tetrakis-(2-pyridyl)pyrazine(tppz) along with its binding modes with reference to ruthenium complexes.

\section{Properties and Suitability of Ruthenium in Complexing with tppz}

Ruthenium chemistry is interesting largely due to their fascinating redox, [28] catalytic 
$[29,30]$ photophysical [31] and biological properties [32,33]. Ruthenium belongs to platinum group of metals with electronic configuration $[\mathrm{Kr}] 4 \mathrm{~d}^{\top} 5 \mathrm{~s}^{1}$. The interesting feature of this element is its variable oxidation state ranging from -2 in $\left[R u(C O)_{4}\right]^{2 ;}$; to +8 in $\left[\mathrm{RuO}_{4}\right]$. This property of the metal is exploited in complexing it with bridging tppz which allows electron transfer between metal centers through its $\pi$-conjugation. It is worth mentioning that in spite of the steric bulk of the ligand, it allows facile formation of dinuclear complexes. This may be due to the fact that the ligand is non-planar in its bridging bonding mode.

\section{Synthesis of Ruthenium-2,3,5,6-tetrakis-(2-pyridyl)pyrazine (tppz) complexes [2,5- 10,12]}

A study of the recent works revealed that Ruthenium(III) chloride hydrate is the most common source of ruthenium to synthesize tppz bridged ruthenium complexes. In addition ruthenium-tppz complexes, once synthesized, are further used as starting materials in obtaining mixed ligand complexes having tppz as one of the binding ligand. (Table 1, Serial Number 3,7,8) Although, tppz acts as a bridging ligand, mononuclear complexes of ruthenium tppz has also been synthesized under certain reaction conditions. (Table 1, Serial Number 1,6,7). The most common binding mode of the ligand is found to be $\mu-\mathrm{N}, \mathrm{N}, \mathrm{N}$. (Figure 2, VII). The solvents and starting materials commonly used are given in Table 1. In some cases, the reactions are carried out in inert atmosphere such as argon or dinitrogen atmosphere (Table 1, Serial Number 3,8). All reactions mentioned in Table 1 were carried out either at room temperature or at refluxing conditions.

\section{Table 1: Solvents and starting materials commonly used}

\begin{tabular}{|c|l|l|l|}
\hline $\begin{array}{c}\text { Serial } \\
\text { Number }\end{array}$ & \multicolumn{1}{|c|}{$\begin{array}{c}\text { Ruthenium Starting } \\
\text { Material }\end{array}$} & Reaction Solvent & $\begin{array}{c}\text { Binding Mode of } \\
\text { tppz }\end{array}$ \\
\hline 1 & $\mathrm{RuCl}_{3} \cdot 3 \mathrm{H}_{2} \mathrm{O}$ & Absolute Ethanol & $\begin{array}{l}\text { N,N,N-binding } \\
\text { mode, mononuclear }\end{array}$ \\
\hline 2 & {$\left[\mathrm{Ru}^{\mathrm{II}}(\mathrm{dmso})_{4} \mathrm{Cl}_{2}\right]$} & Dimethylsulfoxide & $\begin{array}{l}\text { N,N,N-binding } \\
\text { mode, dinuclear }\end{array}$ \\
\hline 3 & {$\left[\mathrm{Cl}_{3} \mathrm{Ru}^{\mathrm{III}}(\mu-\mathrm{tppz}) \mathrm{Ru}^{\mathrm{III}} \mathrm{Cl}_{3}\right]$} & Absolute Ethanol & $\begin{array}{l}\text { N,N,N-binding } \\
\text { mode, dinuclear }\end{array}$ \\
\hline 4 & $c i s-\left[\mathrm{Ru}^{\mathrm{II}}(\mathrm{bpy})\left(\mathrm{dmso}_{2} \mathrm{Cl}_{2}\right]\right.$ & $N, N$-dimethylformamide & $\begin{array}{l}\text { N,N,N-binding } \\
\text { mode, dinuclear }\end{array}$ \\
\hline 5 & $c i s-\left[\mathrm{Ru}^{\mathrm{II}}(\mathrm{tpy})\left(\mathrm{dmso}_{2}\right)_{2} \mathrm{Cl}_{2}\right]$ & $N, N$-dimethylformamide & $\begin{array}{l}\text { N,N,N-binding } \\
\text { mode, dinuclear }\end{array}$ \\
\hline 6 & {$\left[\mathrm{Ru}^{\mathrm{II}} \mathrm{Cl}_{2}\left(\eta^{6}-\mathrm{C}_{6} \mathrm{H}_{6}\right)\right]_{2}$} & Dry Acetonitrile & $\begin{array}{l}\text { N,N,N-binding } \\
\text { mode, mononuclear }\end{array}$ \\
\hline 7 & {$\left[\mathrm{Ru}^{\mathrm{III}}\left(\mathrm{tppz}_{2} \mathrm{Cl}_{3}\right]\right.$} & Acetonitrile & $\begin{array}{l}\text { N,N,N-binding } \\
\text { mode, mononuclear }\end{array}$ \\
\hline 8 & {$\left[\left(\mathrm{tppz}_{2} \mathrm{Ru}_{2}\left(\mathrm{PF}_{6}\right)_{2}\right.\right.$} & Acetonitrile & $\begin{array}{l}\text { N,N,N-binding } \\
\text { mode, dinuclear }\end{array}$ \\
\hline
\end{tabular}




\section{Conclusion}

To conclude, 2,3,5,6-tetrakis-(2-pyridyl)pyrazine (tppz) is a ligand that has been explored considerably in preparing ruthenium complexes. The reaction conditions are simple and easy to handle. Thus, synthesis being easy it allows a varied range of applications. Another wide field of research is preparation of ruthenium complexes with substituted tppz ligands which is being investigated by the researchers at present.

\section{References}

1. Hadadzadeh, H., Mansouri, G., Rezvani, A., Khavasi, H. R., Skelton, B. W., Makha, M., \& Charati, F. R. (2011). Mononuclear nickel (II) complexes coordinated by polypyridyl ligands. Polyhedron, 30(15), 2535-2543. https://doi.org/10.1016/j.poly.2011.06.037.

2. Daryanavard, M., Hadadzadeh, H., Khalaji, A. D., \& Weil, M. (2009). The mononuclear ruthenium (III)-2, 3, 5, 6-tetrakis (2-pyridyl) pyrazine complex [Ru (bpy)(tppz) Cl][PF 6] 2: synthesis, crystal structure, electrochemical, and spectroelectrochemical studies. Transition metal chemistry, 34(7), 779-786. https://doi.org/10. 1007/s11243-009-9262-4.

3. Hadadzadeh, H., Olmstead, M. M., Rezvani, A. R., Safari, N., \& Saravani, H. (2006). Synthesis, structure, spectroscopic, magnetic and electrochemical studies of Nill phendione complex. Inorganica chimica acta, 359(7), 2154-2158. https://doi.org/ 10.1016/ j.ica.2006.02.015.

4. Haghighi, F. H., Hadadzadeh, H., Darabi, F., Jannesari, Z., Ebrahimi, M., Khayamian, T., \& Rudbari, H. A. (2013). Polypyridyl Ni (II) complex,[Ni (tppz) 2] 2+: Structure, DNAand BSA binding and molecular modeling. Polyhedron, 65, 16-30. https://doi.org/ 10.1016/j.poly.2013.08.013.

5. Kundu, T., Chowdhury, A. D., Laha, B., Mobin, S. M., \& Lahiri, G. K. (2011). Ruthenium complexes of two different non-innocent ligands. Investigation of electronic structural aspects by experimental and DFT analysis. http://nopr.niscair.res.in /handle/ $123456789 / 12779$.

6. Chen, W., Rein, F. N., Scott, B. L., \& Rocha, R. C. (2011). Catalytic Photooxidation of Alcohols by an Unsymmetrical Tetra (pyridyl) pyrazine-Bridged Dinuclear Ru Complex. Chemistry-A European Journal, 17(20), 5595-5604. https://doi.org/10.1002/chem. 201002168.

7. Kundu, T., Sarkar, B., Mondal, T. K., Fiedler, J., Mobin, S. M., Kaim, W., \& Lahiri, G. K. (2010). Carboxylate Tolerance of the Redox-Active Platform [Ru ( $\mu$-tppz) Ru] n, where tppz $=2,3,5$, 6-Tetrakis (2-pyridyl) pyrazine, in the Electron-Transfer Series [(L) CIRu ( $\mu$ tppz) $\mathrm{RuCl}(\mathrm{L})] \mathrm{n}, \mathrm{n}=2+,+, 0,-, 2-$, with 2-Picolinato, Quinaldato, and 8-Quinolinecar boxylato Ligands (L-). Inorganic chemistry, 49(14), 6565-6574. https://doi.org/10. 1021/ic100500p. 


\section{2,3,5,6-tetrakis-(2-pyridyl) pyrazine complexes of ruthenium}

8. Wadman, S. H., Havenith, R. W., Hartl, F., Lutz, M., Spek, A. L., van Klink, G. P. \& van Koten, G. (2009). Redox chemistry and electronic properties of 2, 3, 5, 6-tetrakis (2pyridyl) pyrazine-bridged diruthenium complexes controlled by N, C, N'biscyclometalated ligands. Inorganic chemistry, 48(13), 5685-5696. https://doi.org/ 10.1021/ic801897k.

9. Zhao, S., Arachchige, S. M., Slebodnick, C., \& Brewer, K. J. (2008). Synthesis and Study of the Spectroscopic and Redox Properties of Rull, Ptll Mixed-Metal Complexes Bridged by 2, 3, 5, 6-Tetrakis (2-pyridyl) pyrazine. Inorganic chemistry, 47(14), 61446152. https://doi.org/10.1021/ic7023296.

10 Hadadzadeh, H., Yap, G. P. \& Crutchley, R. J. (2006). cis, cis- $\mu-2,3$, 5, 6-Tetra-2pyridylpyrazine-k3N1, N2, N6: K3N3, N4, N5-bis [dichloro (dimethyl sulfoxide-kS) ruthenium (II)] dihydrate acetone disolvate. Acta Crystallographica Section E: Structure Reports Online, 62(8), m2002-m2004. https://doi.org/10.1107/S1600536806028959.

11. Carranza, J., Sletten, J., Brennan, C., Lloret, F., Cano, J., \& Julve, M. (2004). Mono-, di-and trinuclear 2, 3, 5, 6-tetrakis (2-pyridyl) pyrazine (tppz)-containing copper (II) complexes: syntheses, crystal structures and magnetic properties. Dalton Transactions, (23), 3997-4005. https://doi.org/ 10.1039/b412034p.

12. Chanda, N., Laye, R. H., Chakraborty, S., Paul, R. L., Jeffery, J. C., Ward, M. D., \& Lahiri, G. K. (2002). Dinuclear ruthenium (ii) complexes [\{(L) CIRu Il\} 2 ( $\mu$-tppz)] $2+(L=a n$ arylazopyridine ligand) incorporating tetrakis (2-pyridyl) pyrazine (tppz) bridging ligand: synthesis, structure and spectroelectrochemical properties. Journal of the Chemical Society, Dalton Transactions, (18), 3496-3504. https://doi.org/ 10.1039/b204862k.

13. Luo, J., Quu, L., Liu, B., Zhang, X., Yang, F., \& Cui, L. (2012). Synthesis, Structure and Magnetic Properties of Two Cobalt (II) Dicyanamide (dca) Complexes with Heterocyclic Nitrogen Donors Tetra (2-pyridyl) pyrazine (tppz) and 2, 4, 6-Tri (2-pyridyl)-1, 3, 5-triazine (tptz):[Co2 (tppz)(dca) 4]. CH3CN and [Co (tptz)(dca)(H2O)](dca). Chinese Journal of Chemistry, 30(3), 522-528. https://doi.org/10.1002/ cjoc.201100553.

14. Velázquez-Palenzuela, A., Zhang, L., Wang, L., Cabot, P. L., Brillas, E., Tsay, K., \& Zhang, J. (2011). Carbon-Supported Fe-N x Catalysts Synthesized by Pyrolysis of the Fe (II)-2, 3, 5, 6-Tetra (2-pyridyl) pyrazine Complex: Structure, Electrochemical Properties, and Oxygen Reduction Reaction Activity. The Journal of Physical Chemistry C, 115(26), 12929-12940. https://doi.org/10.1021/jp2020897.

15. Alves, W. A., Pfaffen, V., Ortiz, P. I., Torresi, S. I., \& Torresi, R. M. (2008). Spectroscopic characterization and investigation of the dynamic of charge compensation process of supramolecular films derived from tetra-2-pyridyl-1, 4-pyrazine ligand. Journal of the Brazilian Chemical Society, 19(4), 651-659. https://doi.org/10.1590/S010350532008000400007.

16. Fantacci, S., De Angelis, F., Wang, J., Bernhard, S., \& Selloni, A. (2004). A Combined 
Computational and Experimental Study of Polynuclear Ru- TPPZ Complexes: Insight into the Electronic and Optical Properties of Coordination Polymers. Journal of the American Chemical Society, 126(31), 9715-9723. https://doi.org/10.1021/ja048421u.

17. Yuasa, J., \& Fukuzumi, S. (2008). OFF- OFF- ON Switching of Fluorescence and Electron Transfer Depending on Stepwise Complex Formation of a Host Ligand with Guest Metal lons. Journal of the American Chemical Society, 130(2), 566-575. https://doi.org/ 10.1021/ ja0748480.

18. Flores-Torres, S., Hutchison, G. R., Soltzberg, L. J., \& Abruña, H. D. (2006). Ruthenium molecular wires with conjugated bridging ligands: Onset of band formation in linear inorganic conjugated oligomers. Journal of the American Chemical Society, 128(5), 1513-1522. https://doi.org/10.1021/ja0552139.

19. Goodwin, H. A., \& Lions, F. (1959). Tridentate chelate compounds. Il1. Journal of the American Chemical Society, 81(24), 6415-6422.

20. Metcalfe, C., Spey, S., Adams, H., \& Thomas, J. A. (2002). Extended terpyridyl and triazine complexes of d 6-metal centres. Journal of the Chemical Society, Dalton Transactions, (24), 4732-4739. https://doi.org/10.1039/B208211J

21. Chen, X., Femia, F. J., Babich, J. W., \& Zubieta, J. (2001). Synthesis, characterization and crystal structures of mono-, di-and trinuclear rhenium (I) tricarbonyl complexes with 2, 3, 5, 6-tetra (2-pyridyl) pyrazine. Inorganica chimica acta, 315(1), 66-72. https://doi.org/ 10.1016/S0020-1693(01)00335-8.

22. Carranza, J., Brennan, C., Sletten, J., Clemente-Juan, J. M., Lloret, F., \& Julve, M. (2003). Crystal structures and magnetic properties of 2, 3, 5, 6-tetrakis (2-pyridyl) pyrazine (tppz)-containing copper (II) complexes. Inorganic chemistry, 42(26), 87168727. https://doi.org/10.1021/ic030244v.

23. Teles, W. M., Speziali, N. L., \& Filgueiras, C. A. (2000). Synthesis of a polymetallic Pt, Sn complex containing square planar and trigonal bipyramidal platinum centres: Crystal and molecular structure of bis \{chlorotriethylphosphinoplatinum (II)\} $\mu-2,3,5$, 6-tetrakis (a-pyridyl) pyrazinetetrakis (trichlorostannyl) triethylphosphinoplatinate (II). Polyhedron, 19(7), 739-742. https://doi.org/10.1016/S0277-5387(99)00394-0.

24. Burkholder, E., Golub, V., O'Connor, C. J., \& Zubieta, J. (2003). Solid state coordination chemistry: one-, two-, and three-dimensional materials constructed from molybdophosphonate subunits linked through binuclear copper tetra-2-pyridylpyrazine groups. Inorganic chemistry, 42(21), 6729-6740. https://doi.org/10.1021/ic030169o.

25. Kuehl, C. J., Da Re, R. E., Scott, B. L., Morris, D. E., \& John, K. D. (2003). Toward new paradigms in mixed-valency: ytterbocene-terpyridine charge-transfer complexes. Chemical communications, (18), 2336-2337. https://doi.org/10.1039/B306484K.

26. Kaim, W. (2002). The coordination chemistry of 1, 2, 4, 5-tetrazines. Coordination 


\section{2,3,5,6-tetrakis-(2-pyridyl) pyrazine complexes of ruthenium}

Chemistry Reviews, 230(1-2), 127-139. https://doi.org/10.1016/S0010-8545(02)00044-9.

27. Demadis, K. D., Hartshorn, C. M., \& Meyer, T. J. (2001). The localized-to-delocalized transition in mixed-valence chemistry. Chemical reviews, 101(9), 2655-2686. https://doi.org/10.1021/cr990413m.

28. Chan, S. C., \& Wong, C. Y. (2020). Recent developments in ruthenium-nitrosoarene chemistry: Unconventional synthetic strategies, new ligand designs, and exploration of ligands redox non-innocence. Coordination Chemistry Reviews, 402, 213082. https://doi.org/10.1016/j.ccr.2019.213082.

29. Zeng, Q., Lewis, F. W., Harwood, L. M., \& Hartl, F. (2015). Role of ligands in catalytic water oxidation by mononuclear ruthenium complexes. Coordination Chemistry Reviews, 304, 88-101. https://doi.org/10.1016/j.ccr.2015.03.003.

30. Bruneau, C., \& Achard, M. (2012). Allylic ruthenium (IV) complexes in catalysis. Coordination Chemistry Reviews, 256(5-8), 525-536. https://doi.org/10.1016/j. ccr.2011.10.018.

31. Sun, Q., Mosquera-Vazquez, S., Suffren, Y., Hankache, J., Amstutz, N., Daku, L. M. L., \& Hauser, A. (2015). On the role of ligand-field states for the photophysical properties of ruthenium (II) polypyridyl complexes. Coordination Chemistry Reviews, 282, 87-99. https://doi.org/10.1016/j.ccr.2014.07.004.

32. Simović, A. R., Masnikosa, R., Bratsos, I., \& Alessio, E. (2019). Chemistry and reactivity of ruthenium (II) complexes: DNA/protein binding mode and anticancer activity are related to the complex structure. Coordination Chemistry Reviews, 398, 113011.https://doi.org/10.1016/j.ccr.2019.07.008.

33. Brabec, V., \& Kasparkova, J. (2018). Ruthenium coordination compounds of biological and biomedical significance. DNA binding agents. Coordination Chemistry Reviews, 376, 75-94. https://doi.org/10.1016/j.ccr.2018.07.012. 
doi:10.31674/book.2020.macbs

\title{
Exploration of Hypervalent lodine Reagents in the Synthesis of Nitrogen Containing Bioactive Heterocycles through Oxidative Desulfurization Strategy
}

\author{
Harisadhan Ghosh \\ Department of Chemistry, Surendranath College, West Bengal, India
}

Corresponding Author's E-mail: ghosh.harisadhan@gmail.com

\begin{abstract}
During the last two decades, organo hypervalent iodine reagents have attracted a huge attention of the synthetic organic chemist community. The unique reactivity of these mild oxidizing reagents is demonstrated in their selective nature in several organic transformations, which are very difficult or sometimes impossible to achieve using other common reagents. On the other hand, the heterocyclic compound containing nitrogen as heteroatom is one of the most privileged structural motifs that is found in a plethora of bioactive molecules, natural products and pharmaceuticals. So, the development of the synthetic methodology for construction of $\mathrm{N}$-heterocyclic compounds is a great challenge for synthetic organic chemists. Hypervalent iodine chemistry has played an important role to replace transition metal for construction of a large number of bioactive natural products. Thiophilic character of the hypervalent iodine reagents have been used for the synthesis of various five, six or seven membered biologically relevant heterocycles. So, it is an interesting and useful chemistry that is flourishing rapidly. In the present report, a few very significant progresses where the desulfurization ability of hypervalent iodine reagents have been used to synthesized nitrogen containing bioactive heterocyclic compounds will be covered.
\end{abstract}

Keywords: Hypervalent lodine, Desulfurization, N-Heterocycles, Bioactive Heterocycles

\section{Introduction}

\subsection{Ecofriendly Nature of Hypervalent lodine Reagents}

In the recent years, organo hypervalent iodine reagents (such as diacetoxy iodobenzene or DIB, hydroxytosyloxy iodobenzene or HTIB, iodosylbenzene, 2iodoxybenzoic acid or IBX, Dess-Martin Reagent or DMP etc (Figure-1) have attracted a great deal of attention as metal-free mild oxidizing agents [1, 2].
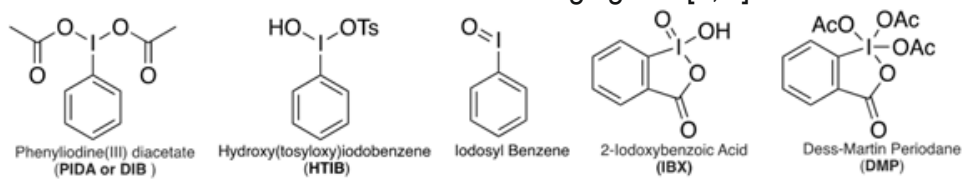

Figure 1: Common Hypervalent lodine Reagents 
Hypervalent iodine reagents have numerous advantages such as- (a) they have nonmetallic character with low toxicity issues, (b) easy and safe to handle in common organic laboratory setup, (c) most of the hypervalent iodine reagents are commercially available [3]. These environmentally benign reagents allow organic transformations under very mild reaction conditions. Many well-known stoichiometric reactions are now, carried out using hypervalent iodine replacing toxic heavy metal reagents such as lead-, mercury-, thallium- based reagents [4].

\subsection{Reactivity of Hypervalent lodine Reagents}

lodine atom is a member of halogen family at the $5^{\text {th }}$ period, Group VIIA of the periodic table. It has a large size and it is highly polarizable element. So, it can extend its valency more than eight to form hypervalent compounds [5].
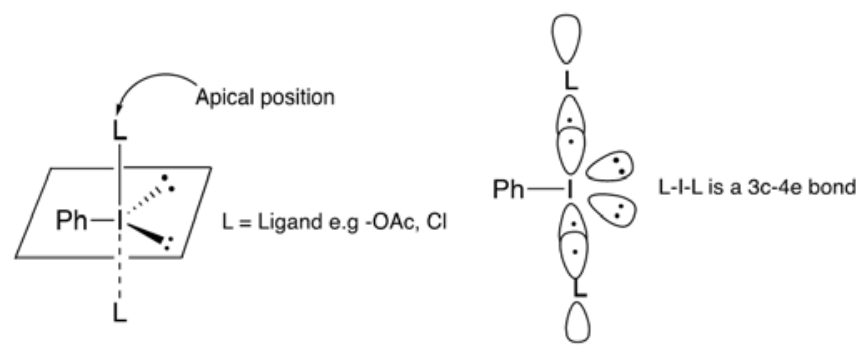

Figure 2: Bonding and reactivity of hypervalent iodine

The stability and reactivity of hypervalent iodine compounds mainly depend on the character of hypervalent bonds which is actually a three-center-four-electron (3c-4e) bond in the apical position (Figure 2) [6]. The hypervalent bonds in the apical position has longer bond length than usual so, they are easily cleaved, and the cleavage causes trivalent iodine with ten electrons to be reduced to monovalent iodine with stable eight electron structure. Because of this, it exhibits very good oxidizing property and it is used as a metal-free oxidizer in organic synthesis [7].

The soft lodine center of hypervalent iodine reagent has an inherent propensity to interact with soft center (such as alkene functional group, sulfur atom) of any organic compounds. Due to this distinctive reactivity pattern of hypervalent iodine reagents, the synthetic organic chemists have been increasingly interested to explore them for the generation of various important synthetic intermediate/biologically active molecules such as $\mathrm{N}$-acylureas [8], guanidine [9], carbodiimide [10], cyanamide [11], 1,3benzothiazepine [12] etc. So, thiophilic character of the hypervalent iodine reagents is an interesting property that has been manipulated wisely to use in versatile organic synthesis.

\subsection{Importance of Nitrogen Containing Bioactive Heterocycles}

Most of the chemical compounds which are having active biological effects are heterocyclic compounds. Among the various heterocyclic compounds, nitrogen 
containing heterocyclic compounds are an important class of heterocyclic compounds that have a significant contribution towards medicinal chemistry $[13,14,15]$.

\section{Hypervalent lodine Reagents in Nitrogen Containing Heterocyclic Compounds Synthesis}

Sureshbabu et al demonstrated the synthesis of 2-amino-1,3,4-oxadiazoles starting from corresponding acylhydrazides by cyclodesulfurization of intermediate acylthiosemicarbazides using the hypervalent iodine $(\mathrm{V})$ reagent o-iodoxybenzoic or IBX in one-pot strategy (Scheme-1) [16]. The 2-amino-1,3,4-oxadiazole moiety has a broad range of biological activities such as antimicrobial agents, anti-inflammatory agents, anticancer agents, muscle relaxants etc [17].

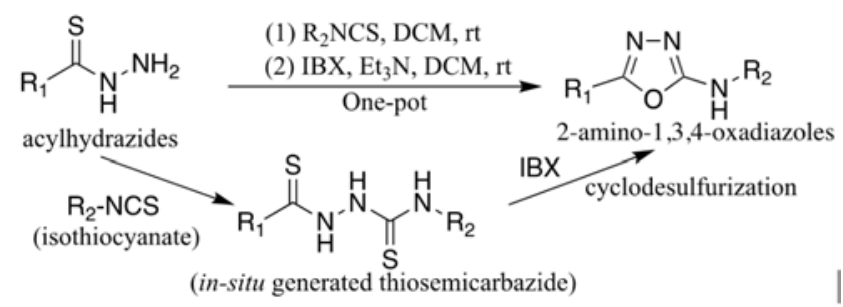

Scheme-1: Synthesis of 2-amino-1,3,4-oxadiazole in one-pot

Prof. Akamanchi group reported the synthesis of two very important group of nitrogen containing bioactive heterocyclic compound namely 2,5-diamino-1,3,4-thiadiazoles and 3-(substituted amino)-1,2,4-triazoles through hypervalent iodine mediated oxidative desulfurization protocol (Scheme-2) [18]. The 1,3,4-thiadiazoles scaffold shows versatile biological properties such as antimicrobial, antituberculosis, antiinflammatory and antifungal properties [19]. 5-Amino tetrazoles are regarded as useful synthetic intermediate in pharmaceutical and natural product [20].
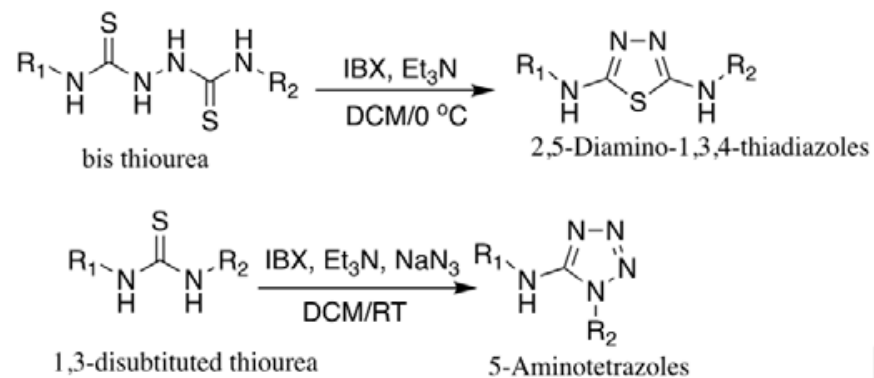

Scheme-2: Synthesis of 1,3,4-thiadiazole and aminotetrazole

Another important bioactive material is 1,2,4-thiadiazoles. This is scaffold is the main building block towards the synthesis of various anti-microbial agents [21], fungicides [22], herbicides [23], and antibiotics [24]. Hypervalent iodine reagents have been used 
as excellent metal-free mild oxidative desulfurizing agent to synthesize 1,2,4thiadiazoles. Chen et al demonstrated an environmentally benign method to achieve 1,2,4-thiadiazoles scaffold in excellent yield through oxidative dimerization of thioamide mediated by diacetoxyiodo benzene (DIB) on polymer support (Scheme-3) [25].

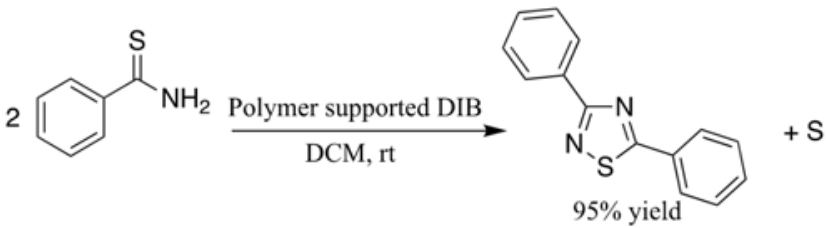

Scheme-3: Synthesis of 1,2,4-thiadiazoles

Prof. B. K Patel's group has been working extensively on the exploration of thiophilic nature of hypervalent iodine reagents. In a series of publication, they have demonstrated that in a suitable reaction condition, hypervalent iodine reagent can be used as an excellent desulfurizing agent to achieve various quite essential synthetic intermediates such as isothiocynate, cyanamide [11]. They have demonstrated the synthesis of four types of heterocycles-2-aminobenzimidazole, aminobenzoxazole, benzoxazine and 1imidazolidinecarbothioamide (Figure 3) by hypervalent iodine(III) reagent, (diacetoxyiodo)benzene(DIB) mediated desulfurizaton strategy [26].<smiles>[R]Nc1nc2ccccc2[nH]1</smiles><smiles>[R]Nc1nc2ccccc2o1</smiles><smiles>[R]NC1=Nc2ccccc2CO1</smiles><smiles>S=C(Nc1ccccc1)N1CCCCC1=Cc1ccccc1</smiles>

Figure 3: Various heterocycles synthesized by Patel's Group using DIB

2-(N-substituted)-aminobenzimidazoles are a class of biologically active molecules which have found extensive application in medicinal chemistry. These structural motifs have been used as anticancer [27], antihistamine [28], and antiviral agents [29].

A one-pot procedure for the synthesis of 2-aminobenzimidazole has been developed by treating o-phenylenediamine with the in situ generated isothiocyanates in presence of DIB and triethyl amine (Scheme 4).<smiles>[R]Nc1nc2ccc(N(CC)CCOc3ccccc3)cc2[nH]1</smiles>

Scheme-4: Synthesis of 2-aminobenzimidazole

The most probable mechanism of this transformation has been depicted in Scheme 5. At first, monothiourea is formed by reacting isothiocyanate with o-phenylenediamine. Then, the soft sulfur atom of the thiourea attacks the soft iodine atom of Phl(OAc)2 
removing one of its acetate ligands to furnish the intermediate $B$ (Scheme 5). The intermediate $(B)$ produces a carbodiimide intermediate $(C)$ with expulsion of iodobenzene and metallic sulfur. The carbodiimide intermediate immediately undergoes intramolecular cyclization to yield the desired product, as shown in Scheme 5. The authors were able to isolate and identify elemental sulfur and phenyl iodide which support their proposed mechanism.

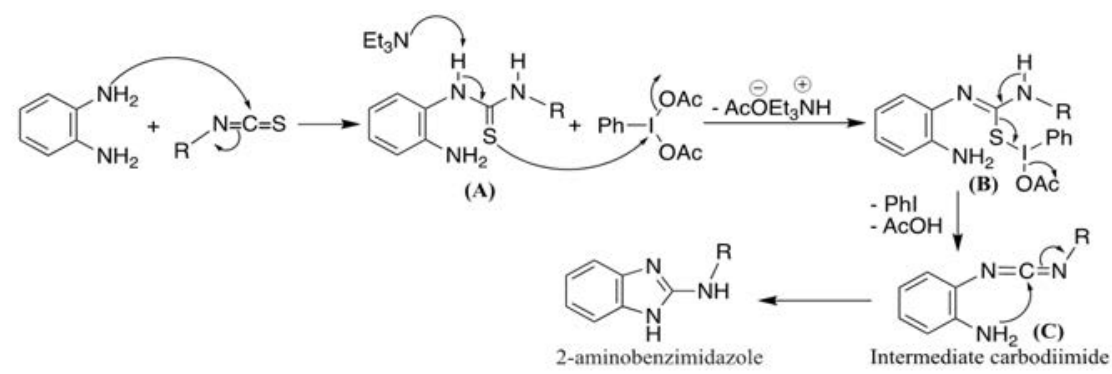

Scheme-5: Mechanism of formation of 2-aminobenzimidazole

The 2-aminobenzoxazole moiety has great potential as drug candidates, and its use is under investigation in the treatment of a wide variety of disorders, such as HIV, neurogeneration, and inflammatory diseases [30]. The strategy adopted for the synthesis of 2-aminobenzimidazole was also applied for the synthesis of aminobenzoxazoles (Scheme 6). The isothiocyanate was reacted with o-amino phenol to yield the monothiourea which on treatment with hypervalent iodine reagent DIB produced the desired aminobenzoxazoles. The proposed mechanism is expected to be similar to the one proposed in Scheme 5.

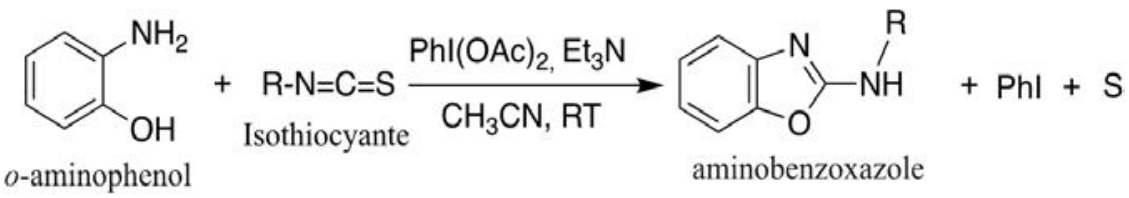

Scheme-6: Synthesis of aminobenzoxazole

The six membered nitrogen and oxygen containing heterocycle oxazine structural motif is great of interest in modern organic chemistry because it can be used as therapeutic agent [31]. The benzoxazine can be prepared from the precursor (2-aminophenyl) methanol and isothiocyanate in presence of DIB (Scheme-7).<smiles>Nc1ccccc1CO</smiles>

(2-aminophenyl)methanol Isothiocyante<smiles>CCN(CC)[C@H](Br)c1ccc2c(c1)COC(Nc1ccccc1)=N2</smiles>

benzoxazine

Scheme-7: Synthesis of benzoxazine 
The five membered nitrogen containing heterocycle 1-Imidazolidinecarbothioamides are useful as insecticides, particularly for the control of Epilachna varivestis [32]. When isothiocyanate (2 equiv.) was treated with ethylenediamine (1 equiv.), it produced bis(thiourea), which, on reaction with DIB, gave an excellent yield of imidazolidinecarbothioamide(Scheme 8).

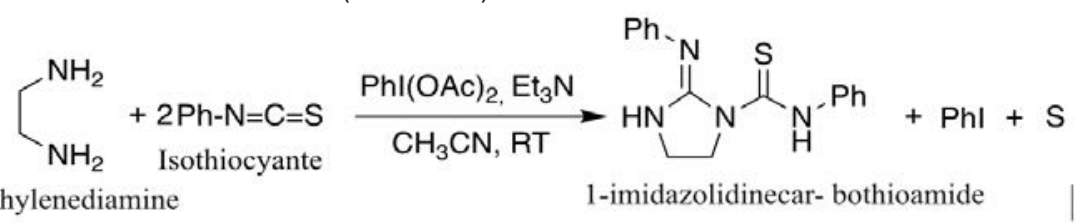

Scheme-8: Synthesis of 1-imidazolidinecarbothioamide

The plausible mechanism for the formation of imidazolidinecarbothioamide is shown in Scheme 9 .

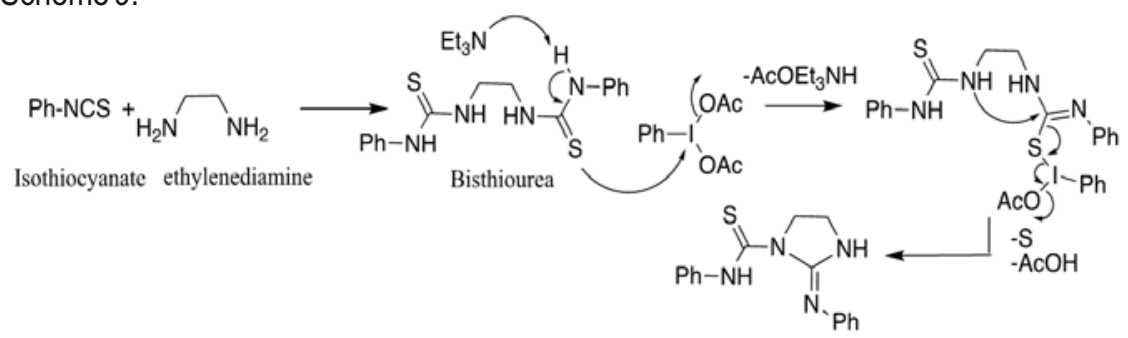

Scheme-9: Mechanism of formation of 1-imidazolidinecarbothioamide

In an interesting observation, it is reported, when the flexible ethylenediamine moiety was replaced by a rigid aromatic system such as o-phenylenediamine, the course of the reaction was completely changed to give benzimidazole and isothiocyanate instead of imidazolidinecarbothioamide. The driving force for this reaction is the gain in the aromatic character of the product benzimidazole due to loss of isothiocyanate (Scheme 10), which was not observed with aliphatic analogue ethylenediamine bis(thioureas) (Scheme9).

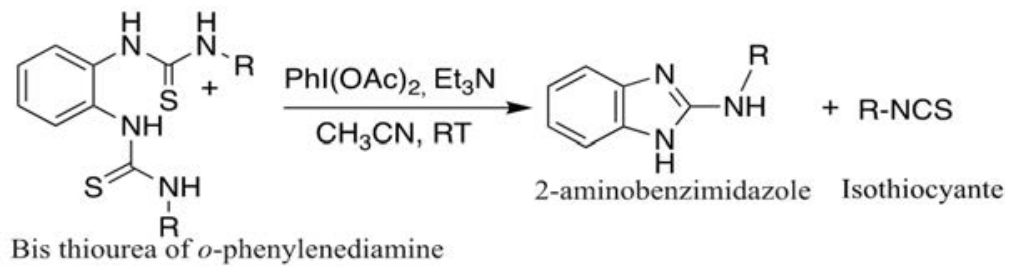

Scheme-10: Reactivity of (bis)thiourea of o-phenylenediamine towards DIB

\section{Conclusion}

In conclusion, the desulfurizing abilities of hypervalent iodine reagents have emerged as an important green synthetic tool to synthesize a wide range of nitrogen containing 
bioactive heterocycles with a diverse application in medicinal chemistry. Design of suitable sulfur containing starting material and then subjected to hypervalent iodine mediated desulfurization strategy would lead to many more important synthetic intermediates, heterocycles. This particular reactivity of hypervalent iodine reagents is going to flourish near future.

\section{References}

1. Zhdankin, V. V., \& Stang, P. J. (2008). Chemistry of polyvalent iodine. Chemical reviews, 108(12), 5299-5358. https://doi.org/10.1021/cr800332c

2. Yoshimura, A., \& Zhdankin, V. V. (2016). Advances in synthetic applications of hypervalent iodine compounds. Chemical reviews, 116(5), 3328-3435. https://doi.org/ 10.1021/acs.chemrev.5b00547

3. Kita, Y., \& Wirth, T. (2016). Hypervalent iodine chemistry (Vol. 373). T. Wirth (Ed.). Cham: Springer International Publishing. https://doi.org/10.1007/978-3-319-33733-3

4. Zhdankin, V. V. (2013). Hypervalent iodine chemistry: preparation, structure, and synthetic applications of polyvalent iodine compounds. John Wiley \& Sons. https://doi.org/10.1002/9781118341155

5. Akiba, K. Y. (Ed.). (1998). Chemistry of hypervalent compounds. John Wiley \& Sons. https://doi.org/10.1021/ja995694u

6. Martin, J. C. (1983). "Frozen" Transition States: Pentavalent Carbon et al. Science, 221(4610), 509-514. doi: 10.1126/science.221.4610.509

7. Zhdankin, V. V. (2009). Synthesis of Hypervalent lodine Compounds for Oxidation Reactions. PATAI'S Chemistry of Functional Groups, 1-40. https://doi.org/10.1002/ 9780470682531.pat0943

8. Singh, C. B., Ghosh, H., Murru, S., \& Patel, B. K. (2008). Hypervalent iodine (III)mediated regioselective $\mathrm{N}$-acylation of 1, 3-disubstituted thioureas. The Journal of organic chemistry, 73(7), 2924-2927.. https://doi.org/10.1021/j0702628g

9. Srisa, J., Tankam, T., Sukwattanasinitt, M., \& Wacharasindhu, S. (2019). Micelle-Enabled One-Pot Guanidine Synthesis in Water Directly from Isothiocyanate using Hypervalent lodine (III) Reagents under Mild Conditions. Chemistry-An Asian Journal, 14(19), 3335-3343. https://doi.org/10.1002/asia.201900982

10. Zhu, C., Xu, D., \& Wei, Y. (2011). A new synthetic protocol for the preparation of carbodiimides using a hypervalent iodine (III) reagent. Synthesis, 2011(05), 711-714.

11. Ghosh, H., Yella, R., Ali, A. R., Sahoo, S. K., \& Patel, B. K. (2009). An efficient synthesis of cyanamide from amine promoted by a hypervalent iodine (III) reagent. Tetrahedron Letters, 50(20), 2407-2410. https://doi.org/10.1016/j.tetlet.2009.03.017 
12. Guo, W. S., Gong, H., Zhang, Y. A., Wen, L. R., \& Li, M. (2018). Fast Construction of 1, 3-Benzothiazepines by Direct Intramolecular Dehydrogenative C-S Bond Formation of Thioamides under Metal-Free Conditions. Organic letters, 20(20), 6394-6397. https://doi.org/10.1021/acs.orglett.8b02697

13. Bentley, K. W. (2003). The Isoquinoline Alkaloids; Harwood Academic: Amsterdam, 1998. (b) Eicher, T.; Hauptmann, S. The Chemistry of Heterocycles.

14. Saracoglu, N. (2007). Functionalization of indole and pyrrole cores via Michael-type additions. In Bioactive Heterocycles V (pp. 1-61). Springer, Berlin, Heidelberg.

15. Hili, R., \& Yudin, A. K. (2006). Making carbon-nitrogen bonds in biological and chemical synthesis. Nature chemical biology, 2(6), 284-287.

16. Prabhu, G., \& Sureshbabu, V. V. (2012). Hypervalent iodine (V) mediated mild and convenient synthesis of substituted 2-amino-1, 3, 4-oxadiazoles. Tetrahedron Letters, 53(32), 4232-4234. https://doi.org/10.1016/j.tetlet.2012.05.154

17. Patel, K. N., Jadhav, N. C., Jagadhane, P. B., \& Telvekar, V. N. (2012). A novel strategy for the construction of azole heterocycles via an oxidative desulfurization approach using iodobenzene and oxone®. Synlett, 23(13), 1970-1972.

18. Chaudhari, P. S., Pathare, S. P., \& Akamanchi, K. G. (2012). o-lodoxybenzoic acid mediated oxidative desulfurization initiated domino reactions for synthesis of azoles. The Journal of organic chemistry, 77(8), 3716-3723. https://doi.org/10.1021/j02025509

19. Jain, A. K., Sharma, S., Vaidya, A., Ravichandran, V., \& Agrawal, R. K. (2013). 1, 3, 4-Thiadiazole and its derivatives: A review on recent progress in biological activities. Chemical biology \& drug design, 81(5), 557-576.

20. Upadhayaya, R. S., Jain, S., Sinha, N., Kishore, N., Chandra, R., \& Arora, S. K. (2004). Synthesis of novel substituted tetrazoles having antifungal activity. European Journal of Medicinal Chemistry, 39(7), 579-592. https://doi.org/10.1016/j. ejmech. 2004.03.004

21. Craig, E. M., George, A. B. U.S. (1980). Patent4, 209, 522,

22. Lamrencce, E. K. U.S.(1981). Patent 4, 263,312,

23. Walter,A. G. U.S. (1980). Patent 4, 207,089,

24. Teraji, T., Sakane, K.; Goto, J. E.P. (1981). Patent 27599,

25. Cheng, D. P., \& Chen, Z. C. (2002). Hypervalent iodine in synthesis. 84. facile synthesis of 3,5 -disubstituted 1, 2, 4-thiadiazoles by oxidative dimerization of thioamides using polymer-supported iodobenzene diacetate. Synthetic communications, 32(14), 2155-2159. https://doi.org/10.1081/SCC-120005423

26. Ghosh, H., Yella, R., Nath, J., \& Patel, B. K. (2008). Desulfurization mediated by 
hypervalent iodine (III): A novel strategy for the construction of heterocycles. European Journal of Organic Chemistry, 2008(36), 6189-6196. https://doi.org/10.1002/ejoc. 200800901

27. Mukhopadhyay, T., Sasaki, J. I., Ramesh, R., \& Roth, J. A. (2002). Mebendazole elicits a potent antitumor effect on human cancer cell lines both in vitro and in vivo. Clinical cancer research, 8(9), 2963-2969. https://clincancerres.aacrjournals.org/ content/8/9/2963

28. Janssens, F., Torremans, J., Janssen, M., Stokbroekx, R. A., Luyckx, M., \& Janssen, P. A. (1985). New antihistaminic N-heterocyclic 4-piperidinamines. 2. Synthesis and antihistaminic activity of 1-[(4-fluorophenyl) methyl]-N-(4-piperidinyl)-1 H-benzimidazol-2amines. Journal of medicinal chemistry, 28(12), 1934-1943. https://doi.org/10. 1021/jm00150a028

29. Navarrete-Vázquez, G., Cedillo, R., Hernández-Campos, A., Yépez, L., HernándezLuis, F., Valdez, J., \& Castillo, R. (2001). Synthesis and antiparasitic activity of 2(trifluoromethyl) benzimidazole derivatives. Bioorganic \& medicinal chemistry letters, 11(2), 187-190. https://doi.org/10.1016/S0960-894X(00)00619-3

30. N. V., Fenton, G. World Pat.( 2002) (b) Surleraux, D. L. N. G.; Vendeville, S. M. H., Verschueren, W. G., De Bethune, M.-P. T. M. M. G., De Kock, H. A., Tahri, A. World Pat. 2002092595.

31. Panek, J. S., \& Masse, C. E. (1998). An improved synthesis of (4 S, 5 S)-2-phenyl-4(methoxycarbonyl)-5-isopropyloxazoline from (S)-phenylglycinol. The Journal of Organic Chemistry, 63(7), 2382-2384. https://doi.org/10.1021/j0972013

32. William, B. T. UK Pat. (1979)Appl. GB 2010816 , 


\title{
Synthesis, Characterization and Potential Application of Novel Hybrid Nanoporous Materials
}

\author{
Krishanu Sarkar \\ Assistant Professor, Department of Chemistry, Netaji Mahavidyalaya, Arambagh, \\ Hooghly, WestBengal, India \\ Corresponding Author's E-mail: krishanu79@gmail.com
}

\begin{abstract}
Organic-inorganic hybrid fluorescent materials have been prepared, characterized and their behaviour against nitroaromatic explosives were tested. MCM-41 silica was used as inorganic scaffold and pyrene, dansyl and fluorescein fluorophores have been anchored via co-condensation method. Among total six sensing materials three were hydrophilic and three were hydrophobic in nature. The fluorescent behaviour of the six sensory materials were tested in the presence of various explosives (PETN, RDX, TNB, TNT, DNT, Tetryl and PA). Only nitroaromatics were able to quench emission data. PA and Tetryl explosives showed best quenching phenomena upon interacting with the fluorophores. The observed quenching was supposed to $\pi-\pi$ stacking interactions between the electron donor fluorophores and the electron withdrawing nitroaromatic explosives. Detection limits using pyrene derivative for Tetryl and PA were 8.5 and 1.4 ppm respectively, whereas for dansyl derivative were 14.4 and $1.2 \mathrm{ppm}$.
\end{abstract}

Keywords: Sensing materials, Fluorophores, Nitroaromatics, Explosives

\section{Introduction}

In modern times the detection of explosives is crucial for preventing terrorist activities, homeland security, environmental cleaning, etc. [1]. In this field the development of quick and reliable methods to detect these chemicals is a particularly interesting issue. Among different chemical explosives, nitroaromatics are perhaps the most commonly used [2]. Current methods to detect nitrated explosives are based on enzymatic assays [3], gas and liquid Chromatography [4], mass spectrometry [5], ion-mobility spectroscopy [6], electrochemical procedures [7], optodes [8], etc. While each method provides advantages, none is ideal. Principal deficiencies are a lack of portability or a susceptibility to false positive results due to environmental contaminants, or false negative results as consequence of interfering compounds. As an alternative to these instrumental procedures optical probes have been extensively researched for signaling applications due to their potential for high sensitivity, selectivity, portability, and costeffectiveness [9]. Another important technique viz. optical detection system focused on either colorimetric or fluorescence methods [10]. For these reasons, it is important to 
develop optical probes for detection of nitrated explosives based in fluorescence methods has attracted plenty of attention in recent years [11]. As general trend, the designed probes take advantage of the electron-deficient character of nitrated explosives that renders them to form charge-transfer complexes with electron-rich molecules. The stacked ensembles usually results in a quenching of the fluorophore through electron and energy transfer processes [12]. Applying this concept, molecular fluorescent probes for the detection of nitrated explosives have been explored in the last years [13]. In spite of this, one of the most important drawbacks of the use of molecular fluorophores for the sensing of nitrated explosives is the lack of selectivity. In order to overcome this lack of selectivity, researchers have incorporated molecular fluorophores into inorganic supports [14]. Here the synthesis, characterization, sensing behavior and fluorescence response of the six chemosensors toward nitrated explosives are reported.

\section{Experimental Section}

Methods: Powder XRD and $\mathrm{N}_{2}$ adsorption/desorption studies were employed to characterize the synthesized materials. Fluorescence spectroscopy was used for kinetic and quenching study of the materials after interaction with different explosives. Powder X-ray diffraction measurements were taken in a Bruker D8 Advance diffractometer using $\mathrm{Cu}$ Ka radiation. ASAP2010 automated sorption analyser was used for $\mathrm{N}_{2}$ adsorption/desorption isotherms. Fluorescence spectroscopy was carried out with a JASCO FP-8500 spectrofluorometer.

Chemicals: Tetraethylorthosilicate (TEOS) and (3-isocyanatopropyl)triethoxysilane as silica sources, 1-pyrenemethylamine hydrochloride, dansyl chloride, fluorescein isothiocyanate chemicals as fluorophore moieties, cetyltrimethylammonium bromide (CTAB) as structure directing agent and all other chemicals Sodium hydroxide, triethanolamine (TEAH3), triethylamine, sodium sulphate, ammonium nitrate, 1,1,1,3,3,3-hexamethyldisilazane (HMDS), 2,4-dinitrotoluene (DNT), nitrobenzene (NB) and picric acid (PA), 2,4,6-trinitrophenylmethylnitramine (Tetryl), 2,4,6trinitrotoluene (TNT), hexahydro-1,3,5-trinitro-1,3,5-triazine (RDX), pentaerythritol tetranitrate (PETN) were purchased from Sigma-Aldrich and other reputed companies were used as received. Highly explosives chemicals were handled with immense care and used in small quantities.

\section{Results and Discussion}

Synthesis of the hybrid sensing materials: At first different fluorophores (pyrene, dansyl an fluorescein) were derivatized with trialkoxysilane moieties in order to anchor them on the MCM-41 inorganic support (Scheme 1). For this purpose, 1-pyrenemethylamine (1) was reacted with (3-isocyanatopropyl)triethoxysilane (2) yielding the ethoxysilane derivative P. Similarly, D and F derivatives were synthesized. In particular, the reaction 
of (3-aminopropyl)triethoxysilane (3) with dansyl chloride (4) yielded product D, whereas $\mathrm{F}$ was obtained through the reaction of 3 with fluoresceinisothiocyanate (5).

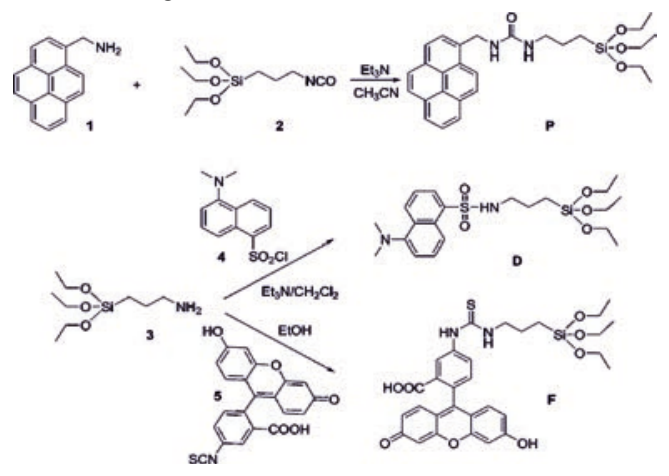

Scheme 1: Schematic diagram for the preparation of silica derivatives $P, D$ and $F$. The functionalised hybrid MCM- 41 materials were prepared using a mixture of TEOS and the corresponding derivatized fluorophore (P, D and F) in a 99:1 TEOS-derivatized fluorophore ratio. The structure directing agent (CTAB) was removed using repeated extraction procedure with ammonium nitrate and finally hydrophilic solids SP, SD and SF were obtained. Again, these template-free hydrophilic solids were reacted with 1,1,1,3,3,3-hexamethyldisila zane to get the hydrophobic materials SPh, SDh and SFh.

\section{Materials characterization}

The powder X-ray diffraction patterns (PXRD) of as-synthesized solids MD, SD and SDh are shown in Figure 1. These materilas clearly showed four small-angle defractions that are characteristic of the ordered hexagonal array and indexed as (100), (110), (200), and (210) Bragg's peaks. A slight shift of the (100) reflection and a broadening of the (110) and (200) peaks in the diffraction pattern of the extracted and hydrophobized sample are clearly seen and are related with a larger reduction in contrast. But the clear presence of (100) reflexion peak in all PXRD patterns confirmed that the functionalisation with the fluorophore and the subsequent hydrophobation did not significantly change the mesoporous MCM-41 scaffold.

Figure 1: Low-angle PXRD patterns of as-synthesized $(M D)$, extracted (SD) and hydrophobic (SDh) fluorophores.

The $\mathrm{N}_{2}$ adsorption/desorption isotherms of the extracted (SP) and hydrophobic material (SPh) are shown in Figure 2. The isotherms can be classified as typical type IV which are characteristic of mesoporous supports

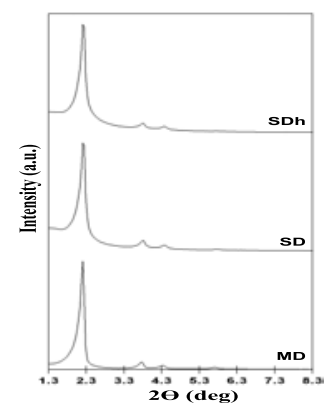


Figure 2: $\mathrm{N}_{2}$ adsorption/desorption isotherms of SP and SPh.

Again from the figure it is clear that a sharp increase in $N_{2}$ uptake was seen at $P / P_{0}$ region of 0.28 to 0.4 which indirectly confirms the presence of uniform mesopores in the fluorophores. Pore size distributions of these samples, was calculated by employing the Barret-JoynerHalenda (BJH) method. The probable porediameters were in agreement with those found from the XRD patterns.

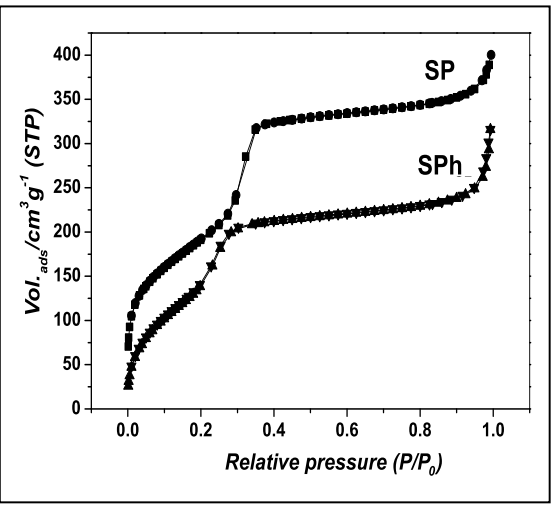

Fluorescence studies: The emission response of the six sensory materials were tested in acetonitrile in the absence and in the presence of Tetryl explosive.
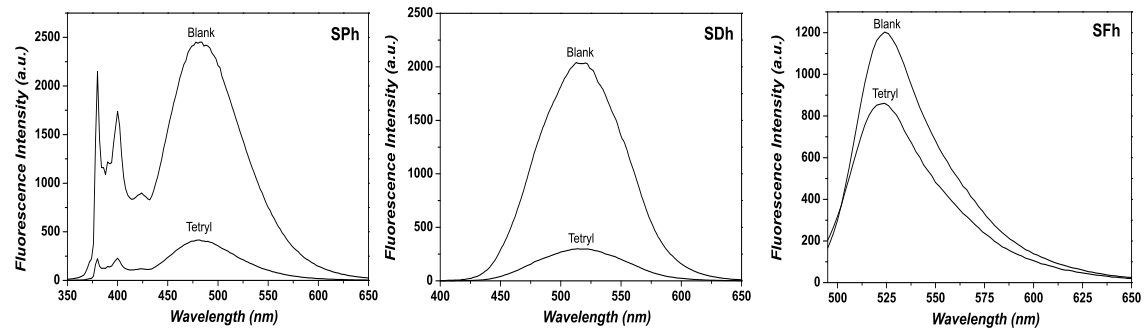

Figure 3: Fluorescence spectra of the solids SPh, SDh and SFh alone (blank) and with Tetryl.

It is evident from the Figure 3 that a significant quenching of the emission data was observed after interaction of the hydrophobized solids with Tetryl. More in particular, acetonitrile suspensions of SPh, showed, upon excitation at $341 \mathrm{~nm}$, the typical structured pyrene monomer emission band in the 370-420 nm interval together with broad unstructured band at $474 \mathrm{~nm}$ that was ascribed to the excimer pyrene emission. Addition of Tetryl induced a 3.5-fold quenching of both monomer and excimer emission of SPh. Again, acetonitrile suspensions of SDh show the distinctive broad emission band of the dansyl fluorophore centered at $516 \mathrm{~nm}$ upon excitation at $347 \mathrm{~nm}$ and induced a 6 -fold emission quenching upon interaction with Tetryl. Finally, suspensions of SFh showed the narrow emission band of fluorescein at $525 \mathrm{~nm}$ upon excitation at 493 $\mathrm{nm}$ however here addition of Tetryl showed a relatively low 1.4 -fold quenching of the fluorescein emission band. Aditionally, the limit of detection study showed that the detection limits using SPh for Tetryl and PA were 8.5 and 1.4 ppm whereas for SDh were 14.4 and 1.2 ppm respectively. 


\section{Conclusion}

Novel fluorescent organic-inorganic hybrid MCM-41 type materials have been prepared, characterized and used for the detection of nitroaromatic explosives. As grafted fluorophores pyrene, dansyl and fluorescein were used. Of the six materials, three were hydrophilic (SP, SD and SF) and the other three were hydrophobic (SPh, SDh and SFh). Addition of nitroaromatic explosives induced several degrees of quenching being the most remarkable those obtained with the hydrophobic SPh and SDh materials. The quenching observed was clearly related with the electron acceptor character of the nitroaromatic explosives, being the most important emission change obtained upon addition of PA and Tetryl. These emission quenching were ascribed to $\pi-\pi$ stacking interaction between the electron rich fluorophores and electron deficient nitroaromatic explosives. SPh and SDh materials presented good results toward PA and Tetryl with limits of detection of 1.4 and $8.5 \mathrm{ppm}$ (for SPh) and of 1.2 and $14.4 \mathrm{ppm}$ (for SDh) respectively.

\section{References}

1. Singh, S. (2007). Sensors-An effective approach for the detection of explosives. Journal of hazardous materials, 144(1-2),15-28.https://doi.org/10.1016/j. jhazmat. 2007.02.018

2. Yang, J. S., \& Swager, T. M. (1998). Fluorescent porous polymer films as TNT chemosensors: electronic and structural effects. Journal of the American Chemical Society, 120(46), 11864-11873. https://doi.org/10.1021/ja982293q

3. Emon, J. M. V., \& Lopez-Avila, V. (1992). Immunochemical methods for environmental analysis. Analytical Chemistry, 64(2), 78A-88A. https://doi.org/10.1021/ac00026a715

4. Walsh, M. E. (2001). Determination of nitroaromatic, nitramine, and nitrate ester explosives in soil by gas chromatography and an electron capture detector. Talanta, 54(3), 427-438. https://doi.org/10.1016/S0039-9140(00)00541-5

5. Håkansson, K., Coorey, R. V., Zubarev, R. A., Talrose, V. L., \& Håkansson, P. (2000). Low-mass ions observed in plasma desorption mass spectrometry of high explosives. Journal of mass spectrometry, 35(3), 337-346. https://doi.org/10.1002/(SICI)10969888(200003)

6. Eiceman, G. A., \& Stone, J. A. (2004). Peer reviewed: ion mobility spectrometers in national defense. https://doi.org/10.1021/ac041665c

7. Krausa, M., \& Schorb, K. (1999). Trace detection of 2, 4, 6-trinitrotoluene in the gaseous phase by cyclic voltammetry. Journal of electroanalytical chemistry, 461(1-2), 10-13. https://doi.org/10.1016/S0022-0728(98)00162-4

8. Albert, K. J., \& Walt, D. R. (2000). High-speed fluorescence detection of explosiveslike vapors. Analytical Chemistry, 72(9), 1947-1955. https://doi.org/10.1021/ac991397w 
9. Germain, M. E., \& Knapp, M. J. (2009). Optical explosives detection: from color changes to fluorescence turn-on. Chemical Society Reviews, 38(9), 2543-2555. https://doi.org/10.1039/B809631G

10. Moragues, M. E., Martínez-Máñez, R., \& Sancenón, F. (2011). Chromogenic and fluorogenic chemosensors and reagents for anions. A comprehensive review of the year 2009. Chemical Society Reviews, 40(5), 2593-2643. https://doi.org/10.1039/ COCS00015A

11. Salinas, Y., Martínez-Máñez, R., Marcos, M. D., Sancenón, F., Costero, A. M., Parra, M., \& Gil, S. (2012). Optical chemosensors and reagents to detect explosives. Chemical Society Reviews, 41(3), 1261-1296. https://doi.org/10.1039/C1CS15173H

12. Toal, S. J., \& Trogler, W. C. (2006). Polymer sensors for nitroaromatic explosives detection. Journal of Materials Chemistry, 16(28), 2871-2883. https://doi.org/ 10.1039/B517953J

13. Germain, M. E., Vargo, T. R., Khalifah, P. G., \& Knapp, M. J. (2007). Fluorescent detection of nitroaromatics and 2, 3-dimethyl-2, 3-dinitrobutane (DMNB) by a zinc complex:(salophen) Zn. Inorganic chemistry, 46(11), 4422-4429. https://doi.org/ 10.1021/ic062012c

14. Climent, E., Marcos, M. D., Martínez-Máñez, R., Sancenón, F., Soto, J., Rurack, K., \& Amorós, P. (2009). The determination of methylmercury in real samples using organically capped mesoporous inorganic materials capable of signal amplification. Angewandte Chemie, 121(45), 8671-8674. https://doi.org/10.1002/anie.200904243 


\title{
Evolution of Adaptive Immune System
}

\author{
Suman Tamang \\ Assistant Professor, Department of Zoology, Surendranath College, Kolkata, India \\ Corresponding Author's E-mail: suman_nbu@yahoo.com
}

\begin{abstract}
All organisms are connected in a complex web of relationships. Although many of these are benign, not all are, and everything alive devotes significant resources to identifying and neutralizing threats from other species. From bacteria through to primates, the presence of some kind of effective immune system has gone hand in hand with evolutionary success. The pressure that natural selection exerts is inexhaustible and unending. Emerging infectious diseases have as much potential to shape future human history as the epidemics and pandemics of the past. Managing this threat depends on understanding how to maximize the potential of our sophisticated immune system in the service of human health. The adaptive immune system (AIS) in mammals, which is centred on lymphocytes bearing antigen receptors that are generated by somatic recombination, arose approximately 500 million years ago in jawed fish. This intricate defence system consists of many molecules, mechanisms and tissues that are not present in jawless vertebrates. Two macro evolutionary events are believed to have contributed to the genesis of the AIS: the emergence of the recombination-activating gene (RAG) transposon, and two rounds of whole-genome duplication. It has recently been discovered that a non-RAG-based AIS with similarities to the jawed vertebrate AIS including two lymphoid cell lineages - arose in jawless fish by convergent evolution. The latest research works and findings along with the sophisticated and meticulous research methodology in the field of Immunology, Evolutionary biology, Genetics and Molecular biology have offered deep insights into the latest advances in this field and speculate on the selective pressures that led to the emergence and maintenance of the AIS.
\end{abstract}

Keywords: Adaptive immune system, lymphocytes, Seceptors, Somatic recombination, Macroevolution, Recombination activating gene, Vertebrates.

\section{Introduction}

Life began on our planet more than 3.5 billion years ago, and evolving single-cell organisms, eubacteria, archaebacteria, and eukaryotes, have flourished ever since. Around 600 million years ago, multicellular organisms (metazoans) began to form in conjunction with a dramatic increase in atmospheric oxygen levels. This development was followed by a remarkable diversification of metazoan species in such a relatively short time period that it has been termed the "Evolutionary Big Bang". Each metazoan lineage that we recognize today, including the vertebrate lineage to which we belong, appeared more than 500 million years ago. 
Vertebrates with jaws (gnathostomes) possess a remarkably adaptive immune system that can recognize and initiate a protective response against potentially lethal pathogens, including bacteria, viruses, fungi, and parasites. Our adaptive immune system also remembers previous pathogen encounters and can either repel a second invasion or quickly eliminate the recurrent invader by mobilizing a faster and more efficient immune response. For a long time, the origin of adaptive immunity was shrouded in mystery, but the fog is surely rising and a clear picture is beginning to emerge. The evolution of adaptive immunity appears to have been made possible by the invasion of a putative immunoglobulin-like gene by a transposable element, almost certainly a retroposon. This conferred on the ancestral gene the ability to undergo gene rearrangement, and thus generate diversity [1].

There are, however, still many unanswered questions, and probably many others that have not yet been thought of. The first key question is - What was the nature of the piece of DNA that was invaded? It must have resembled a member of the immunoglobulin gene superfamily, and may have already been functioning as some type of antigen receptor, for it to operate appropriately in its changed form; this narrows the field considerably. The second key question is - What was the nature of the cell in which this receptor was expressed? The retroposon itself must have integrated into the host DNA within a germ cell, in order for the two genes RAG-1 and RAG-2 to be inherited together with their targets, called recognition signal sequences, or RSS for short. As RAG-1 and RAG-2 are inherited as a tightly linked pair of genes, while there are at least seven locations to which the ends of the retroposon dispersed (these are the T-cell receptor $\alpha$, $\beta, \gamma$, and $\delta$ chain loci plus the immunoglobulin $H, k$, and $\lambda$ loci), there must be powerful positive selection for these to persist, and that suggests that there was a significant advantage to the organism in expressing a somatically rearranging receptor. Lastly What then was the function of this receptor and the function of the cell type in which it was expressed, that could then make good use of this new diversity in recognition? It must have been something like a lymphocyte, but was it more like a macrophage, a polymorphonuclear leukocyte, an NK cell, or some other cell unlike a lymphocyte that no longer exists in vertebrates? And finally, how did the signalling machinery develop to support this new device, a receptor gene that could rearrange its gene segments? The answers to these questions will, with a firm prediction, fill thousands of papers in the years to come [1].

\section{Why do we need an adaptive immune system?}

Every living organism must maintain some defensive barrier with the outside, and essential to this barrier is the ability to combat pathogens. Even bacteria have defense mechanisms such as antiviral enzymes that allow them to evade bacteriophages. Multicellular organisms have specialized cells for defense, and examples of this can be seen even in the most ancient organisms such as dictyostelium. Importantly, the defense mechanisms employed must be flexible to keep pace with the ever-changing 
strategies that pathogens use to evade the immune system. So at least in principle, would it not seem ideal to have a system that makes boundless amounts of receptors with specificity and memory towards any antigen that it might encounter? If so, why are there so many organisms that lack it?

Initial speculations stated that vertebrate organisms live longer, are bigger and have more complex lifestyles than invertebrates, and so there is a greater need for the AIS. However, there are plenty of invertebrate species, such as squids and octopuses, that are larger and have longer lifespans than many vertebrates yet lack an AIS. So this school of thought has been heavily criticized and rebuked. Likewise many scientists and immunobiologists working in this particular field have come up with many such theories. Recently, Margaret McFall-Ngai suggested that the AIS has allowed vertebrates to have more complex interactions with their commensal bacteria, whereas David Usharauli proposed that the AIS arose to reduces the collateral damage to the tissue during chronic infection. According to Dr. Jonathan Rast, "one can think of warm blooded animals, size, life span etc., but nothing completely correlates with the appearance of the adaptive immune system" [2].

In addition, the presence of the AIS has its costs. Besides the maintenance of many different genes required for diversity, it also runs the risk of creating autoimmunity in the individual. In a Darwinian sense, specific traits are selected based on a cost-benefit ratio. So at least initially there must have been an advantage to maintain a complex system like the AIS, but the advantage, Rast explains, could be "a double edge sword, something that locks itself." Along the same lines, Stephen M. Hedrick proposed in 2004 that there is no optimal solution to the problem of parasitism because pathogens will eventually find a way to evade the system. He points out that "evolution does not have foresight" and the AIS, once created, became an "appendage that generates its own necessity" [2].

\section{Adaptive Immunity appears abruptly in the cartilaginous fish}

It has been known for at least 50 years that all jawed fish can mount an adaptive immune response. On the other hand, hagfish and lampreys, which are jawless vertebrates, lack all signs of an adaptive immune system: they do not have organized lymphoid tissue, they lack primary immune responses, and most importantly, they do not exhibit immunological memory. By contrast, even cartilaginous fish, the earliest jawed fish to survive to the present day, have organized lymphoid tissue, albeit primitive, T-cell receptors and immunoglobulins, and the ability to mount adaptive immune responses. What makes the two phylogenetically related groups so different? And why are they so different? That is the mystery of the evolution of adaptive immunity, and what a mystery it is!

It was only in 1998 that the answers to these questions began to become apparent. In jawed fish and all 'higher' vertebrates, adaptive immunity is possible because of what 
many of the immunobiologists like to think of as the "Immunological Big Bang,' which occurred in some ancestor of the jawed fish. A transposable element invaded a stretch of DNA, presumably a gene that was similar to an immunoglobulin gene or a T-cell receptor gene, and rapidly segregated the transposon sequences encoding the recombinase enzymes used for the invasion from the recognition sequences for these enzymes (Fig 1).
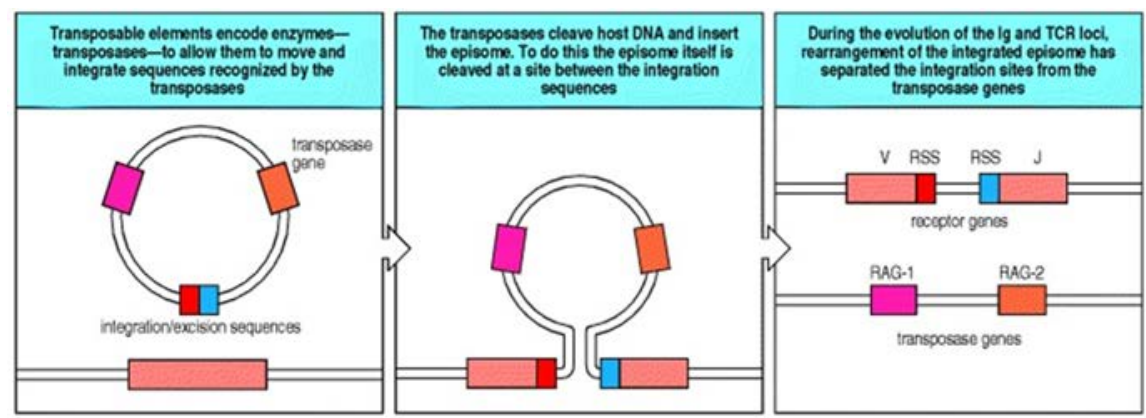

Figure 1: The integration of a transposable element into a cell-surface receptor gene was the event that ultimately gave rise to the immunoglobulin and T-cell receptor genes and their somatic recombination

These remnants of the original transposon became the recombination signal sequences of immunoglobulin and T-cell receptor genes. Invasion by a retrotransposon had been speculated on for years as an explanation of the presence of the RAG genes, which encode recombination enzymes essential for the rearrangement of immunoglobulin and T-cell receptor genes. Like other retroposons, RAG genes lack introns. The action of $R A G$ proteins at the recognition signal sequences was well known for many years. But it was only in 1998, after many extensive research works by scientists came to a startling conclusion that they had their hands on the key discovery to explain the origin of immunoglobulin and T-cell receptor rearrangement [3].

\section{Animals generate antigen receptor diversity in many different ways:}

Most animals that we are familiar with generate a large part of their antigen receptor diversity as humans do, by putting together gene segments in different combinations. The rule that governs the gene rearrangement and combination is called the 12/23 rule of gene segment joining, and the requirement for RAG proteins. The requirement for RAG proteins is essentially absolute. Some animals use gene rearrangement to always join together the same $V$ and $J$ gene segment initially, and then go on to diversify this recombined $V$ region in various ways. In chickens and rabbits, the recombined $V$ region is diversified by gene conversion in the bursa of Fabricius (in chickens) or another 
intestinal lymphoid organ (in rabbits) (Fig 2).

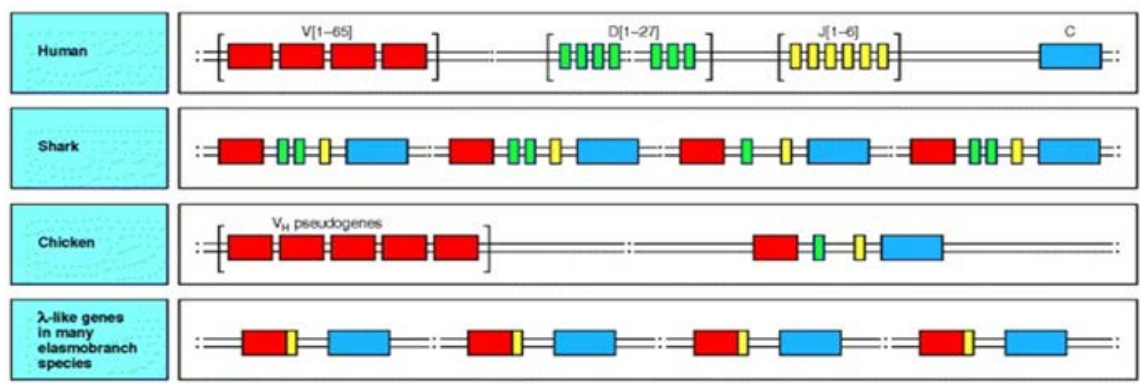

Figure 2: The organization of immunoglobulin genes is different in different species, but all are capable of generating a diverse repertoire of receptors

Other animals generate their diverse repertoire mainly by somatic hypermutation of a fairly invariant recombined $V$ region, as does the sheep in its ileal Peyer's patch. Some primitive fish have multiple copies of discrete $V_{L}-J_{L}-C_{L}$ and $V_{H}-D_{H}-J_{H}-C_{H}$ cassettes, and

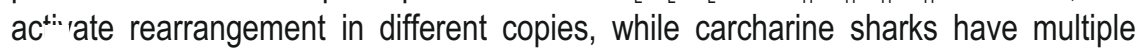
'rearranged' $V_{L}$ regions in the germline genome and apparently generate diversity by activating transcription of different copies. All these animals have survived in a hostile environment because they have the other benefit of adaptive immunity, namely, immunological memory. This is the single greatest advantage conferred on animals that have rearranging gene segments [4].

\section{Summary:}

Gene rearrangement has been known since the early 1970s, and the 'Immunological Big Bang' has been known for about a few years. These two events well explain the development of adaptive immunity. Gene rearrangement is the result of a chance insertion of a retroposon into an unknown cell that must have been either a sperm or an ovum, as it is inserted in the germline. Somehow, still not explained adequately, this retroposon had the good luck to invade a member of the immunoglobulin gene family, and to carry its invasive ends that allow retroposons to move from cell to cell into the right place in the target primordial immunoglobulin gene [4]. At the same time, the RAG genes were preserved, presumably from the same retroposon, but were carried by a different chromosome. These two events, which allowed adaptive immunity to occur, also made immunological memory possible, but they did not make it necessary. Therefore, our present endeavour for understanding the evolution of adaptive immune system leaves us with the questions of - how immunological memory evolve?, What were the evolutionary forces acting on the immune system that not only guaranteed the survival of the species that were lucky enough to inherit this trait, but expanded them to 
the multitudes that occupy the Earth's surface? and what contribution did the possession of immunological memory make to the ability of vertebrates to occupy most of the ecological niches currently present (although we should not forget that insects and many other invertebrates cohabit with us)?

\section{References}

1. Nicholson, L. B. (2016). The immune system. Essays in biochemistry, 60(3), 275-301.

2. Alder, M. N., \& Cooper, M. D. (2006). The Evolution of Adaptive Immune Systems. Cell, 124(4), 815-822.

3. Janeway Jr, C. A., Travers, P., Walport, M., \& Shlomchik, M. J. (2001). Infectious agents and how they cause disease. In Immunobiology: The Immune System in Health and Disease. 5th edition. Garland Science.

4. Tleugabulova, M. C. (2013). The Adaptive Immune System; Is it all it seems to be? Impress Magazine. January 21. 
doi:10.31674/book.2020.macbs

\title{
Effects of Plant Extract on the Metabolic Activity of Rumen Flukes in vitro
}

\author{
Sutapa Datta \\ Assistant Professor, P.G. Department of Zoology, Bethune College, Kolkata, India \\ Corresponding Author's E-mail: dattasutapa@gmail.com
}

\begin{abstract}
Rumen flukes cause serious disease in ruminants including cattle, goats, sheep, and water buffaloes. Mature worms cause rumenitis, irregular rumination and loss of body condition. The disease causes a lower nutrition conversion, decrease in milk production resulting in considerable economic loss. This study was performed to investigate the in vitro anthelmintic efficacy of solvent extracts of leaves of Justicia adhatoda $L$ on trematode Paramphistomum cervi collected from local abattoirs in Kolkata, West Bengal. Mature fresh leaves of Justicia adhatoda were shade-dried, powdered and extracted using absolute ethanol. Adult rumen flukes recovered from the rumen of naturally infected goats were exposed to ethanolic extracts of plants at four different dose levels (10, 25, 50 and $100 \mathrm{mg} / \mathrm{ml}$ ) in PBS supplemented with 1\% DMSO, antibiotics cocktail and $10 \%$ goat blood serum. Tegument and ovary were affected most. The observed anthelmintic effects of the plant extracts were recorded in terms of loss of motility. Dose of $50 \mathrm{mg} / \mathrm{ml}$ and100 $\mathrm{mg} / \mathrm{ml}$ showed drastic changes in tegument and degeneration in ovary. Release of eggs, apparent quiescent state and MTT assay indicate that flukes were under stress due to drug exposure as compared to drug free control. The present study does not indicate total death of organism for which other viability assays need to be addressed.
\end{abstract}

Keywords: Paramphistomiasis, Justicia adhatoda, Albendazole, Praziquintal, MTT assay

\section{Introduction}

Rumen flukes, also known as paramphistomes, are parasites infecting ruminants including cattle, goats, sheep, and water buffaloes. Paramphistomum spp. are Platyhelminth (flat-worm) parasite (Phylum- Platyhelminthes; Class- Trematoda; subclass - Digenea; family-Paramphistomidae) responsible for Paramphistomiasis i.e. gastrointestinal parasitic disease in domesticated animals, which causes heavy economic loss [1] to the livestock industry. Economic loss caused by Paramphistomiasis may be greater than those caused by many other parasites [2,3]. Distribution of Paramphistomumsp is worldwide but the prevalence is high throughout tropical and subtropical regions. Adult flukes are located in the rumen of ruminants and immature flukes in the small intestine mainly in the duodenum $[4,5]$. The immature worms migrating in the 
In vitro effects of plant extract on rumen flukes

small intestine cause more severe damage (including death) than the adult worms [6].

In the present study Justicia adhatoda which have reportedly significant anthelmintic effect in traditional usage, were screened in vitro for its anti-cestoidal activity against Paramphistomumsp.

\section{Materials and Methods}

Preparation of leaf extracts : The leaves of medicinal plant, Justicia adhatoda, were collected from locality, washed properly, shade dried and powdered and extracted with ethanol $(100 \%)$ for 21 days at room temperature in dark condition. The final crude extract was recovered by evaporation and the extracts were resuspended in $1 \%$ DMSO for in vitro evaluation against adult flukes.

Preparation of antibiotics cocktail: Antibiotics cocktail were prepared using $100 \mathrm{u} / \mathrm{ml}$ streptomycin, Penicillin and Gentamycin $(80 \mathrm{mg} / 2 \mathrm{ml})$. Albendazole Tablets I.P.(400mg, Aurio Pharma Pvt. Ltd, India) and Praziquantel 600mg (PZQ) (Healthy life Pharma Ltd, India) were purchased.

Collection of parasites and in vitro treatment: Live parasites were collected from goat in $0.9 \%$ phosphate-buffered saline, $\mathrm{pH} 7.4$ from freshly slaughtered goats. The worms $(6$ to 10) were kept in each of the well in 96 well microtiter plates and exposed to 5, 10, 25, 50, $100,200 \mathrm{mg} / \mathrm{ml}$ concentrations of crude ethanolic leaf extracts of Justicia adhatoda containing PBS cocktail (PBS $+10 \%$ fresh goat serum + antibiotics mixture) and were incubated at $37^{\circ} \mathrm{C}$ for $48 \mathrm{hr}$ in $\mathrm{CO}_{2}$ incubator. Time of no metabolic activity was recorded when no movement of any sort were observed in any body parts of the fluke.). Another set of worms with only PBS cocktail and 1\% dimethylsulfoxide (DMSO) used as solvent for extract, was taken as control. Each set was repeated twice.

MTT assay: In each microtiter well $0.5 \mathrm{mg} \mathrm{MTT/} \mathrm{ml}$ was mixed with $0.1 \mathrm{ml} \mathrm{PBS}$ and kept at $37^{\circ} \mathrm{C}$ for $48 \mathrm{hr}$ in $\mathrm{CO}_{2}$ incubator at dark. Blue formazan crystals were formed and then dissolved in DMSO at room temperature for 1 hour and in a double beam spectrophotometer OD was recorded at $595 \mathrm{~nm}$ for all control and treatment sets.

Post treatment Microscopic study: Parasites were taken from treatment groups of different concentrations of drugs and were stretched and kept in AFA (acetic acid, formaldehyde and acetone) for overnight and stained with carmine for microscopic study.

\section{Results and Discussion}

The plant extracts were screened for anticestodal activity against Paramphistomum cervi. Dose dependent efficacy was observed on exposure to various concentrations of leaf extract of Justicia adhatoda. Although significant mortality was not observed in lowest concentrations (5 or $10 \mathrm{mg} / \mathrm{ml}$ ), still a considerable significant paralysis occurred as opposed to respective controls. The extracts of Justicia adhatoda showed $100 \%$ loss of motility of parasite at $100 \mathrm{mg} / \mathrm{ml}$ (Figure 3). The Trematodes release their eggs at the 
beginning of stress and it was seen from $25 \mathrm{mg} / \mathrm{ml}$ concentrations (Figure 1A,1B).

The ethanolic extracts of Justicia adhatoda showed anticestoidal effects in a dose dependent manner. The observed anticestoidal effects of Justicia adhatoda recorded in terms of loss of motility in comparison to the suitable controls indicate that these can be considered as potential drug candidates, though this should be further confirmed by studying corresponding actual loss of viability of the parasite. These results indicate that certain active compounds present in the extract the actual therapeutic impact depending on their solubility and/or permeability properties. In albendazole treated specimens, minor damage was observed in the acetabulum compared to plant extract treated flukes (Figure 1C). The shape of the mouth also was changed and denaturized tegument was observed in the albendazole-treated specimen (Figure 2A). Progressive erosion of basal lamina was consequent of exposure to the test materials as observed in the present study. In the albendazole + praziquantel treated parasites, most of the damages induced were in the tegument, but degeneration was on a much lesser scale than the plant extract treated ones (Figure 2B).
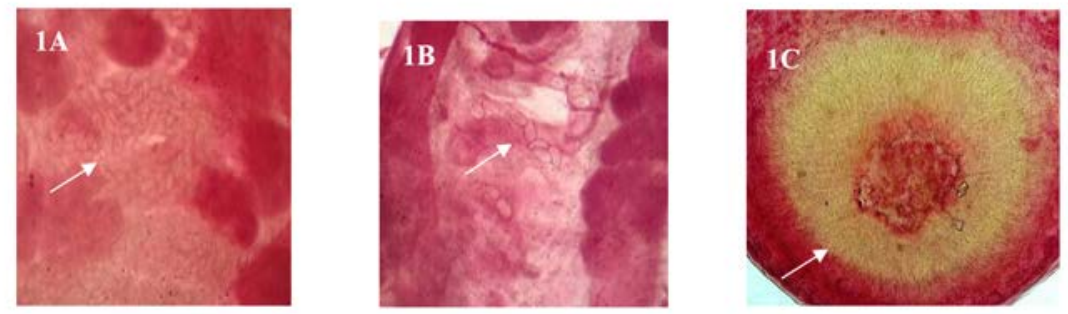

Figure1: In flukes treated with $25 \mathrm{mg} / \mathrm{ml}$ plant extract eggs were released marked as arrows after 15 minutes $(A)$ and 2 hours $(B)$. The acetabulum is degenerated at 4 hour post treatment $(C)$ with $200 \mathrm{mg} / \mathrm{ml}$.
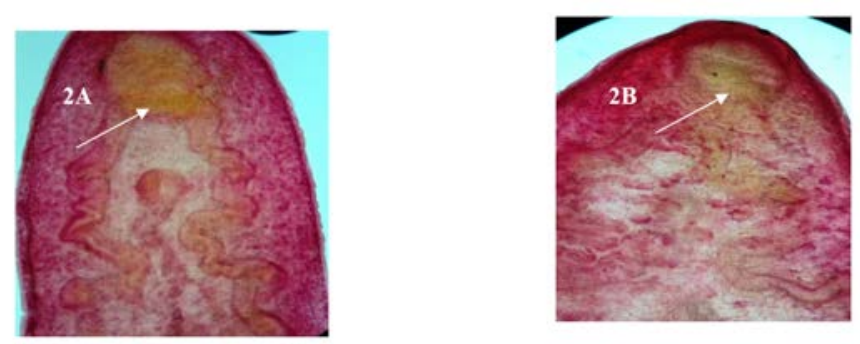

Figure 2: In flukes treated with $200 \mathrm{mg} / \mathrm{ml}$ Albendazole $(2 \mathrm{~A})$ and Albendazole +Praziquantel $(2 \mathrm{~B})$ the oral sucker is degenerated at 4 hour post treatment. 


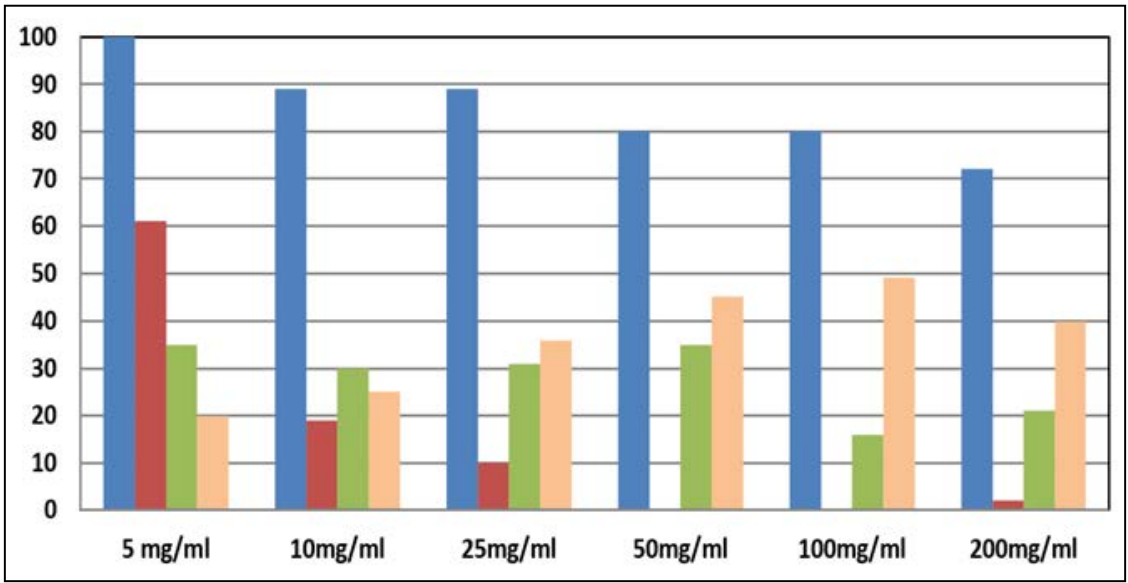

Figure 3: The percentage of metabolic activity of flukes was noted after 4 hour incubation with plant extract, Albendazole (ABZ) and Albendazole+Praziquantel (ABZ+PQZ) in different doses $(5,10,25,50,100$ and $200 \mathrm{mg} / \mathrm{ml})$ separately with a significant change in $50 \mathrm{mg} / \mathrm{ml}$ onwards plant extract and the drugs with no such effects.

\section{Conclusion}

After collection from the host the flukes exhibit active movements in the PBS. But the apparent body movements were very low with time as parasites were exposed to the drugs. These results indicate that flukes try to cope up with the stressful environment by minimizing its metabolic activities as far as possible adopting an apparent immotile state though it remains viable. The flukes almost started releasing eggs from the uterus soon after exposure to drugs and after one hour of exposure there is sharp indication of movement of eggs from uterus to the genital atrium indicating the exit route of eggs thro ugh genital aperture. The present study does not indicate total death of organism for which other viability assays need to be addressed.

\section{References}

1. Horak, I. G. (1971). Paramphistomiasis of domestic ruminants. In Advances in parasitology (Vol. 9, pp. 33-72). Academic Press.

2. Hanna, R. E. B., Williamson, D. S., Mattison, R. G., \& Nizami, W. A. (1988). Seasonal reproduction in Paramphistomum epiclitum and Gastrothylax crumenifer, rumen paramphistomes of the Indian water buffalo, and comparison with the biliary paramphistome Gigantocotyle explanatum. International journal for parasitology, 18(4), 513-521.

3. Panyarachun, B., Sobhon, P., Tinikul, Y., Chotwiwatthanakun, C., Anupunpisit, V., \& 
Anuracpreeda, P. (2010). Paramphistomum cervi: surface topography of the tegument of adult fluke. Experimental Parasitology, 125(2), 95-99.

4. Taylor, M. A. (2012). Emerging parasitic diseases of sheep. Veterinary parasitology, 189(1), 2-7.

5. Arias, M. S., Sanchís, J., Francisco, I., Francisco, R., Piñeiro, P., Cazapal-Monteiro, C., \& Paz-Silva, A. (2013). The efficacy of four anthelmintics against Calicophoron daubneyi in naturally infected dairy cattle. Veterinary parasitology, 197(1-2), 126-129.

6. Chaoudhary, V., Hasnani, J. J., Khyalia, M. K., Pandey, S., Chauhan, V. D., Pandya, S. S., \& Patel, P. V. (2015). Morphological and histological identification of Paramphistomum cervi (Trematoda: Paramiphistoma) in the rumen of infected sheep. Veterinary world, 8(1), 125. 
doi:10.31674/book.2020.macbs

\title{
Impacts of Climate Change on Marine Biodiversity
}

\author{
Tarikul Islam Golder
}

Assistant Professor, Department of Zoology, Surendranath College, Kolkata, India

Corresponding Author's E-mail: tarikulgolder@gmail.com

\begin{abstract}
The climate change is threatening the survival of marine biodiversity like mussels, starfish, corals etc owing to change of chemistry of seawater. Atmospheric $\mathrm{CO}_{2}$ emitted by anthropogenic activities dissolves in sea water and forms carbonic acid causing ocean to acidify called Ocean Acidification. More oceans acidify, less $\mathrm{CO}_{2}$ it can absorb. As a result, green house effect increases. Many marine organisms like starfish, corals, mussels, certain species of planktons suffers more from ocean acidification. Coral reefs have already been destroyed or damaged. If ocean acidification increases, calcification for calcifying organisms like corals, mussels and starfish become difficult. Global warming and acidification lowers survival rate of some fish species. All developed and developing countries should reduce $\mathrm{CO}_{2}$ emission to save marine biodiversity from the changing chemistry of sea water.
\end{abstract}

Keywords: Marine Biodiversity, Anthropogenic activities, Ocean Acidification, Green house effect, Coral reef, Calcification.

\section{Introduction}

Alarming rise of carbon dioxide in the atmosphere causing change of chemistry of ocean and marine ecosystem which affect marine biodiversity negatively. In these review paper how $\mathrm{CO}_{2}$ from air has been fatally damaging ocean chemistry will be discussed. The ocean, gigantic carbon sink, currently dissolves one third of $\mathrm{CO}_{2}$ emission. Marine biodiversity includes coastal and marine plant and animal species, their genetic variety, the habitats and ecosystems they form part of, and the ecological processes that support all of these.

The marine environmenthas a very high biodiversity because 32 out of the 33 described animal phyla are represented in there. Examples of exclusively marine phyla include the echinoderms (starfish and their relatives), ctenophores (comb jellies), hemichordates (acorn worms) and the echiurans (trumpetworms) [2]. (Fig.1)

\section{Why is Marine Biodiversity Important?}

Every ecosystem performs certain functions that are critically important for organisms. One of the most important functions of marine ecosystems is the production of plant biomass from sunlight and nutrients (primary productivity), which represents the basic food source for all life in the ocean, and ultimately also for humans. Around half of the worldwide primary productivity is achieved by microscopically small plants, the 
phytoplankton, which grows and divide in the ocean. Another function performed by ecosystems is the creation of habitats, or structures, in coastal ecosystems. For example, microalgae, sea grass and corals form large undersea forests, meadows or reefs that provide habitats for many other species such as mollusks, crustaceans and fish. Kelp forests and sea grass meadows in the Baltic Sea are vital habitats for the fry and juvenile fish that grow up here before swimming into the open ocean as adults. Gastropods and small crustaceans likewise feed on microalgae growing on the kelp or sea grass. They thereby ensure that the structure-forming plants are not smothered, and are allowed to grow - that is their contribution to the ecosystem. The mollusks and crustaceans that feed on microalgae are the basic food source for larger predatory crustaceansand fish [1].
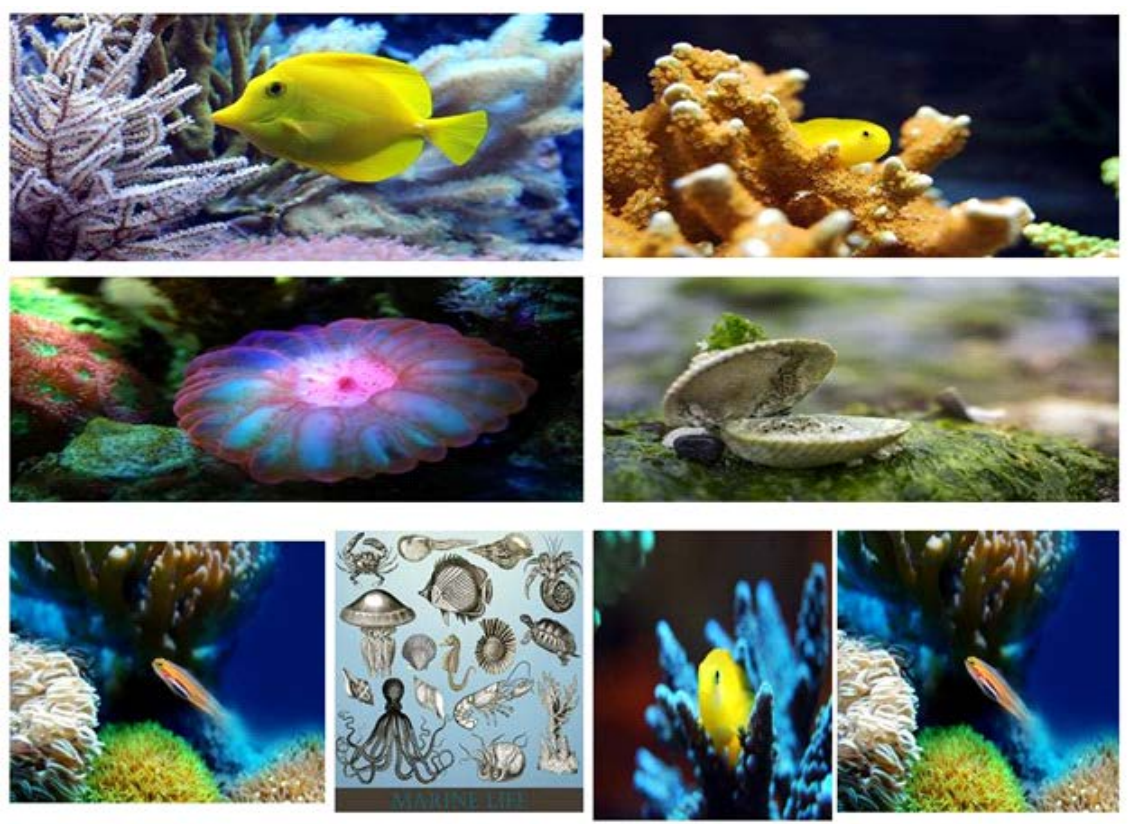

Figure 1: Different Marine Biodiversity [6]

\section{The rapid disappearance of species:}

Biological diversity in the oceans has decreased dramatically since industrialization began in the $19^{\text {th }}$ century. The primary causes for the losses include the destruction of habitats by trawler fishing, pollution and eutrophication of the seas, as well as the steady progress of climate change. Biological diversity is probably declining more rapidly than ever before in the history of the Earth. But at the same time, only a small fraction of the species in the deep sea and polar oceans have so far been identified, making the loss of species in the oceans much more difficult to record and evaluate than on land [4]. 


\section{Causes of Disappearance of Marine Biodiversity:}

- Ocean acidification is called the evil twin of global warming increases the effect of climate change.

- Ocean acidification reduces $\mathrm{CO}_{2}$ absorption ability of ocean. As a result its function as a carbon sink thathelps attenuate climate change will decrease.

- Industrialization in the mid of $19^{\text {th }}$ century resulted release of 440 billion tones(approx.) of $\mathrm{CO}_{2}$ into the atmosphere from burning fossils fuels like natural gas, crude oil and coal.

- $26 \%$ increase in ocean acidity from preindustrial levels till today.

- Rate of Ocean acidification has increased 10 times since the last time i.e. 55 million years ago.

- $40 \%$ increase of atmospheric $\mathrm{CO}_{2}$ since industrial revolution.

\section{Role of Plants and Ocean to ReduceAtmospheric $\mathrm{CO}_{2}$ :}

- Green plants do photosynthesis and use $\mathrm{CO}_{2}$ and water to produce glucose and $\mathrm{O}_{2}$.

- Ocean acts as $\mathrm{CO}_{2}$ sink to dissolve $\mathrm{CO}_{2}$.

- If ocean, the natural store of $\mathrm{CO}_{2}$, would not exit earth would heat up much more and even faster than today.

- So forest, green plants, ocean reduce atmospheric $\mathrm{CO}_{2}$ and slow down climate change particularlyglobal warming [5].

\section{Impacts Of Climate Change On Marine Life:}

- Atmospheric $\mathrm{CO}_{2}$ dissolves in water and forms $\mathrm{H}_{2} \mathrm{CO}_{3}$ causing ocean to acidify rendering death of the variety of marine organism.

- Cumulative effect of increasing ocean acidification has negative impact on food chain and marine ecosystem.

- Corals, mussels, certain species of plankton that make their shells and skeleton from $\mathrm{CaCO}_{3}$ suffer from ocean acidification.

- Echinoderms like starfishare negativelyaffected.

- Carbonic acid in the sea water reduces PH of water, sea water becomes more acidic; to neutralize itself $\mathrm{H}_{2} \mathrm{CO}_{3}$ breaks down into $\mathrm{HCO}_{3}^{-}$and $\mathrm{H}^{+}$ions; some of these $\mathrm{H}^{+}$ ions combine with the carbonate already present in the water to form bicarbonate. Calcifying organisms like starfish, corals, mussels use carbonate to build their shells and skeletons but calcification becomes difficult owing to formation of bicarbonate from carbonate [3].

\section{Impacts of Ocean Acidification and Warming:}

- Reduce survival rate of some fish species

- Affect fish stock 
- $\quad$ Reduce yields of fisheries.

- $\quad$ Affecteconomic activities like small scale coastal fisheries.

- Aquaculture such as shrimp farming is affected.

- Tourism is affected.

\section{Discussion}

It is predicted that the projected increase of ocean acidity by the year 2100 compared to pre-industrial levels is $170 \%$, if high $\mathrm{CO}_{2}$ emission continues Ocean absorbs 24 million tones of $\mathrm{CO}_{2}$ everyday. $\mathrm{CO}_{2}$ causes ocean acidification which reduces $\mathrm{CO}_{2}$ absorption capacity of ocean. Scientists started studying the impacts of ocean acidification since last 10 years but they discovered some adverse impacts which has already discussed. If $\mathrm{CO}_{2}$ is drastically reduced, half of world tropical coral reef could be saved. We should understand that we depend on ocean its services in many ways. So climate change affects everyone and it will be our benefit if we reduce $\mathrm{CO}_{2}$ emission and restrict global warming less than $2^{\circ} \mathrm{C}$. All countries should drastically reduce $\mathrm{CO}_{2}$ emissions by middle of century. The current world climate reports indicates that net -zero emissions are preconditions for restricting global warming below $2^{\circ} \mathrm{C}$. Reducing $\mathrm{CO}_{2}$ emission alone is not enough, we have to remove some of $\mathrm{CO}_{2}$ from atmosphere. This is technically feasible, but challenge is to develop and implement in larger scale.

\section{References}

1. Clarke, A., \& Johnston, N. M. (2003). Antarctic marine benthic diversity. Oceanography and marine biology, 41, 47-114.

2. FAO. (2007). the state of world Fisheries and Aquaculture 2006, pp. 162. http://www.fao.org/3/a-a0699e.pdf

3. Longhurst, A.R.(2001). Ecological Geography of the Sea (Academic Press). March . pp. 398

4. Robison, B.H. (2004). Deep pelagic biology. Journal of Experimental Marine Biology and Ecology. 300,253-272

5. Steele, J. H. (1985). A comparison of terrestrial and marine ecological systems. Nature, 313(6001), 355-358.

6. https://pixabay.com/en/photos/marine $\% 20$ life/ 


\title{
C-reactive Protein: Diagnostic Marker of Inflammation?
}

\author{
Waliza Ansar \\ Assistant Professor, Zoology Department, Behala College, Kolkata, India \\ Corresponding Author's E-mail: waliza_ansar@yahoo.co.in
}

\begin{abstract}
C-reactive protein (CRP) previously considered solely as a biomarker for inflammation, is now referred as a prominent partaker in many diseases. CRP is a plasma protein of hepatic origin, belonging to the highly conserved pentraxin family. Though as a key component of the innate immunity system, it also acts as an adjunct of innate and adaptive immune system. As a consequence to tissue injury or infection, the concentration of CRP may rapidly rise to levels more than 100-1000 folds above normal values. Serving clinically for several years as a non-specific inflammatory marker, CRP, with the advent of high-sensitivity assays, has now emerged a distinct status of a disease marker in cardiovascular diseases. CRP is a routine part of global cardiovascular risk assessment. The present surge of report in a large number of diseases and inflammatory conditions has highly illuminated the role of $\mathrm{CRP}$ as a therapeutic and prognostic reagent. The future prospect of this work lies in the applicability of CRP as a molecule in diagnosis and monitoring of disease biology.
\end{abstract}

Keywords: C-reactive protein, Inflammation, Acute phase response, Diagnosis

\section{Introduction}

The $\mathrm{C}$-reactive protein (CRP) is a homopentameric acute phase plasma protein belonging to highly conserved phylogenetically ancient family of Pentraxin and forms a major component of any inflammatory reaction, thus reviewed as an non-specific yet useful inflammatory biomarker. CRP is a key component of the innate immune system. CRP was initially discovered in 1930 by Tillet and Francis while investigating the sera of patients suffering from the acute stage of Pneumococcus infection and was named for its reaction with the capsular (C)-polysaccharide of Pneumococcus. CRPs are characterized by their calcium-dependent ligand-binding affinity for the phosphocholine (PC) moiety [1]. The wide distribution of PC in polysaccharides of pathogens/microbes and in cellular membranes enables CRP to recognize a range of pathogenic targets as well as membranes of damaged and necrotic host cells. CRP binds to PC present on the surface of microorganisms and triggers the classical complement cascade of innate immunity by activating C1q molecule [2]. CRP has many homologs in some invertebrates and vertebrates [3] and is structurally related other acute phase proteins like serum amyloid $A$ [4]. It bears structural resemblance with IgG molecule and can bind with Fc receptors 
present in different immune cells to activate cell-mediated cascades leading to the release of pro-inflammatory cytokines. CRP is secreted from the liver hepatocyte cells under the stimulation of inflammatory cytokines IL-6 [5]. Other cytokines like IL-1 and TNF-a played stimulatory role in CRP secretion. In humans, the CRP level is low $(0.1-0.5 \mathrm{mg} / \mathrm{L})$ under normal conditions, but the concentration of CRP may rapidly increase to levels more than 1000 folds above nomal values as a consequence to tissue injury or infection. Increase CRP level is considered to be an important risk factor for inflammatory disease, atherosclerosis, myocardial infarction, peripheral vascular disease, and ischemic stroke [6-9].

\section{Inflammation}

Inflammation is the body's immediate response to damage/stress/injury to its cells and tissues by pathogens, noxious physical or chemical stimuli. Inflammation involves stimulation of various immune system cells and release of pro-/anti-inflammatory mediators to trigger or enhance the inflammatory response. Cytokines are the important inflammatory mediators and play a significant role in the development of inflammatory response. Inflammation is divided into two basic types- acute and chronic inflammation. Acute inflammation is the immediate short-term and early response to injury that usually results in healing. Leukocyte cells infiltrate the damaged region, repairing the tissue after the stimulus is removed. It has three major components: (i) vasodilation (alteration in vascular mobility that leads to a local increase in blood flow), (ii) fluid and plasma protein exudation (structural changes in the microvasculature that permit protein to leave the circulation) and (iii) emigration of phagocytes by the increased capillary permeability and accumulation in the focus of injury. These components account for three of the five classic local signs of acute inflammation: heat (calor), redness (rubor), swelling (tumor) and two additional cardinal features are pain (dolor) and loss of function (functio laesa). The processes/pathways by which acute inflammation is initiated and develops are well characterized. In contrast, chronic inflammation is a dysregulated, prolonged, maladaptive involving active inflammation, tissue destruction and finally tissue repair. Persistent inflammation in chronic condition is associated with many human diseases and conditions like allergy, atherosclerosis, arthritis, cancer, and some autoimmune diseases. The associated molecular and cellular pathways of chronic inflammation are complex and it is sometimes difficult to ascertain the cause of a chronic disease[10].

\section{CRP and inflammation}

CRP concentrations are known to increase dramatically in response to infection, injury, and inflammation. CRP is deposited at sites of tissue damage and inflammation in both experimental conditions and naturally [11]. CRP is the principal downstream mediator of the acute-phase response after an inflammatory event and it clears the pathogen by complement activation or phagocytosis. CRP can discriminate self versus non-self molecules as a pattern recognition receptor which other activators like IgG cannot 
achieve because it can only recognize distinct antigenic epitopes [12]. CRP binds to damaged cell membranes during inflammatory responses [13], associated with terminal complement complexes in atheroscleroticlesions [14], localizes to infarcted heart tissue [15] or to the nuclei of synovium cells of rheumatoid arthritis patients [16].Thus CRP is predominantly found in the fluid phase rather than deposited in tissues at sites of injury or inflammation [17].

\section{CRP as marker in diseases}

CRP appears in the serum during bacterial infection; ischemic injury to tissue [7,18], as in myocardial infarction or pulmonary embolism; malignant neoplasms, particularly when associated with tissue necrosis; physical or traumatic injury, such as bone fracture, surgery, or burns; and many inflammatory clinical conditions, as, for example, rheumatic fever, rheumatoid arthritis, vasculitis, chronic active hepatitis, or ulcerative colitis.

Plasma /serum CRP concentration showed marked increase in various conditions like bacterial infection, abscess, Chrohn's disease, connective tissue disorders (except Systemic Lupus Erythromatosus, SLE), neoplasia (except leukemia), trauma and necrosis whereas it showed slight elevation in viral infection, steroids and oestrogen therapy, Ulcerative colitis and SLE. Higher level of CRP in treated Visceral Leishmaniasis $(\mathrm{VL})$ patients predicts higher future incidence of post kala-azar dermal leishmaniasis (PKDL) [19-21]. Currently, CRP levels $1 \mathrm{mg} / \mathrm{L}, 1$ - $3 \mathrm{mg} / \mathrm{L}$, and $3 \mathrm{mg} / \mathrm{L}$ are used to denote low-, intermediate-, and high-risk groups towards heart diseases. CRP measurement in the high normal range predicts an increased long-term risk of angina, myocardial infarction and death.

\section{Discussion}

Knowledge of the structure and function of CRP - including its three dimensional structure alone and complexed with ligands [22] - coupled with experience in developing an inhibitor of the related protein SAP [23-24] establishes an excellent platform for drug design.

\section{Conclusion}

The future scope of this review remains in employing strategies towards application of this wonder molecule as disease marker thus contributing to clinical applications.

\section{References}

1. Tillett, W. S., \& Francis Jr, T. (1930). Serological reactions in pneumonia with a nonprotein somatic fraction of pneumococcus. The Journal of experimental medicine, 52(4), 561.

2. Volanakis, J. E. (2001). Human C-reactive protein: expression, structure, and function. Molecularimmunology, 38(2-3), 189-197. 
3. Black, S., Kushner, I., \& Samols, D. (2004). C-reactive protein. Journal of Biological Chemistry, 279(47), 48487-48490.

4. Gewurz, H., Mold, C., Siegel, J., \& Fiedel, B. (1982). C-reactive protein and the acute phase response. Advances in internal medicine, 27, 345-372.

5. Boras E, Slevin M, Alexander MY, Aljohi A, Gilmore W, Ashworth J, et al. (2014). Monomeric C-reactive protein and Notch-3 co-operatively increase angiogenesis through PI3K signalling pathway. Cytokine . 69:165-79. doi:10.1016/j.cyto. 2014.05.027.

6. Thompson, D., Pepys, M. B., \& Wood, S. P. (1999). The physiological structure of human C-reactive protein and its complex with phosphocholine. Structure, 7(2), 169-177.

7. Ansar, W., \& Ghosh, S. (2013). C-reactive protein and the biology of disease. Immunologic research, 56(1), 131-142.

8. Du Clos TW, Mold C. (2004).C-reactive protein: an activator of innate immunity and a modulator of adaptive immunity. Immunol Res (2004) 30(3):261-77. doi:10.1385/ IR:30:3:261

9. Sproston, N. R., \& Ashworth, J. J. (2018). Role of C-reactive protein at sites of inflammation and infection. Front Immunol 9: 754.

10. Medzhitov, R. (2008). Origin and physiological roles of inflammation. Nature, 454(7203), 428-435.

11. Braig, D., Nero, T. L., Koch, H. G., Kaiser, B., Wang, X., Thiele, J. R., ... \& Mellett, N. A. (2017). Transitional changes in the CRP structure lead to the exposure of proinflammatory binding sites. Nature communications, 8(1), 1-19.

12. Duclos, T. W. (2000). Function of CRP. Ann Med, 32(4), 274-8.

13. Kaplan, M. H., \& Volanakis, J. E. (1974). Interaction of C-reactive protein complexes with the complement system: I. Consumption of human complement associated with the reaction of C-reactive protein with pneumococcal C-polysaccharide and with the choline phosphatides, lecithin and sphingomyelin. The Journal of Immunology, 112(6), 2135-2147.

14. Torzewski, J., Torzewski, M., Bowyer, D. E., Fröhlich, M., Koenig, W., Waltenberger, J., \& Hombach, V. (1998). C-reactive protein frequently colocalizes with the terminal complement complex in the intima of early atherosclerotic lesions of human coronary arteries. Arteriosclerosis, thrombosis, and vascular biology, 18(9), 1386-1392.

15. Lagrand, W. K., Niessen, H. W., Wolbink, G. J., Jaspars, L. H., Visser, C. A., Verheugt, F. W., ... \& Hack, C. E. (1997). C-reactive protein colocalizes with complement in human hearts during acute myocardial infarction. Circulation, 95(1), 97-103.

16. Gitlin JD, Gitlin JI, Gitlin D. (1977).Localizing of C-reactive protein in synovium of patients with rheumatoid arthritis. Nov-Dec. Arthritis Rheum (1977) 20(8):1491-9. doi:10.1002/art. 1780200808 
17. Vigushin, D. M., Pepys, M. B., \& Hawkins, P. N. (1993). Metabolic and scintigraphic studies of radioiodinated human C-reactive protein in health and disease. The Journal of clinical investigation, 91(4), 1351-1357.

18. De Beer, F. C., Hind, C. R., Fox, K. M., Allan, R. M., Maseri, A., \& Pepys, M. B. (1982). Measurement of serum C-reactive protein concentration in myocardial ischaemia and infarction. Heart, 47(3), 239-243.

19. Pepys, M. B., \& Hirschfield, G. M. (2003). C-reactive protein: a critical update. The Journal of clinical investigation, 111(12), 1805-1812.

20. Gasim, S., Theander, T. G., \& ElHassan, A. M. (2000). High levels of C-reactive protein in the peripheral blood during visceral leishmaniasis predict subsequent development of post kala-azar dermal leishmaniasis. Acta tropica, 75(1), 35-38.

21. Ansar, W., Mukhopadhyay, S., Habib, S. H., Basu, S., Saha, B., Sen, A. K., ... \& Mandal, C. (2009). Disease-associated glycosylated molecular variants of human Creactive protein activate complement-mediated hemolysis of erythrocytes in tuberculosis and Indian visceral leishmaniasis. Glycoconjugate Journal, 26(9), 1151.

22. Thompson, D., Pepys, M. B., \& Wood, S. P. (1999). The physiological structure of human C-reactive protein and its complex with phosphocholine. Structure, 7(2), 169-177.

23. Ansar, W., nee Bandyopadhyay, S. M., Chowdhury, S., Habib, S. H., \& Mandal, C. (2006). Role of C-reactive protein in complement-mediated hemolysis in malaria. Glycoconjugate Journal, 23(3-4), 233-240.

24. Allin, K. H., Nordestgaard, B. G., Flyger, H., \& Bojesen, S. E. (2011). Elevated pretreatment levels of plasma $\mathrm{C}$-reactive protein are associated with poor prognosis after breast cancer: a cohort study. Breast Cancer Research, 13(3), R55. 


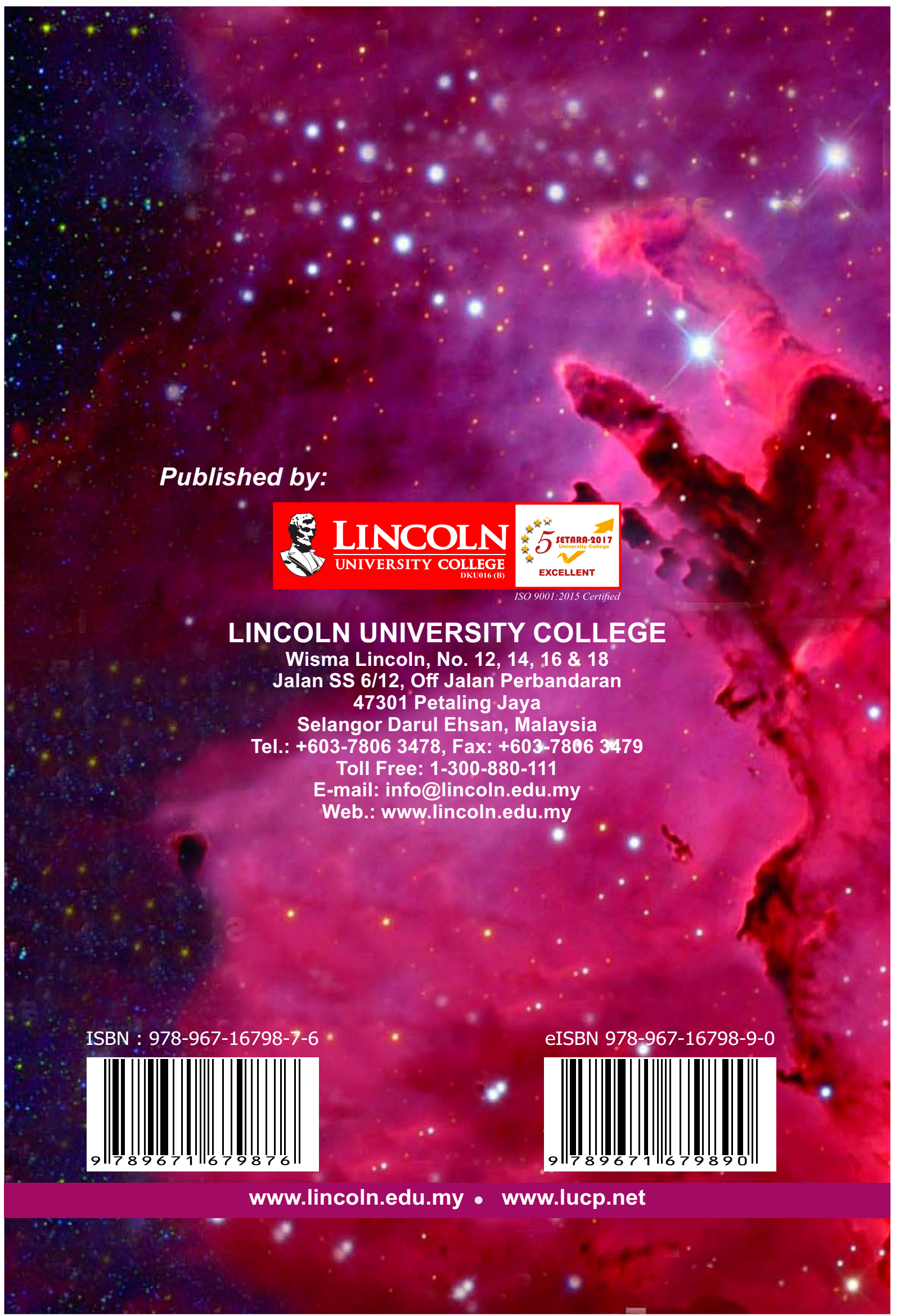

